\title{
Role of atrial dilatation in the development of a substrate for atrial fibrillation
}

Citation for published version (APA):

Eijsbouts, S. C. M. (2005). Role of atrial dilatation in the development of a substrate for atrial fibrillation. [Doctoral Thesis, Maastricht University]. Universitaire Pers Maastricht.

https://doi.org/10.26481/dis.20051125se

Document status and date:

Published: 01/01/2005

DOI:

10.26481/dis.20051125se

Document Version:

Publisher's PDF, also known as Version of record

\section{Please check the document version of this publication:}

- A submitted manuscript is the version of the article upon submission and before peer-review. There can be important differences between the submitted version and the official published version of record.

People interested in the research are advised to contact the author for the final version of the publication, or visit the DOI to the publisher's website.

- The final author version and the galley proof are versions of the publication after peer review.

- The final published version features the final layout of the paper including the volume, issue and page numbers.

Link to publication

\footnotetext{
General rights rights.

- You may freely distribute the URL identifying the publication in the public portal. please follow below link for the End User Agreement:

www.umlib.nl/taverne-license

Take down policy

If you believe that this document breaches copyright please contact us at:

repository@maastrichtuniversity.nl

providing details and we will investigate your claim.
}

Copyright and moral rights for the publications made accessible in the public portal are retained by the authors and/or other copyright owners and it is a condition of accessing publications that users recognise and abide by the legal requirements associated with these

- Users may download and print one copy of any publication from the public portal for the purpose of private study or research.

- You may not further distribute the material or use it for any profit-making activity or commercial gain

If the publication is distributed under the terms of Article $25 \mathrm{fa}$ of the Dutch Copyright Act, indicated by the "Taverne" license above, 
9 Sabine Eijsbouts, Maastricht 2005 ISBN 9052784957

Production by Datawyse/Universitaire Pers Mastricht 


\title{
Role of Atrial Dilatation in the Development of a Substrate for Atrial Fibrillation
}

\author{
Proefschrift \\ ter verkrijging van de graad van doctor \\ aan de Universiteit Maastricht \\ op gezag van de Rector Magnificus, Prof.mr. G.P.M.F. Mols \\ volgens het besluit van het College van Decanen \\ in het openbaar te verdedigen \\ op vrijdag 25 november om 12.00 uur \\ door
}

Sabine Eijsbouts

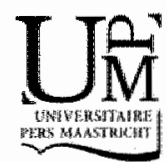




\section{Promotor}

Prof.dr. M.A. Allessie

\section{Beoordelingscommissie}

Prof.dr. H.J.G.M. Crijns (voorzitter)

Prof.dr. J.M. de Bakker

Prof.dr. J.G. Maessen

Prof.dr. H.A.J. Struijker Boudier

This study was supported by the Dutch Organization for Scientific research (NWO). (Grant 902-16$097)$ 
Voor Rink en Willemijn 



\section{Contents}

Chapter 1: Introduction: The Role of Atrial Dilatation in the Genesis of AF.

Chapter 2: The Effects of Acute Atrial Dilatation on Heterogeneity in Conduction in the Isolated Rabbit Heart.

Chapter 3: Synergistic Action of Atrial Dilatation and Sodium Channel Blockade on Conduction in Rabbit Atria.

Chapter 4: Serial Cardioversion by Class Ic Drugs during 4 Months 69 of Persistent Atrial Fibrillation in the Goat.

Chapter 5: Effects of 6 Weeks of Atrial Volume Overload on the 83 Substrate of AF in the Goat.

Chapter 6: Effects of 20 Weeks of Atrial Volume Overload on the Substrate of AF in the Goat.

Chapter 7: General Discussion: Role of Atrial Dilatation in the Stability of AF.

Summary

Samenvatting

Dankwoord 

Chapter 1

\section{Introduction:}

\section{The Role of Atrial Dilatation in the Genesis of AF}

Sabine Eijsbouts 
Atrial dilatation is common in the population aged $\geq 45$ years. The prevalence of left atrial enlargement has been reported to be $12-18 \%$ in a study of 2042 people older than 45 years in the United States. "The high prevalence of atriall dilatation reflects the prevalence of cardiovascular disease in this age group. An increase in left atrial dimension is an important risk factor for atrial fibrillation, stroke and death. ${ }^{2,3}$ Atrial dilatation frequently occurs in patients with hypertension, coronary artery disease, valvular disease, and heart failure. In these patients, atrial dilatation is mainly caused by increased mechanical load due to mitral or tricuspid regurgitation or increased enddiastolic ventricular pressures. Depending on the severity of the underlying heart disease up to $50 \%$ of these patients will develop AF. The incidence of AF is likely to increase in the future, because of both an ageing population and therapeutic advances in the management of cardiac diseases (i.e. acute myocardlal infarction) leading to improved survival of patients with impaired cardiac function. Therefore, AF will become more and more an important sociall and economic health problem.

\section{Dilatation as a Cause of AF}

Since atrial fibrillation was first observed in experimental work by William Harvey in 1628 and later in humans by Cushny in 1907, there is a still growing interest for the mechanisms underlying the arrhythmia. ${ }^{4,5}$ For more than 100 years, experimental and clinical investigations have tried to demonstrate and unravel the relation between atrial size and occurrence and perpetuation of atrial fibrillation.

As early as 1783 , Jean-Baptiste de Senac observed the increased propensity of atria to arrhythmias when the atria are dilated due to mitral valve disease: 4

If the auricles are strained and increased in volume they cause palpitations... One sees the same effects when the auricles are abnormally dilated..their walls are more irritable and they act more actively on the ventricles.

Later in 1887, McWilliam reported that in dogs ventricular fibrillation usually does not recover spontaneouslly, while in hearts of smaller species like cat, rabbit, rat, mouse, hedgehog and fowl, spontaneous recovery may take place readily. ${ }^{6}$ Garrey (1914) was the first to recognize the important role of tissue mass for the induction and perpetuation of fibrillation and demonstrated the same for the fibrillating atrium. ${ }^{7}$ After ligation or clamping of a small piece of the fibrillating atrium (cat, rabbit or dog), the portion separated ceased fibrilllation immediately, whereas the other part of the atrium continued to fibrillate. By cutting always pieces of fibrillating dog ventricle, Garrey showed that larger pieces fibrillated several seconds or even half a minute, while small 
bits ceased immediately. From the early 1930 s atrial dilatation as a cause of human atrial fibrillation began to be considered. Nahum and Hoff were the first to suggest that atrial distension could be an important factor in the occurrence of AF in patients with mitral valve disease. Furthermore, they were the first to mention atrial stretch as the possible "second factor" in the development of AF. ${ }^{8}$ Also in patients with other cardiac diseases the importance of atrial distension for AF was suggested. ${ }^{9,} 10$ However, no experimental evidence was provided yet. During the following years, several animal studies were performed to test the hypothesis that atrial enlargement can cause the atria to fibrillate. In 1943, Smith and Wilson were able to induce atrial fibrillation in dogs with acute atrial dilatation due to acute mitral stenosis. ${ }^{11}$ However, AF accurred only after injection of mecholyl. Scherf et al. demonstrated that acute atrial stretch by either traction or rapid infusion of saline, increased the rate of an aconitine-induced atrial flutter and occasionally converted flutter into fibrillation. ${ }^{12}$ Also Bimbaum et al. noticed that atrial dilatation, caused by rapid infusion of saline, or the gradual inflation of an intraatrial balloon, converted atrial flutter into atrial fibrillation. ${ }^{13}$ This was explained by their observation that stretch shortened the atrial refractory period and ut was suggested that possible changes in conduction, heterogeneity in refractoriness and disruption of the conduction pathways could predispose to formation of multiple wavefronts and AF. Later, animal studies on acute atrial dilatation also focused on the mechanisms underlying the increased vulnerability to atrial fibrillation. ${ }^{14-16}$ Ravelli et al. found that increased atrial pressure in the isolated Langendorff perfused rabbit heart resulted in a significant increase in vulnerability to atrial fibrillation that was closely correlated to shortening of the atrial effective refractory period. ${ }^{16}$ Several other experimental studies related the atrial tissue mass rather than distension of the atria to the occurrence of arrhythmias. Moore at al. tested the hypothesis that atrial mass is one of the important factors in the maintenance of atrial fibrillation. ${ }^{17}$ Atrial fibrillation was induced by burst pacing $(30 \mathrm{~Hz}, 20-30$ sec duration) in adult cattle and mules, which have a large atrial mass, and in calves and adult goats, which have a smaller atrial mass. They concluded that AF persisted over a significantly longer period of time in larger animals. Boswell et al. reported similar findings in dogs whilch were grouped on the basis of body weight. ${ }^{18}$ Although the initiation and maintenance of atrial fibrillation was facilitated by an increased parasympathic tone, they found that in large dogs $(16-30 \mathrm{~kg})$ the arrhythmia persisted for longer periods than in small dogs $(3-6 \mathrm{~kg})$. West and Landa determined the minimal mass required for induction of a sustained arrhythmia by dividing isolated atrial segments from rabbits until the arrhythmia was no longer inducible. ${ }^{19}$ There was a critical minimum atrial mass in which the arrhythmia could not be induced, which corresponded with the mass theoretically required for re-entry excitation. These observations supported the idea as originally discussed by McWilliam in 
the ventricle and by Garrey in the atrium that mass is an important factor in the maintenance of fibrillation. The first experimental studies on chronic atrial dilatation were performed by Boyden et al. in the early 1980's. In 8 dogs with surgically induced tricuspid insufficiency and constriction of the pulmonary artery, the right atrial volume was increased by $39 \%$ after $20-30$ weeks. Spontaneous arrhythmias did not occur, but the inducibility and duration of artificially induced atrial arrhythmias increased significantly. ${ }^{20}$ In another study, dogs with mitral valve fibrosis and left atrial enlargement showed spontaneous atrial arrhythmias. ${ }^{21}$ Clinical and large population-based studies also demonstrated the relationship between atrial size and the development of AF. In 1955, Fraser and Turner showed in patients with mitral valve disease that patients with atrial fibrillation tend to have larger left and right atria than those in sinus rhythm. ${ }^{22}$ In a study of 314 patients with mitral stenosis, decreased mitral valve area and increased right atrial pressure were identified as the most important independent factors associated with AF ${ }^{23}$ Henry et al. reported that $A F$ was rare when left atrial dimension was below $40 \mathrm{~mm}$, but common when left atrial dimension exceeded $40 \mathrm{~mm}$. In addition, they found that when left atrial dimension exceeds $45 \mathrm{~mm}$, cardioversion is unlikelly to produce sinus rhythm that can be maintained for at least six months. ${ }^{24}$ The Framingham study, which prospectively followed adults after routine surveillance $M$-mode echocardiograms, revealed left atrial size as an independent risk factor for the subsequent development of $A F_{\text {, with a hazard }}$ ratio of 1.39 for every $5-\mathrm{mm}$ increase in left atrial size. ${ }^{2}$ The Cardiovascular Health Study also showed a strong and independent association between left atrial size and the development of AF. ${ }^{25}$ Although atrial arrhythmias often occur in enlarged atria, it has not yet been clearly demonstrated that there is a causal relationship between enlarged atria and atrial arrhythmias.

\section{Dilatation as a Consequence of AF}

Apart from being a cause of AF, atrial dilatation can also be a consequence of AF. In a study of 15 patients with normal left atrial size at baseline, the left and right atrial volume increased by about $50 \%$ (14\% in diameter) as a result of 20.6 months of lone AF. ${ }^{26}$ The atrial enlargement could even have been more pronounced since 11 of the 15 patients were maintained on digoxin, which improves atrial contractility and thus may have limited atrial dilatation. ${ }^{27}$ Similar data have been reported in persistent (19\% in LA diameter) and paroxysmal (11\% in LA diameter) lone AF, which were independent of changes in ventricular size or function. ${ }^{28}$ However, not all studies of patients with paroxysmal AF have demonstrated increases in atrial size. ${ }^{29}$ In patients with chronic AF of different etiologies (mitral valve disease, coronary artery disease, hypertension), atrial fibrillation also contributes to a progres- 
sive increase in atrial size, related to the duration of the arrhythmia. ${ }^{30-32}$ Keren et al. showed that patients with mitral stenosis and AF had much larger atria than patients in sinus rhythm. Atrial fibrillation accounted for respectively $11 \%$ and $24 \%$ of the change in left and right atrial size. ${ }^{31}$ Furthermore, successful electrical cardioversion causes a decrease in atrial size, but not if atrial fibrillation recurs after conversion. ${ }^{33}$, 34. Also experimental studies have shown that atrial fibrillation or rapid atrial pacing results in progressive enlargement of the atria. ${ }^{35-37}$ Schotten et al. showed that 5 days of atrial fibrillation resulted in a $12 \%$ increase of the mean right atrial diameter. They also found that the atrial contractile function was nearly abolished (contractile remodeling). Interestingly, contractile remodeling followed the same time course as electrical remodeling. ${ }^{38}$ Since the main cellular mechanism responsible for electrical remodeling is the reduction of the L-type $\mathrm{Ca}^{2+}$ inward current, it has been suggested that this mechanism also leads to a decrease in contractile atrial force. ${ }^{39-42}$ As a result the fibrillatory contractions become weaker and the atria become dilated. ${ }^{43}$ Atrial contractile remodeling takes place during the first days of atrial fibrillation, whille atrial dilatation is a progressive process which may continue for months to years. ${ }^{26}$ Thus, also other mechanisms will contribute to the progressive enlargement of the atria. The loss of atrial contractility will transfer the atrial stretch more to the passive elements of the atrial wall which might lead to elongation of collagen fibers. Stretching of atrial myocytes will activate numerous intracellular signaling cascades resulting in hypertrophy and proliferation of fibroblasts. ${ }^{44}$ Synthesis of connective tissue fibers and cellular hypertrophy could also result in a slow increase in atrial dimensions. A different mechanism by which AF may induce atrial dilatation is the increase in ventricullar rate. In most patients the ventrilcular rate during AF is higher than during sinus rhythm. In goats subjected to 4 weeks of rapid av-pacing ( 240 beats $/ \mathrm{min}$ ), the right atrial diameter progressively increased $(51 \%)$, whereas after rapid atrial pacing alone (ventricular rate: 80 beats/min) the atrial size did not change. ${ }^{45}$ It is suggested that progressive ventricular dysfunction due to the rapid ventricular response (tachycardiomyopathy) caused the atrial enlargement in this model.

\section{Electrophysiological Effects of Atrial Dilatation}

\section{Effects on Atrial Refractoriness}

Studies on the effect of acute atrial stretch on refractoriness show confllicting data. Acute increase in atrial pressure either caused a shortening ${ }^{14}$, $16,46,47$, a prolongation $^{15,48,49}$ or no change $e^{50,51}$ at all. The only common finding of these studies was an increase in the vulnerability to atrial fibrillation. There is evidence that acute atrial dilatation increases dispersion of atrial refractori- 
ness. This may be due to a heterogeneous distribution of wall stress (thin parts of the atrium are stretched more than the thicker parts). ${ }^{52}$ Mechanoelectrical feedback, i.e. electrophysiological changes in response to acute hemodynamic load, can partially be explained by activation of stretchactivated ion channels (SACS). ${ }^{53}$ There is evidence that SACS are also involved in stretch-induced arthythmias. Gadolinium, a widely used nonselective SAC inhibitor, and the more specific blocker GsMtx-4 (a peptide from spider venom) have been found to prevent stretch-induced atrial and ventricular arrhythmias. ${ }^{54-57}$ There are several possible mechanisms how SACs can mediate stretch-induced electrical changes. The membrane can be depolarized during diastole by an aspecific current or a flux of specific ions like $\mathrm{Ca}^{2+}, \mathrm{Na}^{+}$and $\mathrm{K}^{*}$ which may trigger afterdepolarizations. ${ }^{53}$ In addition opening of SACs may lead to $\mathrm{Ca}^{2+}$ overload. The specific SAC blocker GsMtx4 has shown to suppress atrial fibrillation in the rabbit model of acute atrial dilatation. Continuous stretch may increase repolarizing currents and may shorten the action potential and refractory period. However, the stretchinduced shortening of the refractory period in rabbit atria was not prevented by GsMtx -4.57 The possible role of SACs in the accurrence of stretch-induced conduction disturbances is still unknown. In the first experiments on chronic atrial dilatation in the early 1980s, Boyden at al. found no change in action potential duration. ${ }^{20}$ Also recently, Neuberger et al. found no change in atrial effective refractory period due to atrial dilatation ( $\sim 12 \%$ increase in RA diameter) induced by 4 weeks of av-block in the goat. (ref) In animal models of rapid pacing induced heart failure and atrial dilatation the AERP was found to be increased ${ }^{58}$ or not changed at all ${ }^{59}$. Recently in a canine model of mitral regurgitation and left atrial dilatation Verheule et al. found a prolongation of the AERP ${ }^{60}$ Also in patients with atrial enlargement the refractory period was prolonged. ${ }^{61-63}$. Only in isolated cells from patients with enlarged atria ( $>55 \mathrm{~mm}$ ) the action potential duration was shortened and the plateau was markedly depressed. ${ }^{64}$. The conflicting data on the effects of atrial refractory period might be due to the different models used to study atrial dilatation. The etiology of atrial enlargement and its associated cardiac disease may determine to a considerable extent the electrophysiological substrate.

\section{Effects on Atrial Conduction}

Dudel and Trautwein (1954) were the first to study the effects of stretch on the action potential of cat papillary muscle and dog Purkinje fiber. ${ }^{65}$ They found that the resting and action potentials were not affected by stretch up to a tension of $1000 \mathrm{~g} / \mathrm{cm}^{2}$. At higher tensions injury of the preparation occulrred and the amplitude of the action potential decreased. In 1963 Penefsky and Hoffman studied the effects of stretch on conduction in atrial and ventricular myocardium. ${ }^{66}$ They distinguished changes in conduction time between two points separated by a constant distance (apparent conduction 
velocity) and changes in conduction between two landmarks on the surface of the muscle (true conduction vellocity). With mild stretch the true velocity of conduction remained constant and also the transmembrane potential did not change. During excessive stretch the membrane resting potential, upstroke velocity and overshoot of the action potential declined indicating a decrease in the rapid sodium current. Multiple deflections were observed as a sign of discontinuous conduction. Spear and Moore suggested that conduction was blocked by stretch because of disruption of the ellectrical continuity between cells. ${ }^{67}$ Also, in isolated fibers of patients with diseased atria, atrial dilatation was correlated with low resting membrane potentials, prolonged $P$ wave duration (intra-atrial conduction slowing) and occurrence of atrial arrthythmias 68,69

The effects of stretch on the cable properties of cardiac muscle was investigated by Deck and Dominguez and Fozzard. ${ }^{70,} 71$ Deck concluded that changes in membrane resistance (increase) and capacitance (decrease) together with a decrease in core resistance could be responsible for the increase in the apparent conduction velocity. Dominguez and Fozzard argued that geometrical alterations such as unfolding of the membrane and uncoiling of the muscle coulid partly explain the effects of stretch on conduction velocity.

The effects of acute dilatation on atrial conduction in whole hearts has been studied by balloon dilatation and volume loading. ${ }^{14,15,72}$ In the canine heart, an increase of the atrial pressure to $>14 \mathrm{mmHg}$ prolonged the interatrial conduction time by $30-45 \%,{ }^{14},{ }^{15}$ Chorro et al. were the first to use high density mapping during acute atrial dilatation. ${ }^{72}$ In isolated Langendorff perfused rabbit hearts the right atrium was stretched up to $41 \%$ by inflation of a balloon, which decreased atrial conduction velocity by $25 \%$. Different models of chronic atrial dilatation have been used to study the effects on conduction. In an experimental model of congestive heart failure with increased atrial pres sure and extensive atria fibrosis, the conduction velocity during regular pacing was not affected, but conduction was rather heterogeneous with localized regions of slow conduction. ${ }^{59}$ In other models of atrial dilatation due to heart failure, mitral valve disease or atrial septum defect, the overall conduction velocity did not change. $58,60,63$ However, some studies in humans reported anatomically determined conduction delay at the crista terminalis, evidenced by a great number of wide double potentials. ${ }^{63,73}$ So far, studies on chronic atriall dilatation are performed in models with associated cardiac disease and/or only one-silded atrial dilatation. Also in the models of pacing induced heart failure and atrial dilatation the effect of electrical remodeling can not be ruled out. It remains a big hurdle to develop a chronic model of pure atrial dilatation. 


\section{Mechanisms of Perpetuation of AF}

Initiation of AF is the result of a single ectopic focus or re-entry, while the predominant mechanism of persistent AF is multiple re-entry, perpetulated by elther a single source or multiple sources. An important characteristic of AF 'driven' by a single source is that the arrhythmia should terminate after elimination of the rapid source. The single source can be an automatic focus which fires so rapidly that the atria cannot follow $1: 1$ (fibrillatory conduction). Clinical studies have shown that the far majority of these atrial ectopic foci are frequently located in the myocardial 'sleeves" of the pulmonary veins. ${ }^{74}$. Also a single stable macro-reentrant circuit with a short cycle length (high frequency) and a fixed anatomically or functionally determined pathway (mother wave) can lead to fibrillatory conduction in the rest of the atria. AF can also be 'driven' by a stable fixed micro-reentrant circuit with a high frequency (fixed rotor) which can also be drifting through the atria (moving rotor). Rotors may have preferential locations determined by anatomical and functional properties of the atria. AF 'driven' by multiple foci will not be cardioverted to sinus rhythm when one of these foci will be successfully eliminated. Furthermore, multiple reentrant circuits may co-exist in the atria, which can be anatomically or functionally determined. Because they are multiple, the circuits do not have to be stable in order to perpetuate AF. Multiple wavelets can 'drive' AF with a high frequency by wandering simultaneously through the atrial myocardium. The pathways of the wavelets are determined by the anatomical and functional properties of the atrial wall. While traveling through the atria, the wavelets often reenter the tail of refractoriness of other waves (random reentry) and occasionally they can also reenter their own refractory tail. However, stable rotors are not observed during this type of AF. The stability of AF depends on the number of wavelets which 'fit' on the atrial surface. The shorter the wavelength of the atrial impulse the more wavelets will co-exist and the less likely AF will terminate. It is not unlikely that different mechanisms of AF can be operative at the same time. If a rapid focus exists together with randomly reentering multiple wavelets, atrial fibrillation will be highly persistent or even permanent.

The mechanisms by which AF sustains itself are largely dependent on the underlying substrate of AF. Experimental and clinical studies have shown that AF has several different etiologiles, which can cause a different substrate of AF. Thus, depending on the substrate of AF, the mechanism of perpetuation of AF can be diverse. One of the proposed underlying mechanisms for the perpetuation of AF has been elegantly depicted in a scheme by Allessie et al. ${ }^{75}$ They suggested three positive feedback-loops of atrial remodeling on AF, consisting of an electrical, contractile and structural feedback loop (Figure 1). The following three paragraphs will describe the three loops in further detail. 


\section{Electrical Remodeling}

The concept of tachycardia-induced electrical remodeling of the atria was introduced in 1995 by two independent experimental studies. ${ }^{35,} 76$ These studies showed that long-term rapid pacing in dogs or maintenance of AF by burst pacing in goats resulted in a marked shortening of the atrial refractory period and a loss of the normal rate adaptation of the refractory period. This was thought to be due to alternations in the expression of ion channels and was referred to as 'electrical remodeling'. More importantly, it was found that the tachycardia-induced electrical remodeling led to a progressive increase in the vulnerability to atrial fibrillation, leading to the concept that 'Atrial Fibrillation Begets Atrial Fibrillation'. The longer duration of the AF episodes was explained by a shortening of the wavelength of the atrial impulse. ${ }^{77,78}$ When the wavelength is short, small regions of intra-atrial conduction block may already serve as a site for initiation of reentry, thus increasing the vulnerability for AF. A short wavelength is also expected to increase the stability of AF because it allows more reentering wavelets to coexist in the atria. The ionic mechanisms underlying AF-induced electrical remodeling have been extensively studied. ${ }^{39-41}$ Yue et al. were the first to demonstrate that the L-type $\mathrm{Ca}^{2+}$ current $\left(\mathrm{I}_{\mathrm{CaL}}\right)$ was reduced in cardiomyocytes of electrically remodeled atria. ${ }^{39}$ Inhibition of $I_{\mathrm{Cat}}$ by nifedipine produced a shortening of the action potential as observed after prolonged atrial tachycardia, whereas increasing $\mathrm{I}_{\text {CaL }}$ with BayK8644 partly reversed the shortening of the action potential by rapid atrial pacing. These data strongly suggest that a reduction of $I_{C a L}$ underlies the tachycardia-induced shortening of the refractory period.

\section{Contractile Remodeling}

From clinical studies it is known that after successful cardioversion of AF the atrial contractile function is impaired. ${ }^{79}$ The degree of contractile dysfunction seems to be related to the duration of AF. After restoration of sinus rhythm atrial contractile function can recover, although this may take several months. ${ }^{30}$ Schotten et al. hypothesized that the reduction in $\mathrm{I}_{\text {Cat }}$ during AFinduced electrical remodeling may also underlie the atrial contractile dysfunction. ${ }^{38}$ To test this hypothesis, goats were chronically instrumented with ultrasonic piezoelectric crystals on both atria and a pressure transducer was implanted in the right atrium. Atrial volume-pressure loops were obtained and the atrial work index could be measured chronically. Atrial contractility was already significantly impaired after 5 minutes of AF. During the first 5 days of AF atrial contractility progressively declined and already after 2 days the pressure-volume loop showed that the atrial contractile function was almost completely abolished (contractile remodeling). Interestingly, contractile remodeling followed the same time course as electrical remodeling, both during the first 5 days of remodeling and after resumption of sinus rhythm. 
These findings indicate that during the first 5 days of AF electrical and contractile remodeling are closely linked. Since the main cellular mechanism responsible for electrical remodeling is the reduction of the L-type Ca ${ }^{2 *}$ inward current, it has been suggested that this mechanism also leads to a decrease in contractile atrial force. ${ }^{39 * 42}$ As a result the fibrillatory contractions become weaker and the atria become dilated. ${ }^{43}$

\section{Structural Remodeling}

Apart from electrical and contractile remodeling, atrial fibrillation also induces structural changes. Morillo et al. were the first to show that AF causes changes in ultrastructure of atrial myocytes in an experimentall study in dogs subjected to 6 weeks of rapid atrial pacing. ${ }^{35}$ They found marked disarray of atrial myofilaments, increased number and size of mitochondria and disruption of the sarcoplasmic reticulum. Ausma et al. found silmilar changes in the atria of goats in which AF was maintained for 9-23 weeks. ${ }^{81}$ A considerable amount of atrial myocytes $(\sim 92 \%)$ showed marked changes in cellular structure with a phenotypic adaptation toward a more fetal stage of development (dedifferentiation). The AF-induced structural changes were characterized by an increase in cell size, loss of sarcomeres (myolysis), accumulation of glycogen, changes in mitochondrial shape and size, fragmentation of sarcoplasmic reticulum, and dispersion of nuclear chromatin. The remodeling of the cellular ultrastructure in atrial myocardium of the goat develops progressively during AF. ${ }^{2}$ The amount of connective tissue did not change as a result of AF. However, because the atrial cells have become larger the relative amount of interstitial collagen per atrial myocyte was increased. ${ }^{83}$ It was suggested that these ultrastructural alterations closely resembled the changes observed in ventricular myocardium due to low flow ischemia, assigned as 'hibernation' ${ }^{84}$ Hibernating atrial myocardium was heterogeneously distributed, with some cells strongly affected and neighboring cells being virtually normal. The gapjunctions also underwent a remodeling process characterized by a decrease and more heterogeneous distribution of connexin $40 .{ }^{85}$ In two recent studies the reversibility of structural atrial remodeling was evaluated. Ausma et al. investigated the reversibility of structural changes two and four months postAF in atria of goats which had been in AF for 4 months. ${ }^{83}$ After two months of sinus rhythm electrical and gap-junctional remodeling was completely reversible, while 4 months post-AF recovery from structural remodeling was still incomplete. The increased atrial myocyte diameter and the number of myocytes with severe myolysis had almost normalized, whereas myocytes with mild myolysis remained increased. The extracellular matrix fraction per 


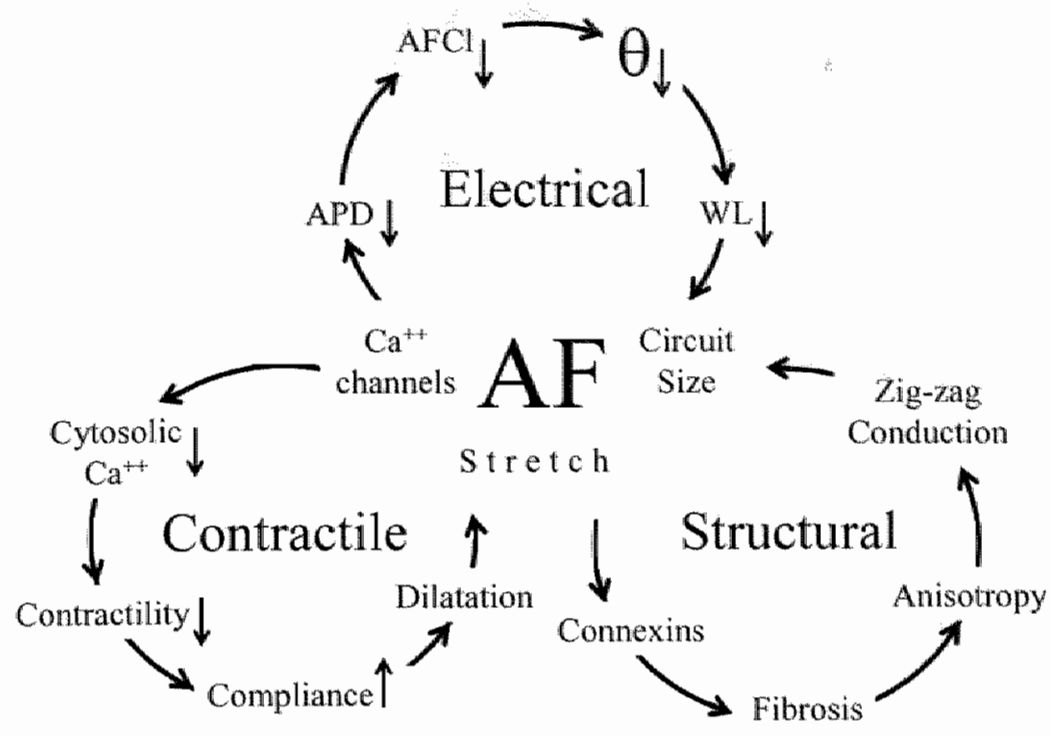

Figure 1: Three proposed positive feedback-loops of atrlal remodeling on AF. Reduction of the Ltype $\mathrm{Ca} 2+$ channels is considered to be the primary cause for electrical and contractlle remodelling. The loss of atrial contractility leads to an increase in compliance of the fibrillating atria which in turn facilitates atrial dillatation. The resulting stretch acts as a stimulus for structural remodeling of the enlarged atria. The combination of electrical and structural remodeling allows intra atrial reentrant circuits of a smaller size, due to a reduction in wavelength (shortening of refractoriness and slowing of conduction) and increased non-uniform tissue anisotropy (zig-zag conduction).(From Allessle et al. $)^{75}$

myocyte remained higher and changes in expression of structural proteins were only partially restored post-AF. Also the duration of AF-episodes was still prolonged (minutes vs. seconds in control goats). Everett et al. found no recovery of structural remodeling 2 weeks after restoration of sinus rhythm in dogs with mitral regurgitation, which were subjected to 2 months of AF. ${ }^{86}$ This might be due to the atrial enlargement, which was still present at that time.

Early studies on atrial pathology in AF patients showed diffuse fibrosis, loss of contractile material, and disruption of the normal cellular ultrastructure. ${ }^{87,88}$ Other human studies showed similar signs of dedifferentiation in atrial myocardium as present in the various animal models. ${ }^{42,69}$ In patients with AF and atrial dilatation also degenerative changes were observed such as apoptotic death of myocytes with myolysis. ${ }^{89}$ However, most of those studies were done in patients with cardiac disease and/or old age which to some extent may account for the structural changes observed. Only few studies investigated the structural changes associated with lone $\mathrm{AF}_{n}{ }^{90,}{ }^{91}$ Frustaci et al. found a wide variety in type of structural changes; Iymphomononuclear infiltrates with necrosis of the adjacent myocytes (diagnosed as myocarditis) in 8 of the 12 patients, interstitial fibrosis (7/12), fibrillolysis (2/12) and hypertrophy (2/12). ${ }^{90}$ Recently, more pronounced myolytic changes of the atria 
were reported in patients with lone AF. ${ }^{91}$ The cellular and gap-junctional changes will result in enhanced nonuniform anisotropy and heterogeneities in atrial conduction. Cellular hypertrophy in itself might slow conduction at least transverse to the cell orientation. ${ }^{92}$ These changes support the hypothesis that the development of areas of slow conduction and intra-atrial conduction block, which promote the stability of atrial rotors and multiple wandering wavelets, form the basis for the increased stability of AF.

\section{Atrial Size and AF}

According to Moe's multiple wavelet hypothesis, the stability of AF is determined by the number of waves that can be present simultaneously in the atria. ${ }^{93}$ This is determined by both the atrial tissue mass and the atrial wavelength. Already 48 years before Moe developed his multiple wavelet hypothesis, Garrey stated that multiple wavelets were underlying the process of atrial fibrillation and recognized the importance of conduction block and tissue mass for the perpetuation of the arrhythmia: ${ }^{94}$

In small masses of tissue, blocks may exist, but the time necessary for the impulse to traverse all available circuits is within the refractory period and the mass contracts as a unit and fibrillation is thus impossible. In larger masses this is not true, for the larger mass the greater the possible number en length of the circuits, and the greater the probability that each impulse will circulate until it reaches tissue which has once contracted but has passed out of the refractory state; thus a continuous circulation of impulses is inaugurated, which is fibrillation. Such a mechanism would account for the greater liability of large hearts to fibrillate and for the greater persistence of the fibrillary state in large tissue masses.

Although atrial dilatation will not directly increase the atrial tissue mass, the atrial surface area will certainly do so, which might allow a larger number of wavelets during AF. Rensma estimated the maximal number of wavelets that can be present simultaneously in atria of different species by relating the wavelength of the earliest premature beat to the atrial surface area (Figure 2). ${ }^{77,95}$ Because the prolongation of the wavelength was not in proportion with the increase in atrial size in larger animals, the maximal number of wavelets increased with body size, thereby explaining the increased propensity for atrial fibrillation in these animals. The atrial wavelength of the earliest premature beat was estimated to be $3.5 \mathrm{~cm}$ in rabbit, $8 \mathrm{~cm}$ in dog, $12 \mathrm{~cm}$ in man, $20 \mathrm{~cm}$ in horse, $30 \mathrm{~cm}$ in elephant and $45 \mathrm{~cm}$ in whale. Because the maximal number of wavelets is given by the surface area divided by the area of a circle with a circumference equal to the wavelength (number of wavelets 
= atrial surface area divided by $W L^{2} / 4 \pi$ ), the rabbit atrium with a surface area of $3 \mathrm{~cm}^{2}$ would allow only 3 wavelets to be present. This is below the critical number of 4-6 wavelets needed for atrial fibrillation to sustain as reported by Allessie. ${ }^{96}$ The estimated maximal number of wavelets in dog and man was about 6 and 5 , which is close to the fibrillation threshold and increased further to 10,13 and 19 in horse, elephant and whale respectively, which is far above the fibrillation threshold. These results are in agreement with the stability of atrial fibrillation in the different species. In rabbits AF is difficult to induce and is usually of short duration, whereas AF is more common in dogs and humans and occurs frequently and is often sustained in cows and horses. ${ }^{97-102}$

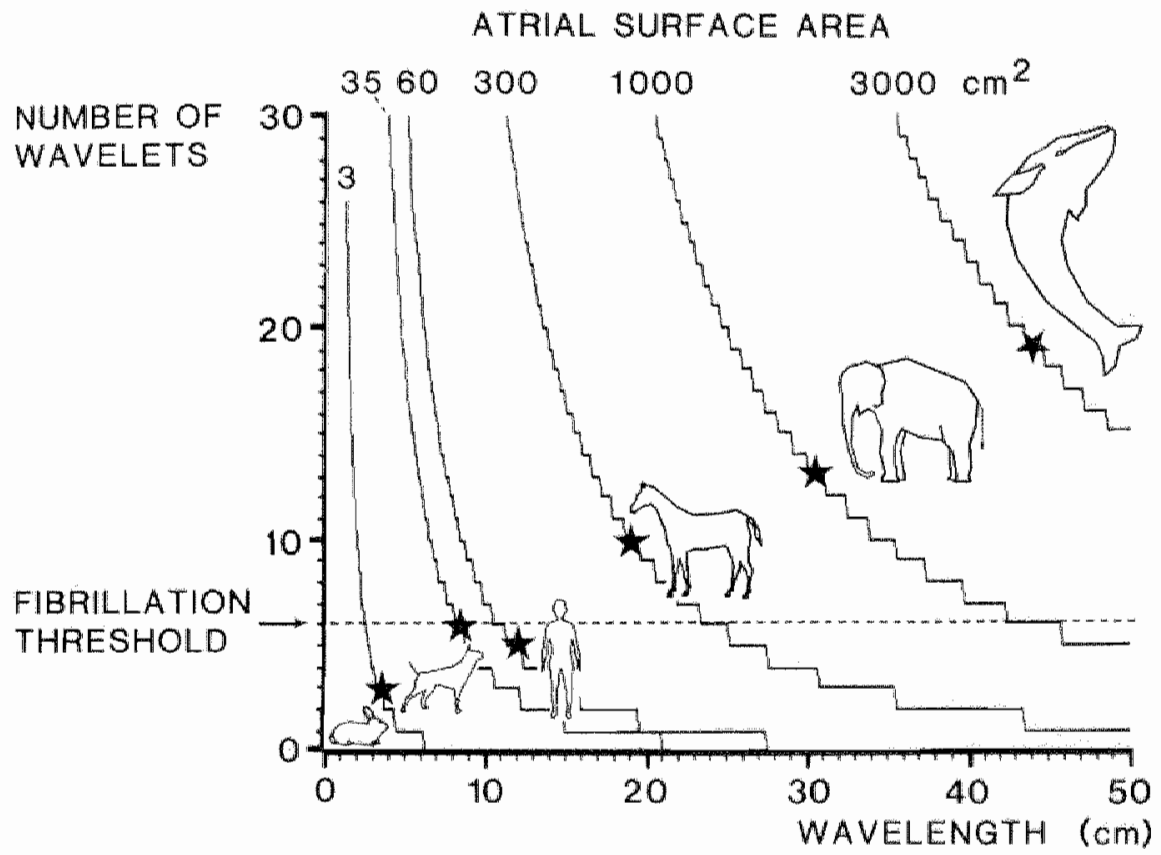

Figure 2:" Relationship between atrial wavelength and the maximal number of circuits in the atria of differently sized amimals. The critical number of wavelets for fibrillation (fibrilation threshold) is indicated by the dotted line. Because the wavelengtin in larger animals is proportionally less than the enlargement if the atrial surface, the maximal number of wavelets increases with body size. In small animals like rabbit, the number of wavelets is fair below the fibrillation threshold, whereas dogs and humans are near the threshold. Larger animals (horse, elephant and whale) the number of wavelets exceeds the critical number for fibillation. (From Rensma et. al.) ${ }^{\text {ss }}$

\section{Aim of the Thesis}

The aim of the thesis was to investigate the effects of acute and chronic atrial dilatation on the development of a substrate for AF. The main question to be studied was whether atrial dilatation causes heterogeneities in conduction. 
Special atterition was paid to the relation between local conduction disturbances and the attrial architecture. Isolated Langendorff perfused rabbit hearts were used to study the effects of acute atrial dilatation on atrial conduction. Spatial heterogeneities in atrial conduction were quantified during acute dilatation of the right and left atrium using high-density mapping (chapter 2). Class IC drugs, which are often used to cardiovert AF in patients, slow conduction by blockade of the rapid sadium channels. We investigated the combination of acute atrial dilatation and a class Ic drug (flecainide) on the degree of atrial anisotropy and conduction (chapter 3). Photographs of the atrium were used to correlate lines of conduction block with the underlying atrial structure.

It is known that atrial fibrillation is a progressive arrhythmia often starting in a paroxysmal form and becoming more and more persistent with time. Electrical remodeling develops within the first days of AF and contributes to an increase in stability of AF. However, there is increasing evidence that the development of persistent AF must also depend on a "second factor" since the persistence of AF continues to increase after electrical remodeling. In a goat model of persistent AF, the hypothesis was tested that in a time period of 4 months during which structural atrial remodeling occurs, the stability of Af further increases (chapter 4). Because during persistent atrial fibrillation, the duration of AF episodes can no longer be used as a measure of the stability of AF, serial pharmacological cardioversion was performed. The success rate and amount of class Ic drug required for cardioversion was used to follow long-term changes in stability of AF.

The effects of chronic atrial dilatation on the substrate of AF were studied in a goat model of chronic volume overload created by a carotid-jugular av-shunt. After 6 and 20 weeks of atrial volume overload (chapter 5 and 6) the effects on atrial electrophysiology were evaluated. Also the effect of chronic atrial dilatation on the stability of AF and on AF induced electrical remodeling was investigated. 


\section{References}

1. Pritchett AM, Jacobsen SJ, Mahoney DW, Rodeheffer RJ, Bailey KR, Redfield MM. Left athal wolume as an index of left atrial size: a population-based study. I Am Coll Cardlol $2003 ; 41(6): 1036-1043$.

2. Vaziri SM, Larson MG, Benjamin EJ, Levy D. Echocardiographic predictors of nonitheumatic atrial fibrillation. The Framingham Heart Study. Circulation $1994 ; 89(2): 724-730$.

3. Benjamin EJ, D'Agostino RB, Belanger $A J$, Wolf PA, Lev' $D$. Left atrial size and the risk of stroke and death. The Framingham Heart Study. Crrculation 1995,92(4):835-841.

4. MoMichael 3. History of atrial fibribation 1628-1819 Harvey - de Senac - Laeninec. Br Heart I $1982 ; 48(3): 193-197$.

5. Cushny AR, Edmunds CW. Paroxysmal irregularity of the heart and auricular fibrillation. Am: I Med Sci 1907;133:67-77.

6. Mewiliam JA. Fibrillar contraction of the heart. Jourmal of Physlology $1887 ; 8: 296-310$.

7. Garrey WE. The nature of fiblillary contraction of the heart. Its relation to tissue mass and from. Am: 1 Physio: 1914; 33:387; 414 .

8. Nahum LH, Hoff HE. Auricular fbrillation in hyperthyroid patients produced by acetyl-Bmethylcholine chloride, with observations on the role of the vagus and some exciting agents in the genesis of auricular fibrillationi. JAMA 1935;105:254-257.

9. Luten $D$. The relationship of tachycardia to cardiac insufficiency, Am Heart Journall $1936 ; 12: 435-442$.

10. Brill IC, Meissner WA. The role of coronary artery disease in the etiology of aumicular fibrillation. Anr Int Med 1941;14:1341-13.47.

11. Smith JR, Wilson KS. Studies on the praduction and maintenance of experimental auricular fibrillation. Am Heart $11943 ; 27: 176-185$.

12. Scherf D, Scharf MM, Goklen MF. Effect of stretch and pressure on stimulus formation In the dog's auricle. Proc Exp Biol 1949;70:708-711.

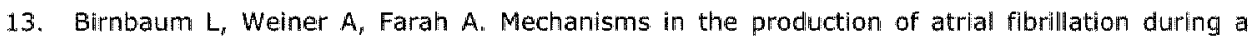
sphyxia. Am Heart 1 1962;63:676-687.

14. Solti $F$, Vecser $T$, kekési $V$, Juhasz-Nagy $A$. The effect of atriall dilatation on the geneshs of atrial arrhythmas. Cardhowasc Res 1989;23:882-886.

15. Siderts $D$, Toumanidis $S_{;}$Thodorakis M, Kostopoulos $K$, Tsielepatiotis E, Langoura 6 , Stringl T, Moulopoulos S. Some observations on the mechanism of pressure related atrial fibrillation. Eur Heart 1 1994; 15:1585-1589.

16. Ravell $F$, Allessie M. Effects of atrial dilatation on refractory period and vulnerability to atrial fibrillation in the isolated Langendorf-perfused rabbit heart. Circulation 1997;96:1686-1695.

17. Moore EN, Flsher $G$, Detweiler DK, Moe GK. The Importanice of atrial mass In the maintenance of atrial fibrillation. Paper presented at: International Symposium on Comparative Medicine, 4962 .

18. Boswell $S H, H o f f$ HE Geddes LA. Body size in the maintenance of experimental atrial fibrilation in the dog. Cardiovasc Res Cent Bull 1968;6(3):99-116.

19. West $T C$, Landa JF. Minimal mass required for Induction of a sustained arthythmla in Isolated atrial segments. Am J Physial 1962;202:232-236.

20. Boyden PA, Hoffman BF. The effects on atrial electrophysiology and structure of surglcally induced right atrial enlargement in dogs. Circ Res 1981;49:1319-1331.

21. Boyden PA, Tilley $L P$, Phaim TD, Liu SK, Fenoglic J1, Jr., Wit AL. Effects of left atrial enlairgement on atrial transmembrane potentials and structure in dogs with mitral valwe flbrosis. Ant 1 Cardiol 1982;49(8):1896-1908. 
22. Fraser HR, Turner RW. Auricular fibrillation; with special reference to rheumatic heart disease. Br Med J 195: 4953$): 1414-1418$.

23. Moreyra $A E$, wilson $A C$, Deac $\mathbb{R}_{s}$ Suciu $C$, Kostis $\mathrm{IB}$, Ortan $F$, Kovacs $T$, Mahalingham $B$. Far. tors associated with atrial fibrillation in patients with mitral stenosis: a cardiac catheterization study. Am Heart J 1998; 135(1): 138-145.

24. Henry WL, Morganroth 3, Pearlman AS, Clark CE, Redwood DR, Itscoitz SB, Epstein SE. Relation between echocardiographically determined left atrial size and atrial fibrillation. Circulation $1976 ; 53: 273-279$.

25. Psaty BM, Manolio TA, Kuller $L H$, Kronmal RA, Cushman M, Fried LP, White $R$, Furberg $C D$, Rautaharju PM. Incidence of and risk factors for atrial fibrillation in older adults. Circulation $1997 ; 96(7): 2455-2461$.

26. Sanfilippo AJ, Abascal VM, Sheehan M, Oertel LB, Harrigan P, Hughes RA, Weyman AE. Atrial enlargement as a consequence of atrial fibrillation. Circulation 1990;82:792-797.

27. Dernellis JM, Panaretou MP. Effects of digoxin on left atrial function in theart failure. Heart $2003 ; 89(11): 1308-1315$.

28. Suarez $G S$, Lampert $S$, Ravid $S$, Lown $B$. Changles in left atrial size in patients with lone atrial fibriliation. Clin Cardiol $1991 ; 14(8) ; 652-656$.

29. Rostagno $C_{d}$ Olivo $G$, Comeglio $M$, Bertini $G$, Gensini $G$, Galanti $G$. Left atrial size changes in patients with paroxysmal lone atrial fibrillation. Angiology $1996 ; 47(8): 797-801$.

30. Petersen P, Kastirup J, Brinch $K$, Godtfredsen J,Boysen $G$. Relation between left atrial dimension and duration of atrial fibrillation. Am \& Cardiol 1987;60:382-384.

31. Keren G, Etzion $T$, Sherez J, Zelcer AA, Megidish R, Miller HI, Laniado S. Atrial fibrillation and atrial enlargement in patients with mitral stenosis. Am Heart $J 1987 ; 114: 1146-1155$.

32. Dittrich $H C_{x}$ Pearce $L A$, Asinger RW, McBride $R$, Webell $R$, Zabalgoitia M, Pennock GD, Safford RE, Rothbart RM, Halperin JL, Hart RG. Left atrlal diameter in nonvalwular atrial fibrillation: An echocardiographic study. Stroke Prevention in Atrial Fibrillation Investigators. Am Heart $J$ $1999 ; 137(3): 494-499$.

33. Manning WJ, Leeman DE, Gotch PJ, Come PC. Pulsed Doppler evaluation of atrial mechanical function after electrical cardioversion of atrial fibrillation. J Am Coll Cardiol 1989;13(3):617623.

34. Van Gelder IC, Crijns HJ, Van Gilst WH, Hamer HP, Lie KI. Decrease of right and left atrial sizes after direct-current electrical cardioversion in chronic atrial fibrillation. Am J Cardlol $1991 ; 67(1): 93-95$.

35. Morillo $C A$, Klein GJ, Jones $D L$, Guiraudon $C M$. Chronic rapid atrial pacing. Structural, functional, and electrophysiological characteristics of a new model of sustained atrial fibrillation. Circulation 1995;91(5):1588-1595.

36. Shi $Y$, Ducharme $A, L i D$, Gaspo $R_{r}$ Nattel $S$, Tardif JC. Remodeling of atrial dimensions and emptying function in canine models of atrial fibrillation. Cardiovasc Res 2001;52(2):217-225.

37. Schotten U. Mechanisms of Atrial Paralysis due to Atrial Fibrillation. An Integrative study in man and goat. Maastricht, Maastricht University; 2003(Thesis).

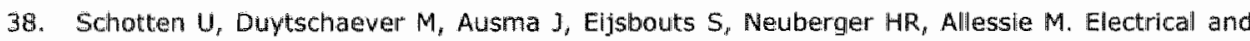
contractile remodeling during the first days of atrial fibrillation go hand in hand. Circulation 2003;107(10):1433-1439.

39. Yue $L$, Feng J, Gaspo $R, L, G$, Wang $Z$, Nattel $S$. Ionic remodeling underlying action potential changes in a canine model of atrial fibrillation. Circ Res 1997;81:512-525.

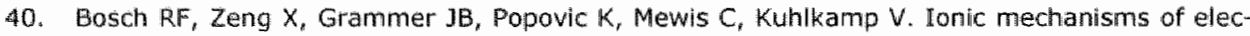
trical remodeling in human atrial fobrlllation. Cardiovasc Res 1999;44(1):121-131.

41. Van Wagoner DR, Pond AL, Lamorgese M, Rossie SS, MCCarthy PM, Nerbonne JM. Atrial L-type Ca2+ currents and human atrial fibrillation. Circ Res 1999;85(5):428-436. 


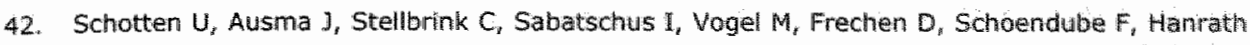
P. Allessie MA. Cellular mechanisms of depressed atrial contractlity in patients with chronic atrial fibrilation. Circuliation $2001 ; 103(5): 691 ; 698$.

43. Schotten $U$, Neuberger HR, Allessie MA. The role of atrial dilatation in the domestication of atrial fibrilation. Prog Biophys Mol Biol 2003;82(1-3):151-162.

44. Goette A, Lendeckel U, Klein HU. Signal transduction systems and atrial fibrilation. Cardiovasc Res $2002 ; 54(2): 247-258$.

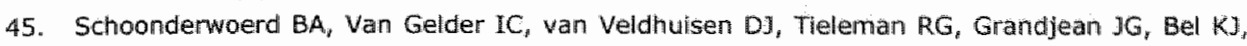
Allessie MA, Crijns $H$ J. Electrical remodeling and atrial dilation during atrial tachycardia are influemced by ventricular rate: role of deweloping tachycardiomyopathy i Cardiovasc Electrophysiol $2001 ; 12(12): 1404-1410$.

46. Nazir $S$, Lab M. Mechanoelectrical feedback in the atrium of the isolated guinea-pig heart. Cardiovasc Res $1996 ; 32: 112-119$.

47. Tse HF, Pelosi F, Oral H, Knight BP, Strickberger SA, Mcrady F. Effects of simultaneous atrioventricular pacing on atrial refractoriness and atrial fibrillation inducibility " role of atrial mechanoelectrical feedback. J Cardlovasc Electrophysiol 2001;12(1):43-50.

48. Kaseda $S$, Zipes DP. Contraction-excitation feedback in the atria: a cause of changes in refractoriness. I Am Coll Cardiol 1988; 1 1 (6):1327-1336.

49. Klein LS, Mlles WM, Zipes DP. Effect of atrioventrlcular interval during pacing or reciprocating tachycardia on atrial size, pressure, and refiactory perlod. Contraction-excitation feedback in human atrium. Circulation 1990;82:60-68.

50. Calkins $H$, el-Atassi $R$, Leon $A$, Kalbfleisch $S$, Borganelli $M$, Langberg $d$, Momady $F$. Effect of the atrioventricular melationship on atrial refractoriness in humans. Pacing Clin Electrophysiol $1992 ; 15(5): 771-778$.

51. Wijffels $\mathrm{MC}_{\text {r }}$ Kirchhof $\mathrm{CJ}$, Dorland $\mathrm{R}$, Power 1 , Allessie MA, Electrical remodeling due to atrlal fibrillation in chronically instrumented conscious gaats: roles of neurohumoral changes, ischemia, atrial stretch, and high rate of electrical activation. Circulation 1997:96(10):37103720 .

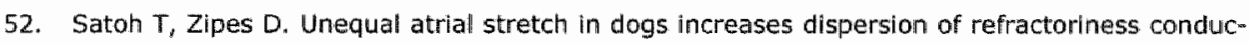
tive to developing atrial fibrillation. I Cardiovasc Electrophysiol 1996;7:833-842.

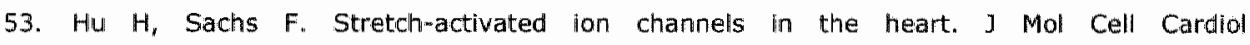
$1997 ; 29(5): 1511-1523$.

54. Hansen DE Borganelli $M$, Stacy GP, Jr., Taylor LK. Dose-clependent Inhilbition of stretchinduced arrhythmias by gadolinium in isolated canine ventricles. Evidence for a unique mode of antiarthythmic action. Circ Res $1991 ; 69(3): 820-831$.

55. Nazir $S_{y}$ Dick D, Sachs F, Lab MJ. Effects of G. spatulata venom, a novel stretch-activated channel blocker in a madel of stretch-induced ventriculall fibrillation in the isolated heart. Circulation 1.995;92(Suppl. 1):641.

56. Bode F, Katchman A, Woosley RL, Franz MR. Gadolinium decreases stiretch-induced wulnerability to atrial fibrillation. Circulation 2000;101(18):2200-2205.

57. Bode $F$, Sachs $F$, Franz MR. Tarantula peptide inhibits atrial fibrillation. Nature $2001 ; 409(6816): 35-36$.

58. Power JM, Beacom GA, Alferness CA, Raman J, Wijffels M, Farish SJ, Burrell LM, Tonkin AM. Susceptibilty to atrial fibrillation: $A$ study in an ovine model of pacing-induced early heart fallure. I Cardiovasc Electrophysial 1998;9(4):423-435.

59. LI D, Fareh $S$, Leung TK, Nattel S. Promotion of atrial fibrillation by heart falure irl dogs: atrial remodeling of a different sort. Circulation 1999;100(1):87 .95 .

60. Verheule $S$, Wilson E, Everett Tt, Shanbhag $S$, Golden $C$, Olgin J. Alterations in atrial electrophysiology and tissue structure in a canine model of chronic atrial dilatation due to mitral rexgurgitation. Circulation $2003 ; 107(20): 2615-2622$. 
61. Chen $Y$, Chen $S A$, Tai $C T$, Yu WC, Feng AN, Ding YA, Chang MS. Electrophysiologic characteristics of a dilated atrum in patients with paroxysmal atrial fibrillation and atrial flutter. I Interv Card Electrophysiol 1998;2(2):181-186.

62. Sparks PB, Mond HG, Vohra JK, Jayaprakash S, Kaiman JM. Electrical remodeling of the atria following loss of atrioventricular synchrony: a long-term study in humans. Circulation 1999, $100(18): 1894-1900$.

63. Morton 1B, Sanders P, Wohra JK, Sparks PB, Morgan JG, Spence S3, Grigg LE, Kalman JM. Effect of chronic right atrial stretch on atrial electrical remodeling in patients with an atrial septal defect. Circulation 2003;107(13):1775 1782.

64. Le Grand $B L$, Hatem $S_{\text {, Deroubaix }} E$, Couetli $J P_{j}$ Coraboeuf $E$. Depressed transient outward and calcium currents in dilated human atria. Cardiovasc Res 1994;28(4):548-556.

65. Dudel 1, Trautwein W. Das Aktionspotential und Mechanogramm des Herzmuskels unter dem Einfluss der Dehnung. Cardiologia 1954;25(6):344-362.

66. Penefsky 2 , Hoffman B. Effect of stretch an mechanical and electrical properties of cardiac muscle. Am J Physiol 1963;204(3):433-438.

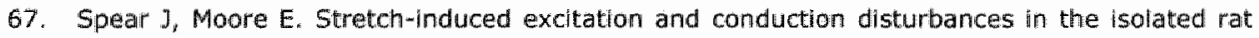
Imyocardium. I Electrocardiol $1972 ; 5(1): 15-24$.

68. Hordof AJ, Edle R, Malm JR, Hoffman BF, Rosen MR. Electrophysiologic properties and response to pharmacologic agents of fibers from diseased human atria. Circulation $1976 ; 54(5): 774-779$.

69. Mary-Rabine L, Albert $A_{v}$ Pham TD, Hordof A, Fenoglio JJ, Jr., Malm JR, Rosen MR. The relationship of human atrial cellular electrophysiology to clinical function and ultrastructure. Circ Res 1983;52(2): 188-199.

70. Deck K. Anderung des Ruhepotentials und der Kabelieigenschaften von Purkinje-Faden bei der Dehnung. Pflugers Archiw 1964;280:131-140.

71. Dominguez $G$, Fozzard $H$. Effect of stretch on conduction velocity and cable properties of cardiac purkinje fibers. Am J Physiol 1979;6(2):C119-C124.

72. Chorro FJ, Egea S, Mainar L, Canoves J, Sanchis J, Llavador E, Lopez Merino V, Such L. Modificaciones agudas de la longitud de onda del proceso de activacion auricular inducidas por la dilatacion. Estudio experimental. Rev Esp Cardiol 1998;51(11):874-883.

73. Sanders $\mathrm{P}$, Morton $\mathrm{JB}$, Davidson $\mathrm{NC}_{\text {, }}$ Spence $\mathrm{SJ}$, Vohra JK, Sparks $\mathrm{PB}$, Kalman JM. Electrical remadeling of the atria in congestive heart failure: electrophysiological and electroanatomic mapping in humans. Circulation 2003; 108(12):1461-1468.

74. Haissaguerre $M_{n}$ Jais $P$, Shah $D C_{n}$ Takahashi $A_{r}$ Hocini $M$, Quiniou $G$, Garrigue $S$, Le Mouroux $A$, Le Metayer $P$, Clementy $\rrbracket$. Spontaneous initiation of atrial fibrillation by ectopic beats originating in the pullmonary veins. $\mathbb{N}$ Engl ] Med 1998;339(10):659-666.

75. Allessle $M$, Ausma J, Schotten U. Electrical, contractile and structural remodeling during atrial fibrillation. Cardiovascular Research 2002;54(2):230-246.

76. Wijffels MCEF, Kirchhof $\mathrm{CJHJ}$, Dorland R, Allessie MA. Atrial fibrillation begets atrial fibrillation. A study in awake chronically instrumented goats. Circulation 1995;92:1954-1968.

77. Rensma $\mathrm{PL}$, Allessie $\mathrm{MA}$, Lammers WJ, Bonke $\mathrm{FI}$, Schallj $\mathrm{MJ}$. Length of excitation wave and susceptibility to reentrant atrial arrhythmias in normal conscious dogs. Circ Res $1988 ; 62(2): 395-410$.

78. Allessie MA, Lammers WJEP, Rensma PL, Schallj MJ, Kirchhof CJHJ. Determinants of reentry in cardiac muscle. Progress Cardiol 198:8;1/2:3-15.

79. Logan WF, Rowlands DJ, Howitt G, Holmes AM. Left Atrial Activity Following Cardioversion. Lancet $1965 ; 10: 471-473$.

80. Manning WJ, Silverman DI, Katz SE, Riley MF, Come PC, Doherty RM, Munson JT, Douglas PS. Impared left atrial mechanical function after cardioversion: relation to the duration of attrial fibrillation. J Am Coll Cardiol 1994;23(7):1535-1540. 
81. Ausma 3 , Wijffels $M$, Thone $F$, Wouters $L$, Allessie M, Borgers $M$. Structural changes of atral myocardium due to sustained atrial fibrillaton in the goat. Circulation 1997,96(9):3157-3163.

82. Ausma 3, Litjens $N_{*}$ Lenders MH, Dumel $H$, Mast $F$, Wouters $L$, Ramaekers F, Allessie M, Borgers M. Time course of atrial fibrilation-induced cellular structural remodeling in atria of the goat. J Mol Cell Cardiol 2001;33(12):2083-2094.

83. Ausma J, van der Velden HM, Lenders MH, van Ankeren EP, Jongsma HJ, Ramaekers FC, Borgers M, Allessie MA. Reverse structural and gap-junctionat remodeling after prolonged atrial fibrillation in the goat. Circulation 2003; 107(15):2051-2058.

84. Borgers $M$, Thone $F$, Wouters $L$, Ausma $J_{n}$ Shivalkar $B$, Flameng $W$. Structural correlates of regional myocardial dysfunction in patients whth critical coronary artery stenosis: Chronic hibernation? Cardiowascular Pathology $1993 ; 2(4): 237-245$.

85. van der Velden HM, Ausma 3, Rook MB, Hellemons AJ, vam Veen TA, Allessie MA, Jonglsma H. Gap junctional remodeling in relation to stabilization of atrial fibrillation in the goat. Cardion vasc Res $2000 ; 46(3): 476-486$.

86. Everett THt, Li H, Mangrum JM, MicRury ID, Mitchell MA, Redick JA, Haines DE. Electrical, morphological, and ultrastructural remodeling and reverse remodeling in a camine model of chronic atrial fibrillation. Circulation $2000 ; 102(12): 1454-1460$.

87. Bailey GW, Braniff BA, Hancock EW, Cohn KE. Relation of left atrial pathology to atrial fibrillation in mitral valvular disease. Ann Intern Med 1968;69(1):13-20.

88. Davies MJ, Pomerance A. Pathology of atrial fibrillation in man. Br Heart 1 1972;34(5):520525.

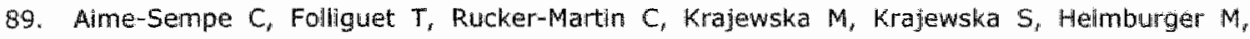
Aubier M, Mercadler J3, Reed JC, Hatem SN. Myocardial cell death in fibrillating and ditated thuman right atria. 3 Am Coll Cardiol 1999;34.(5):1577-1586.

90. Frustaci A, Chimenti C, Bellocd F, Morgante E, Russo MA, Maseri A. Histological substrate af atrial biopsies in patients with lone atrial fibrillation. Circulation $1997 ; 96(4) ; 1180-1184$.

91. Brundieł BJ, Ausma J, wan Gelder IC, Van der Want J1, van Gist WH, Crijns HJ, Henning RH. Actiwation of proteolysis by calpains and structural changes in human paroxysmal amd persistent atrial fibrillation. Cardiowasc Res 2002;54(2):380-389.

92. Spach MS, Heidiage JF, Dolber PC, Barr RC. Changes in anisotropic conduction caused by remodeling cell size and the cellular distribution of gap junctions and $\mathrm{Na}(*)$ channels. I Electrocardiol 2001; 34 Suppl:69-76.

93. Moe GK. On the multiple wavelet hypothesis of atrial fibrillation. Arch Int Pharmacodyn Ther $1962 ; 140: 183-188$.

94. Garrey WE. The nature of fibriliation contraction of the heart; its relaton to tissue mass and form. Am J Physial $1914 ; 33: 397-414$

95. Rensma PL. Atrial arrhythmias and measurement of the wavelength in a chronic dog model. Maasticht: Physiology, University of Limburg; 1987(Thesis).

96. Allessie MA, Lammers WJEP, Bonke FIM, Hollen SJ. Experimental evaluation of Moe's multiple wavelet hypothesis of atrial forillation. NY: Grune \& Stratton, 1985.

97. Holland $W_{C}$ Burm JH. Production of fibrillation in isolated atria of rabbit heart. Br Med $\mathrm{J}$ $1957(5026): 1031-1033$.

98. Bohn FK, Patterson DF, Pyle RL. Atrial fibrillation in dogs. Br Vet 1 1971;127(10):485-496.

99. Petersen $P$, Godtfredsen 1. Atrial fibrillation--a review of course and prognosis. Acta Med Scand $1984 ; 216(1): 5-9$.

100. Moore EN, Spear JF. Natural occurrence and experimental initation of atrial fibrillation in different animal species. Molndal, Sweden, 1982.

101. MCGuirk SM, Muir WW, Sams RA, Rings DM. Atrial fibrillation in Cows: clintcal findings and therapeutic considerations. I Am Vet Med Assoc 1983;182(12):1380-1386. 
102. Deem DA, Fregin GF. Atral fibrillation in horses: a review of 106 clinical cases, with consideration of prevallence, dinical signs, and progniosis. I Am Vet Med Assoc 1982; 180(3):261265 . 


\section{Chapter 2}

\section{The Effects of Acute Atrial Dilatation on Heterogeneity in Conduction in the Isolated Rabbit Heart}

Sabine C.M. Eijsbouts, MD, Mohamed Majidi, Marc van Zandvoort, PhD, Maurits A. Allessie, MD, PhD 


\section{Abstract}

\section{Introduction}

Atrial dilatation plays an important role in the development and persistence of atrial fibrillation (AF). The mechanisms by which atrial dilatation increases the vulnerability to AF are not fully understood.

\section{Methods and Results}

In 11 isolated rabbit hearts the right atrium was acutely dilated by increasing the intra-atrial pressure from 2 to 9 and $14 \mathrm{~cm} \mathrm{H}_{2} \mathrm{O}$. A rectangular mapping array of 240 electrodes (spatial resolution $0.5 \mathrm{~mm}$ ) was positioned on the free wall of the right atrium. The atrium was paced from 4 different sites at intervals of 240 and $125 \mathrm{~ms}$. At normal atrial pressure $\left(2 \mathrm{~cm} \mathrm{H}_{2} \mathrm{O}\right)$ conduction was uniform in all directions with an anisotropy ratio between 1.5 and 1.7 . Increasing the pressure to $9 \mathrm{~cm} \mathrm{H}_{2} \mathrm{O}$ decreased the normalized conduction velocity during rapid pacing by $18 \%$. The incidence of areas of slow conduction and conduction block increased from 6.6 and $1.6 \%$ to 10.2 and $3.3 \%$. At $14 \mathrm{~cm} \mathrm{H}_{2} \mathrm{O}$ conduction velocity decreased by $31 \%$ and the percentage of slow conduction and block further increased to 11.5 and $6.6 \%$ $(p<0.001)$. The appearance of lines of intra-atrial block was largely dependent on the pacing site. Whereas during pacing at the cranial part of the crista terminalis no increase in conduction delays occurred, pacing from the low right atrium unmasked several lines of block oriented parallel to the major trabeculae and the crista terminalis. In an additional series of 6 hearts also the left atrium was mapped. The effect of dilatation of the left atrium was comparable to the right atrium. Increasing the atrial pressure to $14 \mathrm{~cm}$ $\mathrm{H}_{2} \mathrm{O}$ increased the amount of intra-atrial conduction block 3-4 fold.

\section{Conclusions}

Acute atrial dilatation results in slowing of conduction and an increase of the amount of intra-atrial conduction block. The increase in spatial heterogeneity in conduction was related to the anisotropic properties of the atrial wall. 


\section{Introduction}

Atrial dilatation is known to be an important independent risk factor for atrial fibrillation (AF). ${ }^{1,2}$ Several clinical studies have shown a causal relationship between increased left atrial size and the development of AF. ${ }^{3.4}$ Atrial size is also a predictor of successful cardioversion and maintenance of sinus rhythm. ${ }^{5,6}$ In animal studies both acute and chronic atrial dilatation have been shown to increase the vulnerability to $A F .^{7-9}$ On the other hand, dilatation of the atria can also be a consequence of AF. ${ }^{10-14}$ After 20.6 months of lone AF the size of the left atrium was found to be increased from 45.2 to $64.1 \mathrm{~cm}^{3}$ and the right atrial size from 49.2 to $66.2 \mathrm{~cm}^{3}$. $^{13}$ This can be understood by the observation that AF induced electrical remodeling is accompanied by a loss of atrial contractility (contractile remodeling). ${ }^{15}$ The resulting increase in compliance of fibrillating atria will lead to atrial dilatation even without an increase in atrial pressure. ${ }^{16}$ In this way atrial dilatation may play a role in the perpetual cycle leading to persistent AF. ${ }^{17}$

The mechanisms by which atrial dilatation leads to a substrate of AF are not fully understood. Most studies focused on a role of atrial refractoriness, whereas the effect of dilatation on conduction was evaluated only in a few studies. In dogs acute left atrial dilatation by a balloon was found to prolong the interatrial conduction time. ${ }^{8}$ The same was observed during acute volume overload of the right atrium. ${ }^{18}$ In a mapping study in the isolated rabbit heart Chorro et al. found a decrease in conduction velocity in the dilated right atrium of about $25 \% .{ }^{19}$ Whereas these previous studies evaluated the effect of atrial dilatation on the overall conduction velocity, they did not address the occurrence of local conduction delays and block, which may play an important role in the initiation and perpetuation of re-entrant arrhythmias. In the present study we quantified the spatial heterogeneities in atrial conduction during acute dilatation of the right and left atrium using high-density mapping. During pacing from four different directions areas with slow conduction $(10-20 \mathrm{~cm} / \mathrm{s})$ and lines of conduction block $(510 \mathrm{~cm} / \mathrm{s})$ were identified. The creation of heterogeneities in conduction by acute stretch was expressed by the percentage of the tissue area exhibiting slow conduction or conduction block. 


\section{Methods}

\section{Rabbit Model of Atrial Dilatation}

Eleven Giant Flemish rabbits $(3.5-4.5 \mathrm{~kg})$ and six New Zealand rabbits (2.3$2.7 \mathrm{~kg}$ ) of either sex were used for this study. All experiments were carried out according to the Dutch Law on Animal Experimentation and The European Directive on the Protection of Vertebrate Animals. The study protocol was approved by the Animal Investigation Committee of the University of Maastricht. After sedation by intramuscular injection of $0.5 \mathrm{ml} / \mathrm{kg} \mathrm{Hypnorm}^{(2)}$ and 1000 IU heparin i.v. the animals were killed by cervical dislocation. After a midsternal incision the heart was rapicly removed and placed in cold perfusion fluid $\left(10^{\circ} \mathrm{C}\right)$. The aorta was cannulated and perfused at a pressure of $60 \mathrm{mmHg}$. The composition of the perfusion fluid was $(\mathrm{mM}): \mathrm{NaCl} 130$, $\mathrm{NaHCO}_{3} 20.1, \mathrm{KCl} 4.0, \mathrm{CaCl}_{2} 2.2, \mathrm{MgCl}_{2} 0.6, \mathrm{Na}_{2} \mathrm{HPO}_{4} 1.2$ and glucose 12. The solution was saturated with a mixture of $95 \% \mathrm{O}_{2}$ and $5 \% \mathrm{CO}_{2}$. The $\mathrm{pH}$ was 7.35 and temperature was kept at $37 \pm 0.5{ }^{\circ} \mathrm{C}$. The pulmonary artery and inferior caval vein were ligated and the superior caval vein was cannulated to serve as the exclusive outflow tract for the coronary perfusate. By changing the height of this cannula the pressure in the right atrium could be easily controlled. In experiments in which both atria were dilated a large atrial septum defect was created, the pulmonary veins were ligated, and the pressure in the left atrium was measured by a cannula in one of the pulmonary veins. During atrial dilatation coronary perfusion pressure was kept constant by increasing the aortic pressure with the same amount as the right atrial pressure. Figure 1 shows an example of right and left atrial dilatation by increasing the atrial pressure from 2 to 9 and $14 \mathrm{~cm} \mathrm{H}_{2} \mathrm{O}$ respectively. In the rabbit the in vivo mean right atrial pressure has been reported to be $4.4 \pm 0.4 \mathrm{~cm} \mathrm{H} \mathrm{H}_{2} \mathrm{O}$ with a left to right gradient of $2 \mathrm{~cm} .{ }^{20,21}$ Thus, the pressures of 9 and $14 \mathrm{~cm} \mathrm{H}_{2} \mathrm{O}$ used in our study represent a clear increase compared to the normal atrial pressure. The degree of stretch was calculated as the increase in distance between two anatomical landmarks (one dimension) and the increase in surface area between four anatomical landmarks (2-D). The relative amount of stretch at 9 and $14 \mathrm{~cm} \mathrm{H}_{2} \mathrm{O}$ was normalized to the dimension at $2 \mathrm{~cm} \mathrm{H}_{2} \mathrm{O}(0 \%$ stretch).

\section{High Density Mapping}

An area of $7.0 \times 7.5 \mathrm{~mm}$ was mapped by an array of $15 \times 16$ silver electrodes (diameter $0.25 \mathrm{~mm}$, interelectrode distance $0.5 \mathrm{~mm}$ ). In the right atrium the mapping electrode was positioned with one edge on the crista terminalis (CT). Two sutures at the intercaval area were used as reference points. The white dashed boxes in Fig. 1 indicate the same part of the right and left atrial wall at different degrees of dilatation. In the left atrium the reference-sutures 

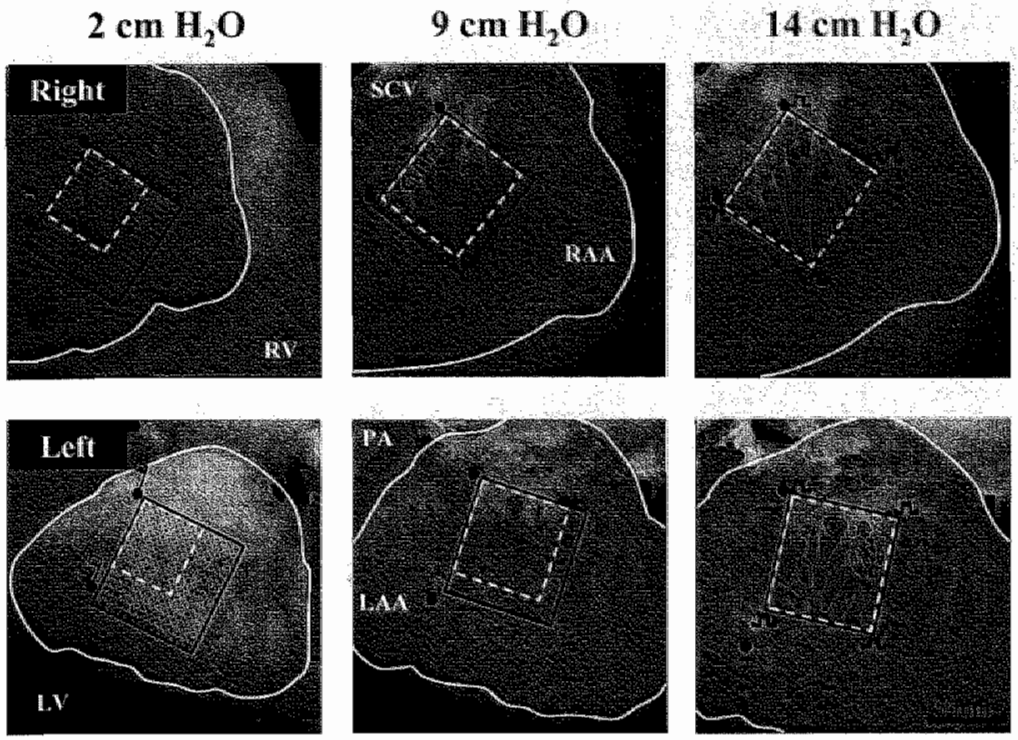

Figure 1: Photographs of the free wall of the right and left atrium at atrial pressures of 2,9 and 14.m H2O. The mapping array ( $15 \times 16$ electrodes) was positioned parallel to a palr of sutures indicated by flags (left panels) with the upper left corner (pacing site A) next to the most cranial suture. The white dashed boxes indicate the same part of the right and left atrial wail at increasing degrees of dilatation. In the right atrium the mid portion of the crista terminalis was mapped together with the trabeculae running obliquely towards the AV-ring. In the left atrium the mid portion of the trabeculated free wall was mapped. The atria were paced from each of the 4 comers of the mapping array (right panels). $R V=$ right ventricle; $L V=l e f t$ ventricle; $S C V=$ superior caval veln; RAA=right atrial appendage; PA=pulmonary artery; $L A A=$ left atrial appendage.

were positioned perpendicular to the AV-groove. Both in the right and left atrium the upper left corner of the mapping electrode was positioned next to the upper suture.

Unipolar electrograms $(n=240)$ were recorded simultaneously using the silver cannula in the aorta as indifferent electrode. After amplification (1000 $x)$ and filtering $(1-500 \mathrm{~Hz})$ the signals were multiplexed and analog to digital converted ( $1 \mathrm{kHz}, 12$ bits) and stored on CD-ROM. The local activation times were determined automatically by an algorithm detecting the steepest negative deflections in the electrograms and edited manually if necessary. Color-coded activation maps were generated by the computer and isochrones were drawn manually at 3 ms intervals. The main direction of activation was indicated by arrows. The conduction velocity (CV) in the mapped area was evaluated by the median of the local conduction velocities calculated from the 4 activation times at the corners of all rectangular areas of $2 \times 2 \mathrm{~mm}$. In the mapping array spatial heterogeneity in conduction was quantified by the conduction vectors calculated from neighboring electrodes (areas of $0.5 \times$ $0.5 \mathrm{~mm}$ ). Slow conduction was defined as a local conduction velocity between 10 and $20 \mathrm{~cm} / \mathrm{s}$. Local conduction block was defined as an apparent conduction velocity of $\leq 10 \mathrm{~cm} / \mathrm{s}$. Measurement of the atrial conduction 
velocity as described above calculates the CV over a fixed distance. However, after atrial dilatation the same distance between the electrodes is covered by less myocardial cells (due to stretch). Thus, when atrial conduction would not be affected, the $C V$ per tissue would actually increase with the same amount as the degree of stretch. To compare the conduction velocities at different degrees of dilatation, the CV was normalized for dilatation by dividing the fixed distance (used to calculate the CV) with the degree of stretch of the underlying tissue. The critical values for slow conduction and local conduction block were equally normalized for the amount of stretch. Figure 2 shows an example of mapping of the free wall of the dilated right atrium during pacing from the lower right comer of the mapping array (atrial pressure $14 \mathrm{~cm} \mathrm{H}_{2} \mathrm{O}$ ). In the middle panel the local conduction velocities are plotted as derived from the conduction vectors of all neighboring electrodes (areas of $0.5 \times 0.5 \mathrm{~mm}$ ). In the right panel the spatial heterogeneity in conduction is visualized by plotting the areas of slow conduction (gray) and conduction block (black).

\section{Experimental Protocol}

At each atriall pressure, the atria were paced from 4 different directions at two frequencies (interval 240 and $125 \mathrm{~ms}$ ) by bipolar silver electrodes at the corners of the mapping array. A custom made computer-controlled stimulator was used to deliver constant-current pulses of $1 \mathrm{~ms}$ duration and $2 x$ diastolic threshold. After every 10-15 stimuli the pacing site was automatically shifted to the next pacing site. The last 2 beats of each series of stimuli were analyzed. First the pacing protocol was performed during a control pressure of $2 \mathrm{~cm} \mathrm{H}_{2} \mathrm{O}$ and then repeated after the atrial pressure was increased to 9 and $14 \mathrm{~cm} \mathrm{H}_{2} \mathrm{O}$. After each change in pressure an equilibration period of at least 5 minutes was taken into account. In case atrial fibrillation of longer than 5 minutes occurred, the atria were defibrillated by lowering the temperature of the perfusion fluid to $10^{\circ} \mathrm{C}$. After cardioversion the heart was rewarmed to $37^{\circ} \mathrm{C}$ and after 5 min the pacing protocol was continued.

\section{Statistical Analysis}

Data are presented as mean $\pm \mathrm{SD}$. Statistical analysis was performed by the paired Student's $t$-test. A value of $P<0.05$ was considered to be statistically significant. 


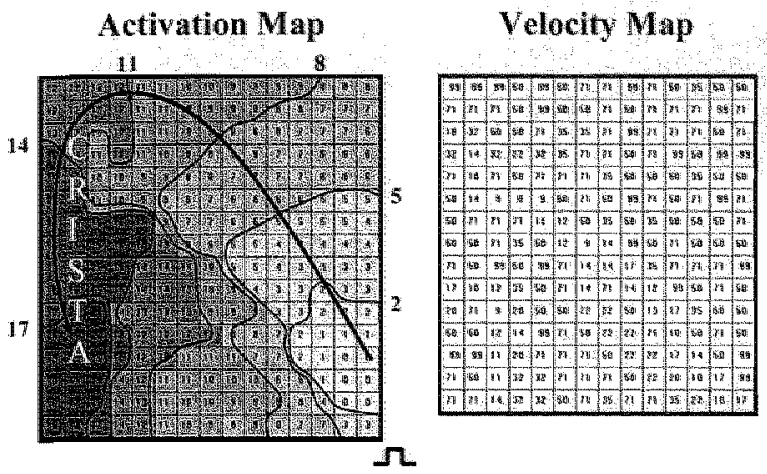

Stow Conduction and Block

Figure 2: High density mapping of the free wall of the dilated right atrium ( $14 \mathrm{~cm} \mathrm{H}_{2} \mathrm{O}$ ) during pacing at the right lower corner of the mapping array (interval 240ms). In the Heft panel the activation map is shown with isochrones drawn at $3 \mathrm{~ms}$ intervals. The arrow indicates the main path of propagation. In the middle panel the local conduction velocities $(\mathrm{cm} / \mathrm{s})$ are plotted, as calculated from the conduction vector of 4 nelighboring electrodes (distance $0.5 \mathrm{~mm}$ ). In case of 4 equal activation times a default value of $99 \mathrm{~cm} / \mathrm{s}$ was attributed. In the right panel the spatial heterogeneity in conduction is visualized by plotting the sites of slow conduction in gray (10$20 \mathrm{~cm} / \mathrm{s})$ and the sites of conduction block in black $(510 \mathrm{~cm} / \mathrm{s})$.

\section{Results}

\section{Effects of Right Atrial Dilatation}

Figure 3 shows an example of right atrial activation during pacing from 4 different sites with a cycle length of $240 \mathrm{~ms}$ both during control and after increasing the atrial pressure to $14 \mathrm{~cm} \mathrm{H}_{2} \mathrm{O}$. The atrial surface was stretched by $31 \%$. The total conduction time (TCT) of the same mapped tissue is shown by the encircled numbers. Pacing site $A$ was positioned at the cranial part of the crista terminalis and resulted in a similar activation as during sinus rhythm. Pacing sites $B, C$ and $D$ were located respectively at the high and low right atrium and the caudal portion of the crista terminalis. At a control pressure of $2 \mathrm{~cm} \mathrm{H}_{2} \mathrm{O}$, activation of the free wall of the right atrium was uniform in all 4 directions and the total conduction times differed by not more than $5 \mathrm{~ms}$. Dilatation of the right atrium changed the main pathway of activation (arrows) and increased the TCT in all directions. Pacing from site A still resulted in smooth uniform conduction. However, pacing from the other directions resulted in local conduction delays at various sites and the directional differences in TCT increased to $10 \mathrm{~ms}$. During control, the majority of the atrial electrograms were single and high in amplitude. After dilatation the atrial electrograms became lower in amplitude due to a reduction of tissue mass under the electrode. In addition, some electrograms became fractionated at sites of slow conduction and conduction block. 

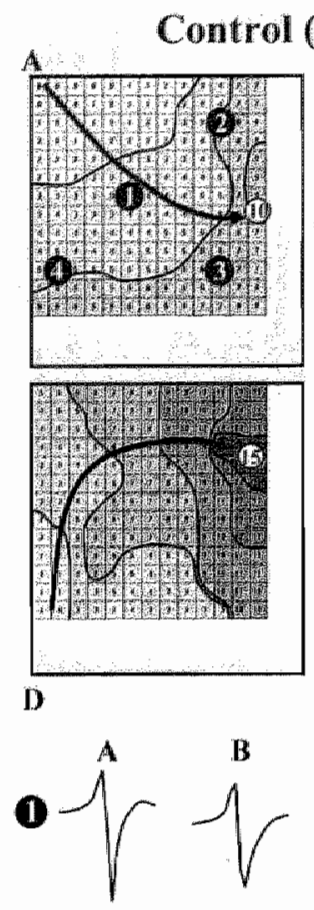<smiles>CCCCCCC</smiles><smiles>CC1CCCCC1=O</smiles><smiles>[C+]CCCC</smiles><smiles>CCCCCC</smiles><smiles>CCCCCCCCCC</smiles><smiles>CCCC1CCC(C)C(C=O)C1</smiles><smiles>CCCCCCC</smiles><smiles>CC1CCC1C</smiles>

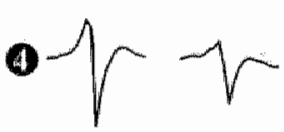

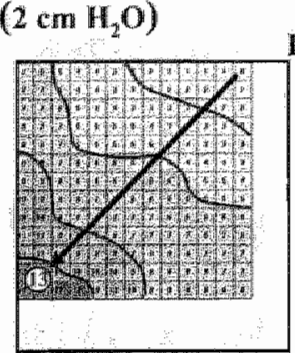

B
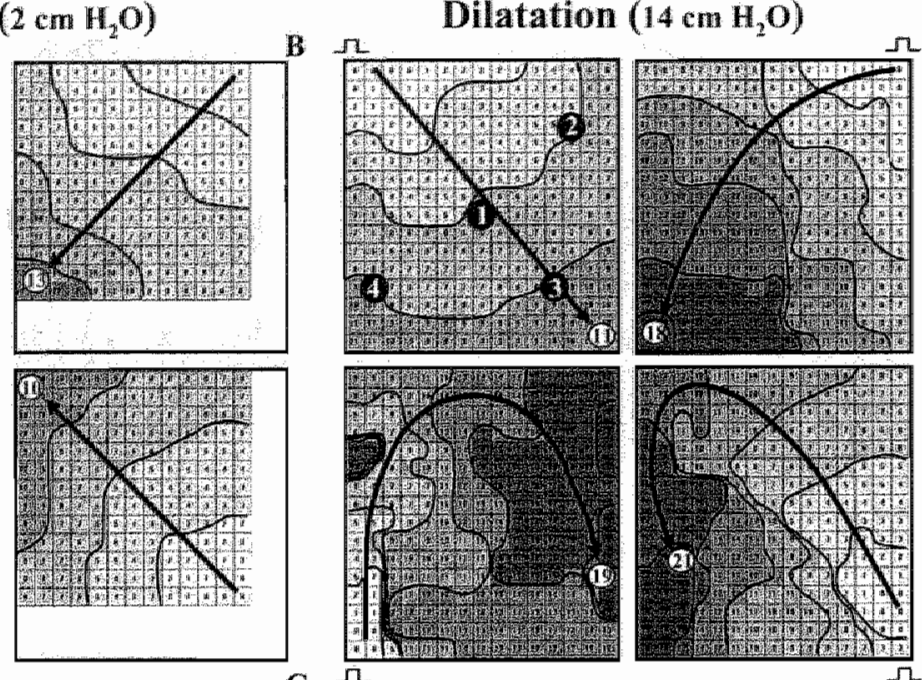

C
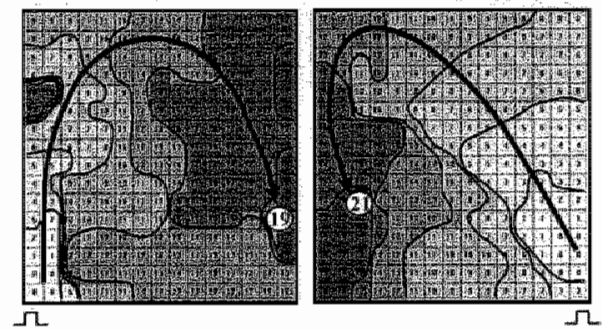

A

B

C

D

Figure 3: High-density maps of the free wall of the right atrium during regular pacing (interwal $240 \mathrm{~ms}$ ) from 4 different directions $\left(A, B, C\right.$ and $D$ ) at an atrial pressure of 2 and $14 \mathrm{~cm} \mathrm{H}_{2} \mathrm{O}$. Activation thimes are given in milliseconds and isochrones are drawn at 3 ms intervals. Arrows indicate the main direction of propagation. The totall conduction time of the mapped tissue is indicated by the encircled black numbers. The sites of recording of the electrograms shown at the bottom are labeled in map A. During dilatation the directional differences were larger and conduction was less uniform due to an increase in local conduction delays (crowding of isochrones). The olectrograms decreased in amplitude and became more fractionated.

Figure 4 shows an example of the increased spatial heterogeneity in conduction at atrial pressures of 9 and $14 \mathrm{~cm} \mathrm{H}_{2} \mathrm{O}$. In the upper panels the distribution of the local conduction velocities during pacing from all 4 directions is shown (resolution $0.5 \mathrm{~mm}$ ). During control $9.9 \%$ of the free wall of the right atrium showed a local conduction velocity of $\leq 20 \mathrm{~cm} / \mathrm{s}$. 
Control

$9 \mathrm{~cm} \mathrm{H}_{2} \mathrm{O}$

Conduction Velocity Histogram
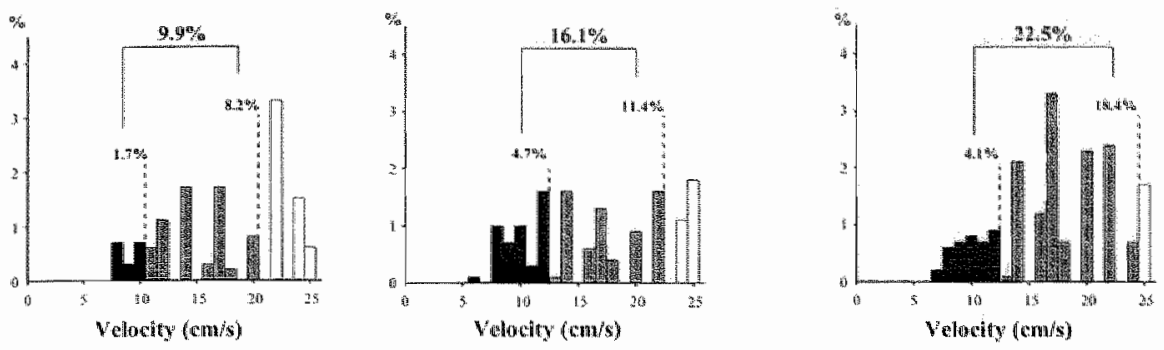

Spatial Distribution of Conduction Block
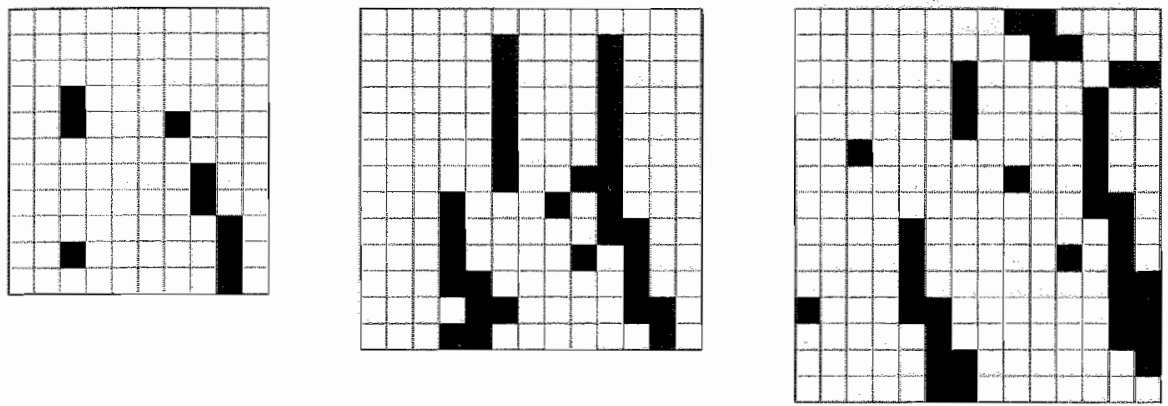

Figure 4: Top: Locall conduction velocity histograms of velocities $\leq 25 \mathrm{~cm} / \mathrm{s}$ during slow pacing from 4 different directions during control and at atrial pressures of 9 and $14 \mathrm{~cm} \mathrm{H}_{2} \mathrm{O}$. The gray and black bars respectively indicate slow conduction and local conduction block. At high atrial pressures the critical value for slow conduction and conduction block was normalized for dilatation (17 and $29 \%$ respectively). During dilatation the incidence of slow conduction and block clearly increased. Bottom: The spatial distribution of local conduction block during control and atrial dilatation. At increased atrial pressures long lines of conduction black appeared.

At 9 and $14 \mathrm{~cm} \mathrm{H}_{2} \mathrm{O}$ the amount of slow conduction and conduction block increased to $16.1 \%$ and $22.5 \%$ respectively. At the bottom the spatial distribution of the areas of intra-atrial conduction block is plotted. Whereas during contral only small areas of conduction block were present, at increased atrial pressures of 9 and $14 \mathrm{~cm} \mathrm{H}_{2} \mathrm{O}$ long lines of conduction block became apparent.

In Table 1 the effects of right atrial dilatation on conduction are given for all 11 hearts. An increase in right atrial pressure to 9 and $14 \mathrm{~cm} \mathrm{H}_{2} \mathrm{O}$ dilated the right atrium by respectively $16 \pm 14 \%(p<0.05)$ and $23 \pm 14 \%(p<0.001)$ (1Dimensional) and $38 \pm 32 \%(p<0.05)$ and $53 \pm 32 \%(p<0.001)$ (surface area). During control $\left(2 \mathrm{~cm} \mathrm{H} \mathrm{H}_{2} \mathrm{O}\right)$ the shortest total conduction time (TCT) occurred during pacing from site $A$ (cranial part of crista terminalis). Pacing from sites $B, C$ or $D$ resulted in a $3-5 \mathrm{~ms}$ increase in conduction time. Atrial dilatation increased the mean TCT of the stretched area from 13 to 15 and $17 \mathrm{~ms}$ during slow pacing and from 13 to 15 and $19 \mathrm{~ms}$ during rapid pacing $(p<0.001)$. 


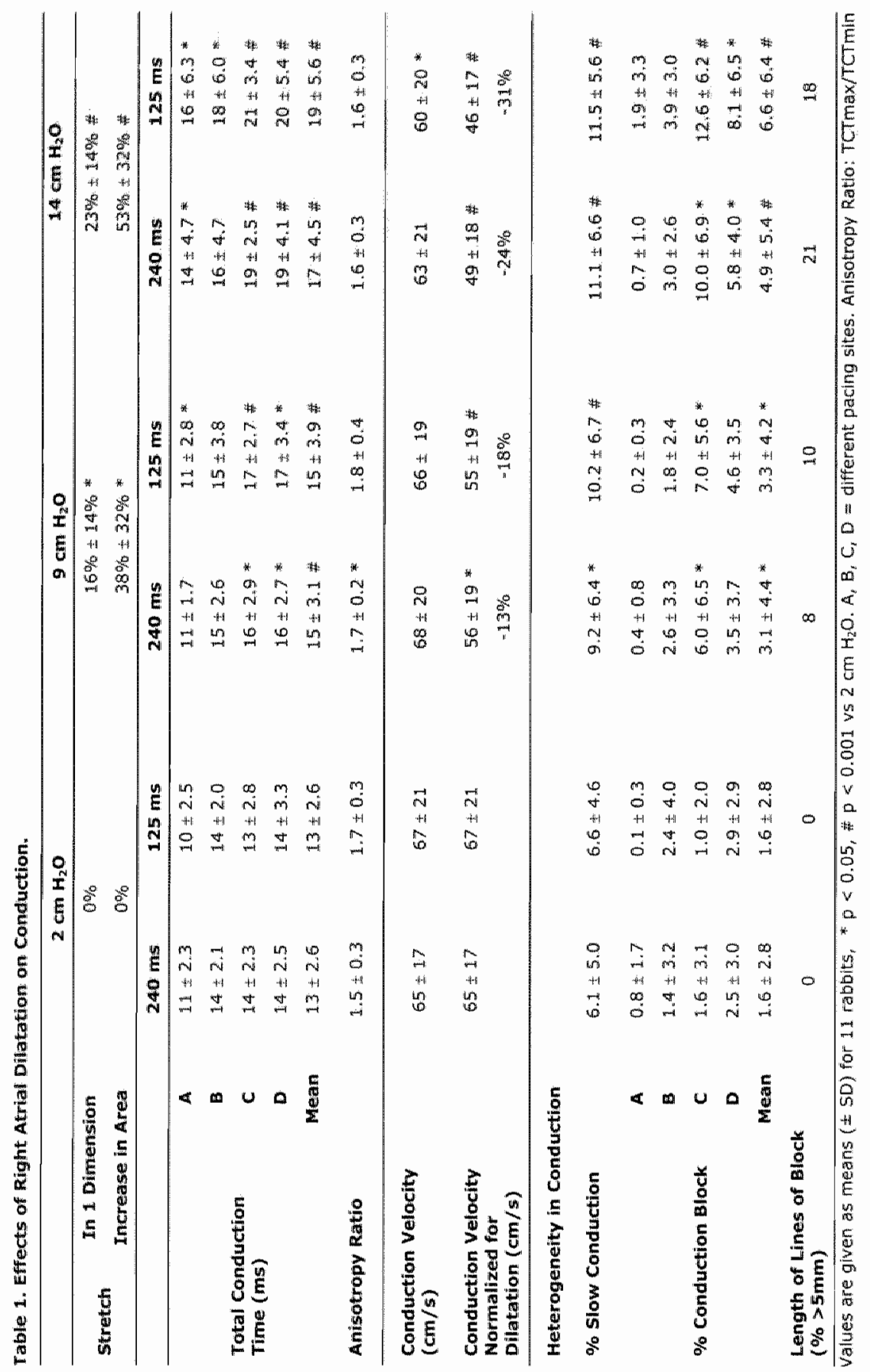


The average anisotropy ratio (the ratio between the longest and shortest TCT during pacing from 4 different directions) increased slightly ( $p<0.05$ at $9 \mathrm{~cm}$ $\mathrm{H}_{2} \mathrm{O}$ ). The median local conduction velocity (pacing interval 240 and $125 \mathrm{~ms}$ ) at $2 \mathrm{~cm} \mathrm{H} \mathrm{H}_{2} \mathrm{O}$ was $65 \pm 17 \mathrm{~cm} / \mathrm{s}$ and $67 \pm 21 \mathrm{~cm} / \mathrm{s}$. During mild stretch $\left(9 \mathrm{~cm} \mathrm{H}_{2} \mathrm{O}\right.$ ) $\mathrm{CV}$ remained unchanged and decreased slightly when the atrium was dilated by a pressure of $14 \mathrm{~cm} \mathrm{H} \mathrm{H}_{2} \mathrm{O}$. After normalization for the degree of stretch, the conduction velocity decreased by 13 and $18 \%$ at $9 \mathrm{~cm} \mathrm{H}_{2} \mathrm{O}$ and by 24 and $31 \%$ at $14 \mathrm{~cm} \mathrm{H}_{2} \mathrm{O}(\mathrm{p}<0.001)$. Spatial heterogeneities in atrial conduction were quantified by calculating the percentage of slow conduction and conduction block in all areas of $0.5 \times 0.5 \mathrm{~mm}$. During control, $6-7 \%$ of all areas exhibited a local conduction velocity between 10 and $20 \mathrm{~cm} / \mathrm{s}$ (slow conduction). After mild and severe dilatation the percentage of slow conduction increased to $9-10 \%$ and $11-12 \%$ respectively. The effects of atrial dillatation on intra-atrial conduction block are given separately during pacing from the 4 different directions (A-D). At normal pressure pacing at site $A$ resulted in less than $1 \%$ intra-atrial conduction block, whereas pacing from the other sites was associated with $1-3 \%$ of local conduction block ( $\mathrm{CV}$ $\leq 10 \mathrm{~cm} / \mathrm{s}$ ). After mild and severe dilatation the occurrence of intra-atrial conduction block became even more dependent on the direction of propagation. Whereas during pacing from sites $A$ and $B$ activation of the dilated atrium remained rather uniform ( $0.2-3.9 \%$ conduction block), pacing at sites $C$ and $D$ resulted in more than $12 \%$ of conduction block $(p<0.001)$. The mean percentage of local conduction block during pacing from 4 different directions was twice as much during mild dilatation and 3-4 fold after severe dilatation. Also the length of the lines of block increased. Whereas at a normal atrial pressure lines of block were always $<5 \mathrm{~mm}$, during mild atrial stretch $8-1.0 \%$ and during severe stretch $18-21 \%$ of the lines of block was $25 \mathrm{~mm}$. At an atrial pressure of $14 \mathrm{~cm} \mathrm{H} \mathrm{H}_{2} \mathrm{O}$ sometimes lines of block longer than $10 \mathrm{~mm}$ were observed. In 7 rabbits we tested whether the changes in conduction due to dilatation were reversible. After an atriall pressure of $14 \mathrm{~cm}$ $\mathrm{H}_{2} \mathrm{O}$ was applied the pressure was lowered again to $2 \mathrm{~cm} \mathrm{H}_{2} \mathrm{O}$ and the pacing protocol was repeated. The mean total conduction time decreased to $13 \pm 2.3 \mathrm{~ms}$ compared to $13 \pm 2.6 \mathrm{~ms}$ during baseline $(p=0.07)$. Also conduction velocity completely returned to baseline values $(69-21 \mathrm{vs} 66 \pm 17 \mathrm{~cm} / \mathrm{s}$; $p=0.21$ ). The amount of slow conduction and intra-atrial conduction block after return to $2 \mathrm{~cm} \mathrm{H} \mathrm{H}_{2} \mathrm{O}$ was the same as during control $(6.9 \pm 5.4 \%$ and $1.4 \pm 2.3 \%$ vs $6.1 \pm 5.0 \%$ and $1.8 \pm 2.9 \% ; p=0.25$ and $p=0.24)$.

\section{Comparison between Right and Left Atrium}

In a separate series of 6 New Zealand rabbits we compared the effects of atrial dilatation on the right and left atrium (Fig 5). In this example the atria were paced from the right upper corner of the mapping array at an interval of $240 \mathrm{~ms}$. 


\section{Control}

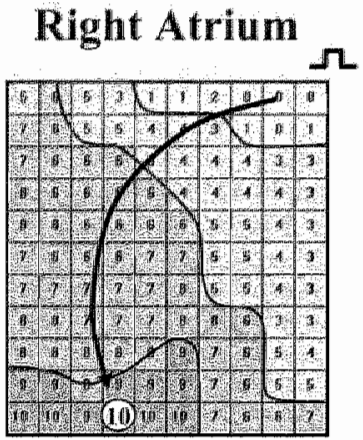

\section{Left Atrium}

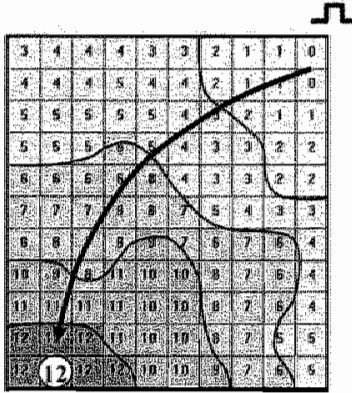

\section{Dilatation}

Right Atrium

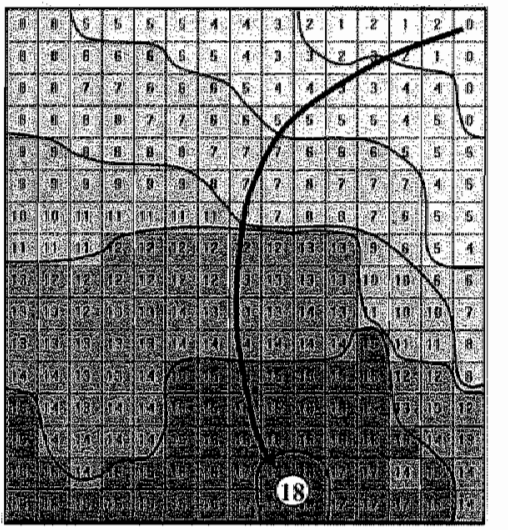

Left Atrium

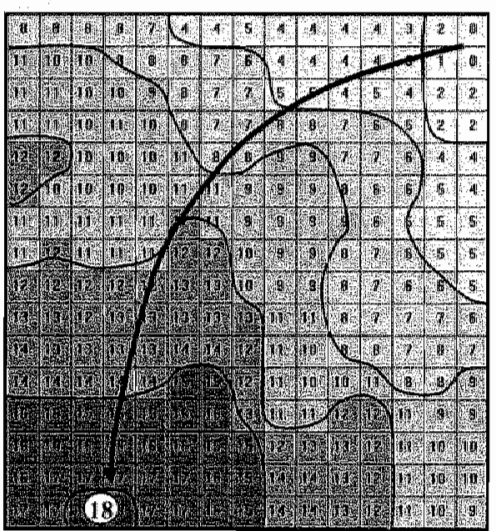

Figure 5: Isochrone maps of the free wall of the right and left atrium during control and after dilatathon (14 cm $\left.\mathrm{H}_{2} \mathrm{O}\right)$. Both atria wera paced at an interval of $240 \mathrm{~ms}$ from the upper right comer of the mapplng array. Isochrones are drawn every 3 ms. Arrows indicate the direction of propagation. During control conduction was slightly slower in the left than in the right atrium. After dilatation the total conduction time of the mapped piece of tissue increased to $18 \mathrm{~ms}$ in both atria.

During control $\left(2 \mathrm{~cm} \mathrm{H}_{2} \mathrm{O}\right.$ ) the conduction time of the mapped area in the right atrium was $10 \mathrm{~ms}$ and in the left atrium $12 \mathrm{~ms}$. Increasing atrial pressure to $14 \mathrm{~cm} \mathrm{H} \mathrm{H}_{2} \mathrm{O}$ increased the TCT of the same piece of tissue to $18 \mathrm{~ms}$ in both atria. In the right atrium the spatial heterogeneity in conduction increased a little more than in the left atrium. In Table 2 the effects of dilatation on right and left atrial conduction are given for all 6 hearts. The degree of atrial dilatation at 9 and $14 \mathrm{~cm} \mathrm{H} \mathrm{H}_{2} \mathrm{O}$ was somewhat higher in the New Zealand than in the Giant Flemish rabbits (compare Table 1). Obviously the compliance of the atrial wall was higher in the smaller hearts of the New Zealand rabbits. 


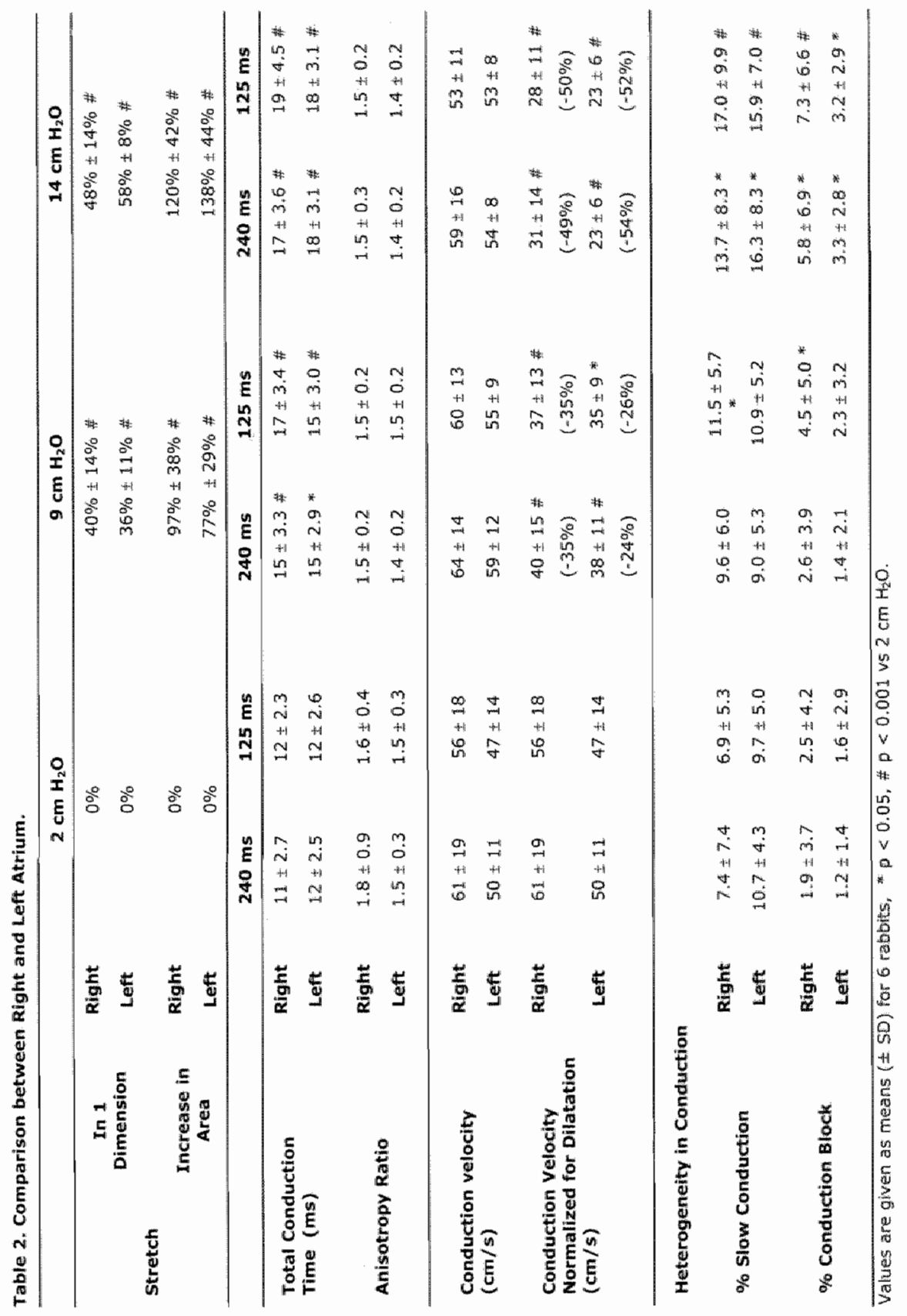


The degree of dilatation at 9 and $14 \mathrm{~cm} \mathrm{H} \mathrm{H}_{2} \mathrm{O}$ was similar in both atria $(p=0.46$ and $p=0.20$ respectively). At $9 \mathrm{~cm} \mathrm{H}_{2} \mathrm{O}$ the right atrial wall was stretched in one dimension by $40 \%$ and the left atrium by $36 \%(p<0.001)$. At $14 \mathrm{~cm} \mathrm{H}_{2} \mathrm{O}$ the stretch was respectively 48 and $58 \% \quad(p<0.001)$. The mean total conduction time during pacing from 4 different directions was similar in the right and left atrium and the effects of dilatation were the same. The effects on TCT and conduction velocity were also similar. At $9 \mathrm{~cm} \mathrm{H}_{2} \mathrm{O}$ the normalized right and left atrial $C V$ decreased by 35 and $25 \%$ (right vs left: $p=0.23$ ). At $14 \mathrm{~cm} \mathrm{H}_{2} \mathrm{O}$ in both atria the normalized $\mathrm{CV}$ decreased by about $50 \%$ (right vs left: $p=0.75)$. During slow pacing at a normal atrial pressure the percentage of slow conduction was slightly higher in the left than in the right atrium $(p<0.05)$. In both atria dilatation increased the incidence of slow conduction. Whereas during control no differences in local conduction block was present between right and left atria, after dilatation $\left(14 \mathrm{~cm} \mathrm{H}_{2} \mathrm{O}\right)$ the percentage of block was higher in the right than in the left atrium $(7.3 \% \pm 6.6$ vs $3.2 \% \pm 2.9$; $\mathrm{p}<0.05$ ). During rapid pacing at an atrial pressure of $14 \mathrm{~cm} \mathrm{H}_{2} \mathrm{O}$ the mean absolute increase in conduction block was $4.7 \%$ in the right, compared to $1.6 \%$ in the left atrium $(p<0.05)$.

In Figure 6 the distribution of the length of lines of block in right and left atrium are plotted both during control and after dilatation $\left(14 \mathrm{~cm} \mathrm{H}_{2} \mathrm{O}\right)$. During control, in both atria the lines of block were short (right atrium $\leq 3 \mathrm{~mm}$, left atrium $\leq 2 \mathrm{~mm}$ ). After dilatation the length of lines block increased to a maximum of $7 \mathrm{~mm}$ in the left and $10 \mathrm{~mm}$ in the right atrium. In the left atrium the far majority of lines of block was still $\leq 2 \mathrm{~mm}$. In contrast, in the right atrium more than 11-14\% of the lines of block were longer than $5 \mathrm{~mm}$.

\section{Discussion}

\section{Effects of Stretch on Cardiac Conduction}

Dudel and Trautwein (1954) were the first to study the effects of stretch on the action potential of cat papillary muscle and dog Purkinje fiber. ${ }^{22}$ They found that the resting and action potentials were not affected by stretch up to a tension of $1000 \mathrm{~g} / \mathrm{cm}^{2}$. At higher tensions injury of the preparation occurred and the amplitude of the action potential decreased. In 1963 Penefsky and Hoffman studied the effects of stretch on conduction in atrial and ventricular myacardium. ${ }^{23}$ They distinguished changes in conduction time between two points separated by a constant distance (apparent conduction velocity) and changes in conduction between two landmarks on the surface of the muscle (true conduction velocity). With mild stretch the true velocity of conduction remained constant and also the transmembrane potential did not change. 


\section{Length of Lines of Conduction Block}
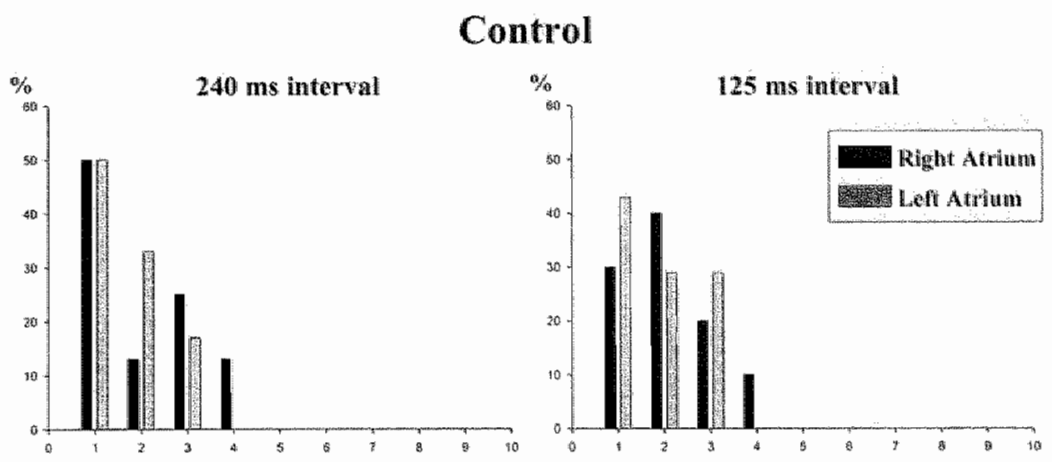

Dilatation
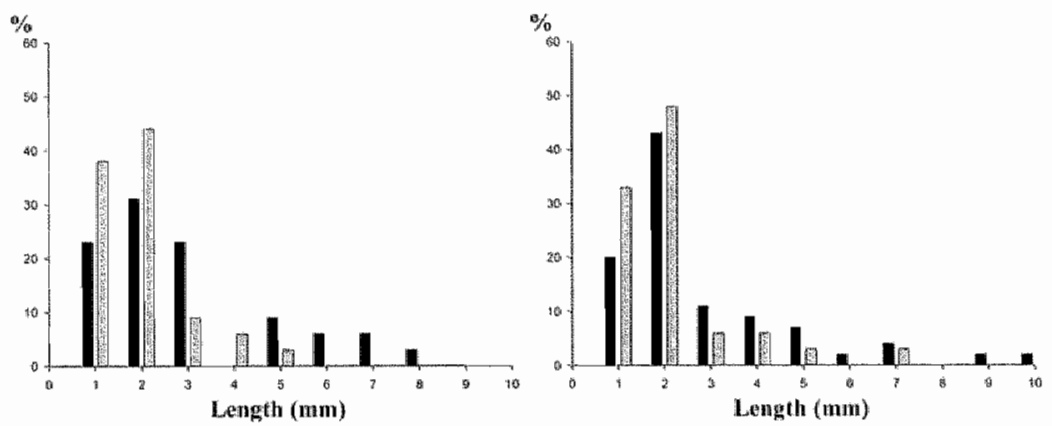

Figure 6: Histograms of the distribution of the length of lines of block in right and left atria $(n=6)$ during control and after dilatation $\left(14 \mathrm{~cm} \mathrm{H}_{2} \mathrm{O}\right)$. The atria were paced at cycle lengths of 240 and $125 \mathrm{~ms}$. During control only short lines of block were present $(\leq 4 \mathrm{~mm})$. After dilatation the length of lines of block increased in both atria. Especially in the right atrium longer lines of block became apparent (5-10 mm).

During excessive stretch the membrane resting potential, upstroke velocity and avershoot of the action potential declined indicating a decrease in the rapid sodium current. Multiple deflections were observed as a sign of discontinuous conduction. Spear and Moore (1972) suggested that conduction was blocked by stretch because of disruption of the electrical continuity between cells. ${ }^{24}$ The effects of stretch on the cable properties of cardiac muscle was investigated by Deck and Dominguez and Fozzard. ${ }^{25,26}$ Deck concluded that changes in membrane resistance (increase) and capacitance (decrease) together with a decrease in core resistance could be responsible for the increase in the apparent conduction velocity. Dominguez and Fozzard argued that geometrical alterations such as unfolding of the membrane and uncoiling of the muscle could partly explain the effects of stretch on conduction velocity.

At a microscopic level, propagation in cardiac tissue is discontinuous in nature. ${ }^{27,28}$ The anisotropic distribution of electrical connections and the 
presence of resistive barriers (collageneous septa) create spatial inhonogeneities in the electrical load imposed on the propagating wavefront. Nonuniform conduction is characterized by local conduction delays at a cellular level reflected by notches in the extracellular electrogram. Such local conduction delays are more prominent during transverse than during longitudinal conduction. The difference between slowing of conduction either by a reduction in excitability or electrical uncoupling was studied by Rohr et al. ${ }^{29}$ They found that uncoupling of gap junctions could reduce the conduction velocity to a much larger extent than a reduction in excitability. In addition, a reduction in excitability caused uniform slowing of conduction, whereas electrical uncoupling caused an increase in the degree of discontinuity. Atrial dilatation thus may affect conduction either by reducing excitability or by increasing the nonuniform anisotropic properties of the myocardium.

Mechanoelectrical feedback, i.e. electrophysiological changes in response to hemodynamic load, can at least in part be explained by activation of stretchactivated ion channels (SACS). ${ }^{30}$ There is evidence that SACs are also involved in stretch-induced arrhythmias. Gadolinium, a widely used nonselective SAC inhibitor, and the more specific blocker GsMtx-4 (a peptide from spider venom) have been found to prevent stretch-induced atrial and ventricular arrhythmias. ${ }^{31-34}$ There are several possible mechanisms how SACs can mediate stretch-induced electrical changes. The membrane can be depolarized during diastole by an aspecific current or a flux of specific ions like $\mathrm{Ca}^{2+}, \mathrm{Na}^{+}$and $\mathrm{K}^{+*}$ may trigger afterdepolarizations. ${ }^{30}$ In addition opening of SACs may lead to $\mathrm{Ca}^{2+}$ overload. The specific SAC blocker GsMtx-4 was shown to suppress atrial fibrillation in the rabbit model of acute atrial dilatation. Continuous stretch may increase repolarizing currents and may shorten the action potential and refractory periad. However, the stretchinduced shortening of the refractory period in rabbit atria was not prevented by GsMtx-4. ${ }^{34}$ Besides the refractory period, local conduction disturbances may play an important role in the creation of a substrate of atrial fibrillation. This possible role of SACs in the occurrence of stretch-induced conduction disturbances still has to be evaluated.

\section{Mapping of the Effects of Dilatation}

The effects of acute dilatation on atrial conduction has been studied by balloon dilatation and volume loading. $8,18.19$ In the canine heart, an increase of the atrial pressure to $>14 \mathrm{mmHg}$ prolonged the interatrial conduction time by $30-45 \%, 18$ Chorro et al. were the first to use high density mapping during acute atrial dilatation. In isolated Langendorff perfused rabbit hearts the right atrium was stretched by inflation of a balloon. Atrial dilatation of 24 and $41 \%$ lowered the atrial conduction velocity from a control value of $73.3 \pm 4.4$ to $66.8 \pm 5.1 \mathrm{~cm} / \mathrm{s}(\mathrm{n} . \mathrm{s}$.$) and 55.2 \pm 3.1 \mathrm{~cm} / \mathrm{s}(p<0.01)$ respectively. In our present study right atrial dilatation up to $48 \%$ did not produce a 
significant slowing in conduction. However, in both studies the conduction velocity normalized for dilatation (conduction time/pre-stretch distance) was clearly decreased, respectively by $56 \%$ (Chorro et al.) and $50 \%$ (present study). Our data further show that atrial stretch increases spatial heterogeneity in conduction. During dilatation, both the incidence of slow conduction $(\leq 20 \mathrm{~cm} / \mathrm{s})$ and lines of intra-atrial conduction block $(510 \mathrm{~cm} / \mathrm{s})$ clearly increased. The role of tissue anisotropy was evalluated by pacing the atria from four directions. Atrial dilatation did not change the differences in conduction time of the mapped area during pacing from different directions. At all atrial pressures the anisotropy ratio of the overall conduction time in the right atrium was $<1.8$ and in the left atrium $<1.5$ (n.s.). During dillatation the occurrence of local conduction delays became highly dependent on the direction of activation. At normal atrial pressure, pacing from the cranial part of the crista terminalis was associated less than $1 \%$ of local conduction block. Pacing from the other sites was associated with 1-3\% of local conduction block. During mild and severe dilatation the difference in degree of block during pacing from different directions became larger. Pacing from the high right atrium still resulted in uniform conduction $(0.2-3.9 \%$ conduction block). In contrast, pacing from the low right atrium now resulted in more than $12 \%$ of local conduction block $(p<0.001)$.

The effects of atrial dilatation on conduction may play a role in the development of a substrate for reentrant arrhythmias. The heterogeneities in conduction by acute atrial stretch, as shown in the present study, may become worse during chronic atrial dilatation. At short atrial wavelengths, the lines of intra-atrial conduction block observed in our study may provide a central obstacle for small reentrant circuits. ${ }^{35}$ Apart from the atrial enlargement itself, thus also an increased heterogeneity in conduction may facilitate initiation and perpetuation of $\mathrm{AF} .^{36}$ The discontinuity in conduction will allow reentry of smaller dimensions. As shown by spach et al., in nomuniform anisotropic tissue reentry can already occur within an area as small as $1-2 \mathrm{~mm}^{2}$ (micro-reentry). ${ }^{27}$

\section{Intra-Atrial Conduction Block and Atrial Architecture}

The architecture of the atrial myocardium is highly heterogeneous. In this respect it is rather surprising that in normal atria the spread of activation is actually quite homogeneous. On a macroscopic scale the conduction velocity in the free wall of the normal right atrium shows an anisotropy ratio ( $\left.\theta_{\mathrm{L}, \mathrm{f}}\right)$ between 1.1 and $1.8 .^{37,38}$ In our experiments the anisotropy ratio of the conduction time of the right and left atrium was between 1.5 and 1.8 . On a microscopic scale however, the degree of anisotropy can be much higher due to the longitudinal orientation of myocytes, the presence of endo- and perimysial collagenous septa, heterogeneous distribution of connexins and branching of trabeculae. $28,39,40$ The anisotropic arrangement of intercellular 
connections in larger muscle bundles, causes marked directionall differences in conduction velocity. Preferential conduction block in the crista terminalis during rapid atrial pacing, flutter or atrial fibrillation has been explained on the basis of structural tissue anisotropy. ${ }^{42-44}$

The architecture of the atrial myocardium may play an important role in conduction disturbances due to dilatation. Lines of intra-atrial conduction block predominantly occur along the border of the crista terminalis and larger atrial trabeculae. In a study by Gray et al. (1996) the orientation of lines of conduction block during AF corresponded to the direction of the major pectinate muscle bundles in the right atrium. ${ }^{37}$ Schuessler at al. reported that dissociation between endo and epicardial activation may occur in areas in which the wall thickness was more than $0.5 \mathrm{~mm}$ and the pectinate muscles were separated from the epicardial surface. ${ }^{45}$ There is experimental evidence that an increase in atrial pressure stretches the thinner parts more than the thicker regions. Early studies have shown that the action potential is severely depressed above a critical tension of $1000 \mathrm{~g} / \mathrm{cm}^{2} .{ }^{22}$ Due to the heterogeneous distribution of wall stress during increased atrial pressure, the thin parts of the atrium might reach this critical value earlier than the thicker bundles. This may explain lines of conduction block in the thin parts between atrial trabeculae.

\section{Limitations}

Although a diastolic atrial pressure of $14 \mathrm{~cm} \mathrm{H}_{2} \mathrm{O}$, as used in our study, can easily occur during various pathological conditions in the human atria, the degree of dilatation due to such a pressure might be less than in the thinner rabbit atria. Because the compliance of the thicker human atria is lower than in the rabbit, a higher atrial pressure is required to produce a comparable degree of dilatation. On the other hand, the degree of atrial dilatation in the present study is comparable with the degree of dilatation found in patients with chronic atrial fibrillation and mitrall valve disease. An important limitation of our study is that we only evaluated the effects of acute atrial dilatation. It is quite likely that prolonged atrial stretch will have different effects on atrial electrophysiology and vulnerability to arrhythmias. Because previous studies already showed that atrial stretch has an important effect on atrial refractoriness, $8,9,18,47,48$ in the present study we did not repeat these measurements. A shortening in atrial refractoriness as found in rabbit atria cannot explain the stretch-induced conduction disturbances. On the contrary, since a shortening in refractory period will allow more time for the atrial celis to recover their excitability, conduction is expected to improve rather than become depressed. 


\section{References}

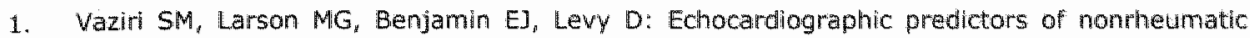
atrial fibrillation. The framingham Heart Study. Circulation 1994;89:724-30.

2. Psaty BM, Manolio TA, Kuller LH, Kronmal RA, Cushman M, Fried LP, White R, Furberg CD, Rautaharju PM: Incidence of and risk factors for atrial fibrillation in older adults. Circulation $1997 ; 96: 2455-61$.

3. Henry WL, Morganroth J, Pearlman AS, Clark CE, Redwood DR, Itscoitz SB, Epstein SE: Relation between echocardiographically determined left atrial size and atrial fibrillation. Circulation 1976;53:273-279.

4. Takahashi $N$, Imataka $K$, Seki $A_{,}$Fujii J: Left atrial enlargement in patients with paroxysmal atrial fibrillation. Ipn Heart $] 1982 ; 23: 677-683$.

5. Brodsky MA, Allen $\mathrm{BJ}$ : Factors determining maintenance of sinus rhythm after chronic atrial fibrillation with left atrial dilatation. Am J Cardiol 1989;63:1065-1068.

6. Hoglund C, Rosenhamer G: Echocardiographic left atrial dimension as a predictor of maintaining sinus thythm after conversion of atrial Fibrillation. Acta Med Scand 1985;217:411-5.

7. Boyden PA, Hoffman BF: The effects on atrial electrophysiology and structure of surgically induced right atrial enlargement in dogs. Circ Res 1981;49:1319-1331.

8. Solti $F$, vecsey $T$, Kekésil $V$, Juhász-Nlagy $A$ : The effect of atrial dilatation on the genesis of atrial arrhythmias. Cardiovasc Res 1989;23:882-8:86.

9. Ravelli F, Allessie M: Effects of atrial dilatation on refractory period and vulnerability to atrial fibrillation in the isolated Langendorff-perfused rabbit heart. Circulation 1997;96:1686-1695.

10. Probst $P$, Goldschlager $\mathbb{N}$, Selzer A: Left atrial size and atrial fibrillation in mitral stenosis: factors influencing their relationship. Circulation 1973;48:1282-1287.

11. Keren G, Etzion T, Sherez J, Zelcer AA, Megidish R, Miller HI, Laniado S: Atrial fibrillation and atrial enlargement in patients with mitrall stenosis. Am Heart J 1987;114:1146-1155.

12. Petersen $P$, Kastrup J, Brinch $K$, Godtfredsen J, Boysen G: Relation between left atrial dimension and duration of atrial fibrillation. Am J Cardiol 1987;60:382-384.

13. Sanfilippo AJ, Abascall VM, Sheehan M, Oentel LB, Harrigan P, Hughes RA, Weyman AE: Atrial enlargement as a consequence of atrial fibrillation. Circulation 1990;82:792-797.

14. Suarez GS, Lampert $S$, Ravid $S$, Lown $B$ : Changes in left atriall size in patients with lone atrial fibrillation. Clin Cardial 1991;14:652-6.

15. Wijffels $\mathrm{MCEF}$, Kirchhof $\mathrm{CJH}$, Dorland $\mathbb{R}_{r}$ Allessie MA: Atral fibrillation begets atrial fibrillation. A study in awake chronically instrumented goats. Circulation 1995;92:1954-1968.

16. Schotten U, Allessie MA. Electrical and mechanical remodeling of the atria: What are the underlying mechanisms, the time course and the clinical relevanice? In: Raviele $A_{x}$ ed. Cardiac Arrhythmias 2001. Venice: Springer; 2001:345-352.

17. Allessie M, Ausma J, Schotten U: Electrical, contractile and structural remodeling during atrial fibrillation. Cardiovascular Research 2002;54:230-246.

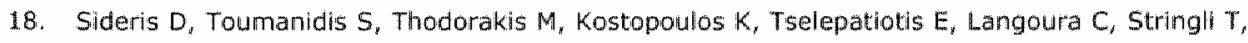
Moulopoulos $S$ : Some observations on the mechanism of pressure related atrial fibrillation. Eur Heart J 1994;15:1585-1589.

19. Chorro FJ, Egea S, Mainar L, Canoves J, Sanchis J, Llavador E, Lopez Merino V, Such L: Modificaciones agudas de la longitud de onda clel proceso de activacion auricular inducidas por la dilatacion. Estudio experimental. Rev Esp Cardial 1998;51:874-83.

20. King KA, Ledsome JR: The effect of tachycardia on right atrial dynamics and plasma atrial natriuretic factor in anaesthetized rabbits. I Physiol 1990;422:289-301. 
21. Ledsome IP, King KA: Atrial dynamics and release of atral natriuretic factor in wivo. Can 1 physiol Pharmacol 1991,69:1507*13.

22. Dudel J, Trawtwein W: Das Aktonspotential und Mechanogramm des Herzmuskels unter dem Eirfluss der Dehriung. Cardiologia 1954;25:344-362.

23. Penefsky $Z$, Hoffman $B$ : Effect of stretch on mechanical and electrical properties of cardiac muscie. Am J Physilol 1963;204:433-438.

24. Spear J, Moone E: Stretch-induced excitation and conduction disturbances in the isolated rat myocardium. I Electrocardiol $1972 ; 5: 15-24$.

25. Deck $K$ : Anderung des Ruhepotentials und der Kabeleigenschaften von Purkinje-Faden bei der Dehnung. Pfugers Archiw 1964;280:131-140.

26. Dominguez $G_{;}$fozzard $H$ : Effect of stretch on conduction velacity and cable properties of cardiac purkine fibers. Am 1 Physiol 1979;6:C119-C124.

27. Spach MS, Dober PC: Relating extracellular potentials and their derivatives to anisotropic propagation at a microscopic level in human cardiac muscle. Evidence for electrical uncoupling of side-to -side fiber connections with increasing age. Circ Res 1986;58:356-371.

28. Spach MS, Miller WT, 3rd, Geselowitz DB, Rarr RC, Kootsey JM, Johnson EA: The discontinuous nature of propagation in normal canine cardiac muscle. Ewidence for recurrent discontinulties of intraceluilar resistance that affect the membrane currents. Circ-Res 1981;48:39-54.

29. Rolw S, Kucera JP, Kleber AG: Slow conduction in cardiac tissue, I: effects of a reduction of excitability versus a reduction of electrical coupling on microconduction. Circ Res $1998 ; 83: 781-94$.

30. Hu $H$, Sachs F: Stretch-activated ion channels in the heart. J Mol Cell Cardiol 1997;29:151123.

31. Hansen DE, Borganelli M, Stacy GP, Jr., Taylor LK: Dose-dependent inhlibition of stretch: Induced arrhythmias by gadolinium in isolated canine ventricles. Evidence for a unique unode of antiarrhythmic action. Circ Res 1991;69:820-31.

32. Nazir S, Dick D, Sachs F, Lab MJ: Effects of G. spatulata wenom, a novel stretch-activated channel blocker in a model of stretch-induced ventiricular fibrilation in the isolated heart. Circullation 1995;92(Suppl.1):641.

33. Bode F, Katchman A, Woosley RL, Franz MR: Gadolinium decreases stretch-induiced vulnerability to atrial fibrillation. Circulation 2000;101:2200-5.

34. Bode F, Sachs F, Franz MR: Tarantula peptide inhibits atrial fibrillation. Nature 2001;409:356 .

35. Allessie MA, Lammers WJEP, Rensma PL, Schalli MJ, Kirchhof CJHJ: Determinants of reentry in cardiac muscle. Progress Cardiol 1988;1/2:3-15.

36. Lammers WJ, Schallj $\mathrm{MJ}_{r}$ Kirchhof CJ, Allessle MA: Quantification of spatial inhomogeneity in conduction and initiation of reentrant atrial arrhythmias. Am-J-Physiol 1990;259:41254-63.

37. Gray RA, Pertsov AM, Jalife J: Imcomplete reentry and epicardial breakthrough patterns during atrial fibrillation in the sheep heart. Circulation 1996:94:2649-61.

38. Hansson $A_{*}$ Holm M, Blomstrom P, Johansson R, Luhrs $C_{x}$ Brandt J, Olsson S: Right atrial free wall conduction velocity and degree of anisotropy in patients with stable sinus rhythm studied during open heart surgery. Eur Heat J 1998; 19:293-300.

39. Spach MS, Dolber PC, Heidage JF: Influence of the passive anisotropic properties on directional differences in propagation following modification of the soditum conductance in human atrial muscie. A model of reentry based on anisotropic discontinuous propagation. Circ-Res $1988 ; 62 ; 811-32$.

40. Dolber PC, Spach MS: Structure of canine Bachmann's bundle related to propagation of excitation. Am J Physiol 1989;257:H1446-57.

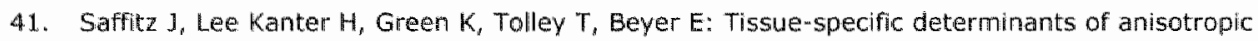
conduction velocity in canine atrial and ventricular myocardium. Circ Res 1994;74:1065-1070. 
42. Schumacher $B_{y}$ Jung $W_{*}$ Schmdt $H_{*}$ Fischenbeck $C_{y}$ Lewalter $T$, Hagendort $A_{x}$ Omrat $H_{n}$ Wotpert C, Luderitz B: Transverse conduction capabinties of the crista terminalis in patrents with atrial flutter and atrilal fibriliation. I Am Coll Cardiol 1999;34:363-73.

43. Becker $R$, Bauer $A$, Metz $S$, Kinscher $R$, Senges JC, Schremer $K D$, Voss F, Kuebler W, Sehoels W: Intercaval block in normal canine hearts: role of the terminal crest. Circulation $2001 ; 103: 2521-6$.

44. Yamabe $H$, Misuml 1 , Fukushima $H$, Ueno $K$, Kimura $Y$, Hokamura $Y$ : Conduction properties of the crista terminalis and its influence on the right atrial activation sequence in pallents with typical atrial futter. Pacing Clin Electrophysiol 2002;25:132-41.

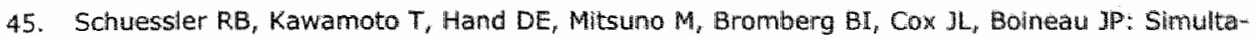
neous epicardial and endocardial activation sequence mapping in the isolated canine right atrium. Circulation $1993 ; 88: 250-263$,

46. Satoh $T$, Zlpes D: Unequal atrial stretch in dogs increases dispersion of refractoriness conductive to developing atrial fibrillation. J Cardiovase Electrophysiol $1996 ; 7: 833-842$.

47. Calkins $H$, El-Atassi R, Kafbifieisch $S$, Langberg 3, Morady F: Effects of an acute increase in atrial pressure on atrial refractoriness in humans. PACE 1992;15: $1674-1680$.

48. Klein LS, Miles WM, Zipes DP: Effect of atrioventricular interwal during pacing or reciprocating tachycardia on atrial size, pressure, and refractory period. Contraction-excitation feedback in human atrium. Circulation 1990;82:60-68. 
Chapter 3

\section{Synergistic Action of Atrial Dilatation and Sodium Channel Blockade on Conduction in Rabbit Atria}

Sabine C.M. Eijsbouts, MD, Richard P.M. Houben, BSc, Yuri Blaauw, MD, Ulrich Schotten, MD, PhD, Maurits A. Allessie, MD, PhD 


\begin{abstract}
Introduction

The purpose of this study was to investigate the interaction of atrial dilatation and blockade of the rapid sodium channel on atrial conduction and degree of anisotropy.
\end{abstract}

\title{
Methods and Results
}

In 14 isolated rabbit hearts the right atrium was acutely dilated by increasing the intra-atrial pressure from 2 to $9 \mathrm{~cm} \mathrm{H}_{2} \mathrm{O}$. A rectangular mapping array of 240 electrodes (spatial resolution $0.5 \mathrm{~mm}$ ) was positioned on the free wall of the right atrium during pacing from 4 different directions at intervals of 240 and $140 \mathrm{~ms}$. In non-dilated atria 0.5 and $1.0 \mathrm{mg} / \mathrm{L}$ of the use-dependent $\mathrm{I}_{\mathrm{Na}}$ blocker flecainide prolonged the total conduction time under the mapping electrode by $15-75 \%$. In dilated atria flecainide depressed conduction by $24-$ $89 \%(p<0.05)$. The incidence of intra-atrial conduction block increased from $0.6-0.8 \%$ to $3.3-7.2 \%$ in non-dilated and from $3.9-4.6 \%$ to $13-21 \%$ in dilated atria $(p<0.05)$. The direction of activation relative to the crista terminalis and major pectinate muscles was of major importance for the occurrence of conduction block. During rapid pacing the degree of anisotropy in conduction increased by the combination of atrial dilatation and flecainide $(1.0 \mathrm{mg} / \mathrm{L})$ from $1.7 \pm 01$ to $2.2 \pm 04(p<0.05)$. The effects of dilatation and flecainide on conduction were clearly synergistic. The effect of flecainide on the atrial refractory period was also enhanced by atrial dilatation.

\section{Conclusion}

In dilated atria, blockade of the rapid sodium channels caused a higher degree of local conduction delay and intra-atrial conduction block than in non-dilated atria. 


\section{Introduction}

Atrial dilatation is known to be an independent risk factor for atrial fibrillation (AF). ${ }^{1}$ Apart from being a cause of AF, dilatation is also shown to be a consequence of atrial fibrillation. ${ }^{2-4}$ In a study of 15 patients by Sanfilippo et al. the atrial volume increased by about $50 \%$ as a result of 20 months of lone AF. Atrial size plays a role in the success rate of pharmacological cardioversion and may determine the chance of maintenance of sinus rhythm..$^{5-7}$ In a previous study we have shown that acute dilatation of isolated rabbit atria increases the amount of spatial heterogeneities in conduction. ${ }^{8}$ Class IC drugs, which are often used to cardiovert AF in patients, slow conduction by blockade of the rapid sodium channels. In the present study we investigated the combination of atrial dilatation and a class IC drug (flecainide) on the degree of atrial anisotropy and conduction. The incidence of lines of intra-atrial conduction block by flecalinide and dilatation was about 3 times higher than expected from the sum of their separate effects (synergism).

\section{Methods}

\section{Rabbit Model of Atrial Dilatation}

Fourteen New Zealland rabbits $(2.9-3.6 \mathrm{~kg})$ of either sex were used for this study. The study was approved by the Animal Investigation Committee of the University of Maastricht. After sedation the animals were killed by cervical dislocation and the heart was rapidly removed and mounted in a Langendorff perfusion system. The pulmonary artery and inferior caval vein were ligated and the superior caval vein was cannulated to serve as the exclusive outflow tract of the coronary perfusate. By changing the height of this cannula the pressure in the right atrium could be easily adjusted. Coromary perfusion pressure was kept constant by increasing the aortic pressure with the same amount as the right atrial pressure. ${ }^{8}$ The degree of stretch was calculated from the distance between 4 anatomical landmarks. Two of the four anatomical landmarks consisted of a cranial and caudal branch of the crista terminalis. At the other side of the mapped area bifurcations of pectinate muscles were chosen as landmarks. Whereas the landmarks at the crista terminalis were quite consistent, the localization of the other two landmarks was more variable due to inter-individual variation in architecture of the pectinate muscles. In each experiment, the same landmarks were used before and after dilatation. 


\section{High Density Mapping}

A $7.0 \times 7.5 \mathrm{~mm}$ array of $15 \times 16$ silver electrodes (diameter $0.25 \mathrm{~mm}$, interelectrode distance $0.5 \mathrm{~mm}$ ) was used to map part of the trabeculated wall of the right atrium. The mapping electrode was positioned parallel to the crista terminalis (CT) with one corner next to a reference suture in the intercaval area. Four bipolar pacing electrodes were attached to the comers of the mapping electrode. ${ }^{8}$ Activation maps were triangulated with a spatial resolution of $1 \mathrm{~mm}$. In each triangle the local conduction vector was calculated from the activation times at the corners of the triangle. ${ }^{9}$ The local conduction velocity was calculated as the mean of two conduction vectors in an epicardial rectangular area of $2 \times 2 \mathrm{~mm}$. Since the population of local conduction velocities was not distributed normally, the median conduction velocity was used to represent the conduction velocity (CV) at the epicardium. Disturbances in conduction were quantified by calculating local conduction vectors with a higher resolution of $0.5 \times 0.5 \mathrm{~mm}$. Conduction velocities between 10 and $20 \mathrm{~cm} / \mathrm{s}$ were assigned as slow conduction. Conduction block was defined as an apparent local conduction velocity of $\leq 10 \mathrm{~cm} / \mathrm{s}$. This criterion for conduction block was chosen because sodium channel blockade can decrease atrial conduction velocity to about $30 \%$ until propagation fails. ${ }^{10}$ Our criterion of $\leq 10 \mathrm{~cm} / \mathrm{s}$ represented a decrease in conduction velocity to about $15 \%$ of the control value. This rather rigorous criterion was chosen to yield a high specificity and to avoid over-estimation of the incidence of intra-atrial conduction block. The atrial conduction velocity was measured over a fixed distance. However, after stretching of the atria the same distance between the electrodes is covered by less myocardial cells. Thus, if atrial conduction is unaffected by stretch, the measured CV will increase with the same degree as the amount of stretch. Therefore, we normalized $\mathrm{CV}$ by dividing the distance between the electrodes used to calculate $\mathrm{CV}$ with the percentage of stretch of the underlying tissue. In the same way, also the critical values for slow conduction and local conduction block were normalized for the amount of stretch.

\section{Quantification of Anisotropy}

The degree of anisotropy in conduction was assessed both at a macroscopic and a sub-macroscopic scale. Isochrone maps of 2 consecutive beats were constructed during pacing from 4 different directions. Macroscopic anisotropy was defined as the largest difference in total conduction time of the mapped area during pacing from 4 different directions. On a sub-macroscopic scale the degree of anisotropy was determined in areas of $1 \mathrm{~mm}^{2}$ ( $3 \times 3$ electrodes). At each electrode an ellipse was fitted through the 4 conduction vectors obtained during pacing from 4 different directions, using the least squares method. ${ }^{11}$ The rotation angle was found by an iterative procedure locating 
the most distal point on the ellipse with respect to the center. The angle of the long axis of the ellipse was used to represent the direction of the fastest conduction (Fig. 1). The ratio between the long and short axis of the ellipse was taken as the degree of local anisotropy in conduction. In case the difference in direction between the 4 conduction vectors was less then $45^{\circ}$, despite pacing from 4 different directions, an anisotropy ratio of 5 was assigned to that area. In four atria, the orientation of the crista terminalis and pectinate muscles was determined from macro-photographs and the direction of the muscle bundles was correlated with the long axis of the fitted ellipses (Fig. 1). A correlation coefficient of $r=0.77\left(p<0.001 ; \mathrm{Cl}_{5-95 \%}=0.73\right.$ $0.80)$ was obtained. The mean estimation error was below 2 degrees $(n=546)$. On the basis of this validation we believe that ellipse fitting of conduction vectors of 4 different directions provides a good estimate of the degree of anisotropy in conduction.
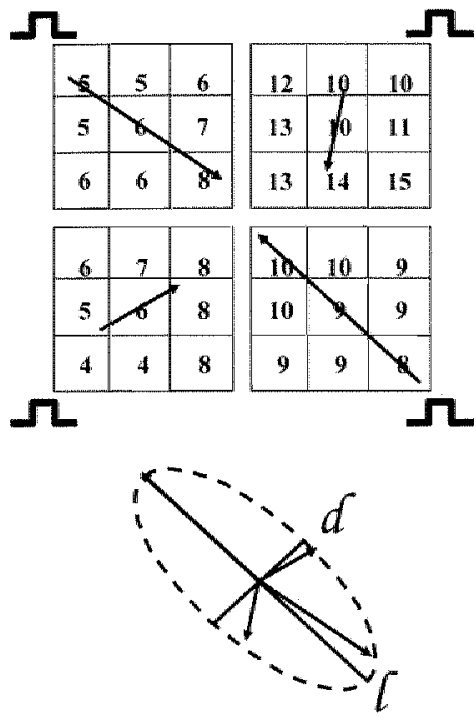

Anisotropy Ratio $=d / d$

$$
0.68 / 0.27=2.5
$$

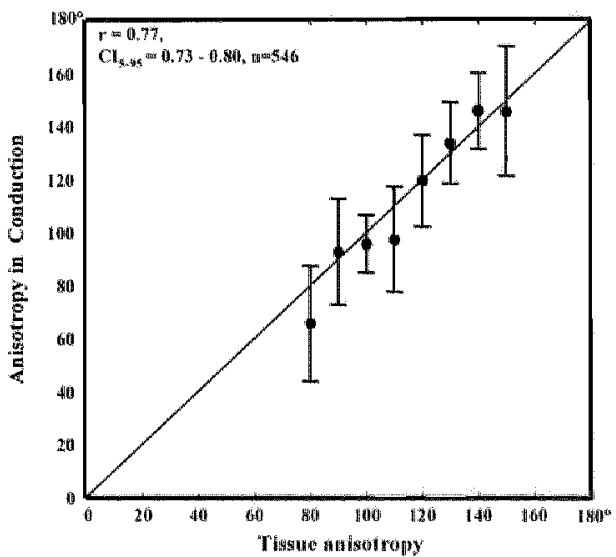

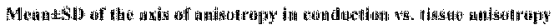

Figure 1: Left: Method to quantify anisotropy in conduction. During pacing from 4 different directions the local conduction wectors (arrows) in each area of $1 \mathrm{~mm}^{2}$ was calculated from an array of $3 \times 3$ electrodes (mumbers indicate local activation times). The best ellipse was fitted through the local vectors obtained during pacing from 4 different directions and the ratio between the long and short axis of the ellipse was taken as an estimate of the local anisotropy in conduction. The direction of the long axis of the ellipse indicates the direction of preferential conduction. Right: Vafidation of the method to quantify anisotropy ir conduction. The direction of the muscle bundles was correlated with the long axis of the fitted ellipses. A correlation coefficient of $r=0.77(p<0,001$; C. $55 \%=0.73-0.80,17=546)$ was obtaned. 


\section{Experimental Protocol}

In 8 rabbits, conduction of the right atrium was mapped during pacing from 4 corners of the mapping array. After every 10-15 stimuli the pacing site was automatically shifted to another site. This pacing protocol was performed at two different pacing rates (interval 240 and $140 \mathrm{~ms}$ ) and at two different atrial pressures $\left(2\right.$ and $9 \mathrm{~cm} \mathrm{H}_{2} \mathrm{O}$ ). An equilibration period of at least 5 minutes was taken into account after each change in pressure. Flecainide was added to the perfusate in a concentration of $0.5 \mathrm{mg} / \mathrm{L}$ and $1.0 \mathrm{mg} / \mathrm{L}$. These concentrations are within the therapeutic range of the free plasma concentration in humans. Twenty minutes after each dosage of flecainide the pacing protocol was repeated. In a separate series of 6 rabbits, the combination of flecainide $(1.0 \mathrm{mg} / \mathrm{L})$ and atrial dilatation $\left(9 \mathrm{~cm} \mathrm{H}_{2} \mathrm{O}\right)$ on the atrial refractory period (AERP) was studied. During regular pacing (S1-S1: $240 \mathrm{~ms}$ ) the AERP was measured at 4 different sites (cranial and caudal end of the crista terminalis, low right atrium, right atrial appendage) by single premature stimuli of $4 x$ threshold. The Iongest S1-52 interval that failed to capture the atrium was taken as the AERP.

\section{Statistical Analysis}

Data are presented as mean $\pm \mathrm{SD}$. Statistical analysis was performed by the paired Student's $t$-test. Synergism between dilatation and flecainide was tested by a two-way ANOVA for repeated measures.

\section{Results}

\section{Effects of Atrial Dilatation and Flecainide on Conduction}

In Table 1 the effects of two concentrations of flecainide with and without atrial dilatation are summarized for all 8 hearts. An increase in pressure from 2 to $9 \mathrm{~cm} \mathrm{H} \mathrm{H}_{2} \mathrm{O}$ stretched the right atrium by $24 \pm 12 \%$ in 1 dimension $(p<0.001)$ and resulted in an increase in surface area by $53 \pm 29 \%(p<0.001)$. During control, atrial dilatation increased the mean conduction time (TCT) of the mapped area by $4 \mathrm{~ms}$ both during pacing with an interval of 240 and $140 \mathrm{~ms}$ ( $p<0.001$ ). In non-dilated atria administration of $0.5 \mathrm{mg} / \mathrm{L}$ flecainide increased the mean TCT by $2 \mathrm{~ms}$ (pacing interval $240 \mathrm{~ms} ; \mathrm{p}<0.001$ ) and $4 \mathrm{~ms}$ (pacing interval $140 \mathrm{~ms} ; \mathrm{p}<0.001$ ) (use dependency). In dilated atria the mean TCT was lengthened by respectively 4 and $7 \mathrm{~ms}(p<0.001)$. At a concentration of $1 \mathrm{mg} / \mathrm{L}$ flecainide prolonged the TCT by 6 and $8 \mathrm{~ms}$ in nondilated and by 10 and $16 \mathrm{~ms}$ in dilated atria $(p<0.001)$. Atrial dilatation alone did not affect $\mathrm{CV}$, but after correction for the degree of stretch (normalized conduction velocity) the conduction velocity was decreased by $24 \%$ $(p<0.001)$ 


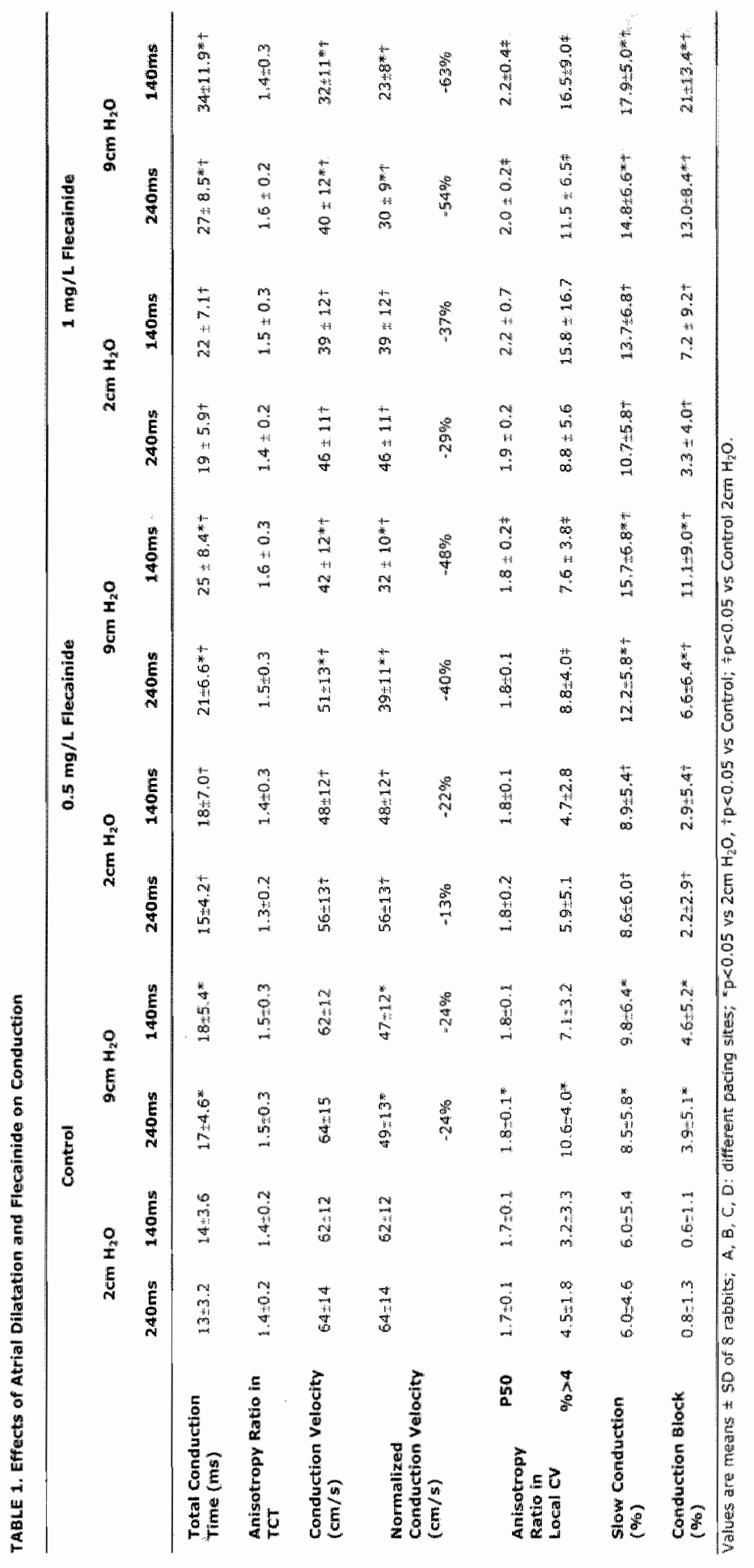




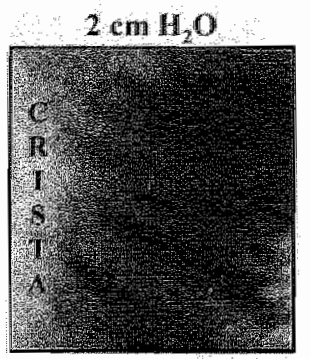

$9 \mathrm{~cm} \mathrm{H}, \mathrm{O}$

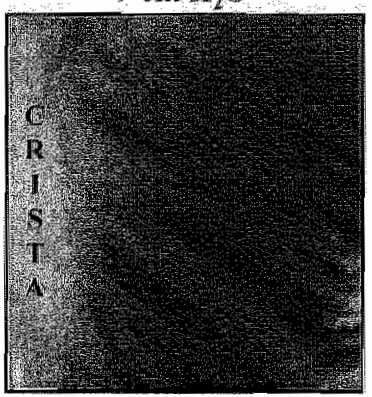

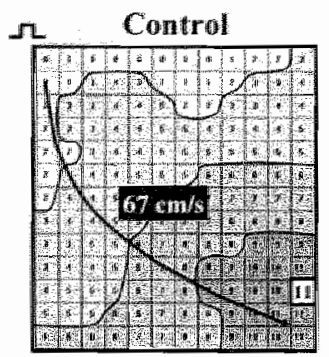

Dilatation

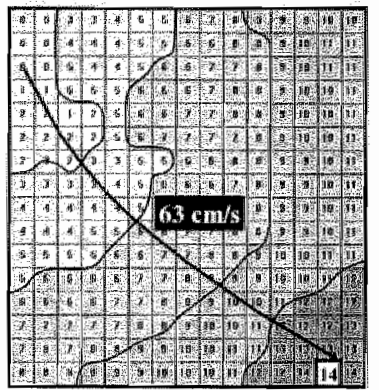

Flecainide

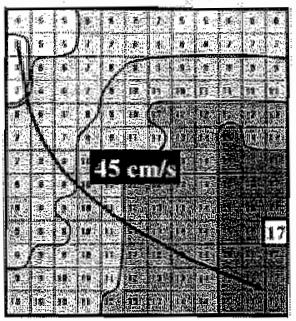

Dilatation + Flecainide

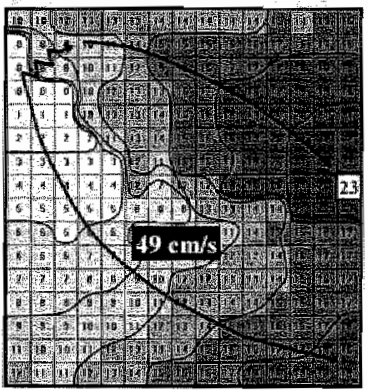

Figure 2: Left: Photographs of the free wall of the right atrium before and after dilatation ( 2 and $9 \mathrm{~cm} \mathrm{H}_{2} \mathrm{O}$ ). The mapping area comprised the crista terminalis and the pectinate muscles running abliquely towards the AV-ring. Right: High-density maps during pacing from the cranial end of the CT (interval 240ms). The four maps show the differences in activation during control, flecainide administratlon ( $1 \mathrm{mg} / \mathrm{L}$ ), dilatation $\left(9 \mathrm{~cm} \mathrm{H}_{2} \mathrm{O}\right.$ ) and the combination of dilatation and flecainide. Activation times are given in milliseconds and isochrones are drawn at $3 \mathrm{~ms}$ intervals. Arrows indicate the main direction of propagation together with the effective $\mathrm{CV}$. The total conduction time of the mapped area is indicated by the enlarged activation times.

At a normal atrial pressure, flecainide $(0.5$ and $1 \mathrm{mg} / \mathrm{L})$ slowed the normalized $\mathrm{CV}$ by 13 and $29 \%$ (pacing interval $240 \mathrm{~ms} ; \mathrm{p}<0.05$ and $p<0.001$ ) and by 22 and $37 \%$ (pacing interval $140 \mathrm{~ms} ; p<0.001$ ) during rapid pacing. The combination of dilatation and $\mathrm{I}_{\mathrm{Na}}$-blockade depressed the normalized $\mathrm{CV}$ by $40-63 \%(p<0.001)$. Figure 2 shows right atrial activation maps during pacing with a cycle length of $240 \mathrm{~ms}$ from the cranial end of the crista terminalis. The total conduction time (TCT) of the mapped area is indicated by the large activation times. The arrows indicate the main pathway of activation together with the effective conduction velocity. After dilatation the same atrial tissue was mapped, which then covered a larger part of the electrode array. During control, the free wall of the right atrium was activated uniformly with a conduction velocity of $67 \mathrm{~cm} / \mathrm{s}$. After dilatation by $44 \%$ the atrium was still activated uniformly although with a slightly slower $\mathrm{CV}(63 \mathrm{~cm} / \mathrm{s})$ and a $3 \mathrm{~ms}$ longer conduction time. Flecainide $(1 \mathrm{mg} / \mathrm{L}$ ) slowed conduction to $45 \mathrm{~cm} / \mathrm{s}$ and prolonged the TCT by $6 \mathrm{~ms}$. Whereas during dilatation or the administration of flecainide alone, conduction remained uniform, the combination of dilatation and flecainide resulted in a clear increase in spatial heterogeneities in conduction (right lower panel). As shown by the crowding of isochrones, a 
long line of conduction delay developed which prolonged the TCT from 17 to $23 \mathrm{~ms}$. In the lower left part of the map, conduction was still uniform with a velocity similar to that during flecainide alone $(49$ vs. $45 \mathrm{~cm} / \mathrm{s})$. In figure 3 activation maps during pacing from 4 different directions are shown during the combination of atrial dilatation $\left(9 \mathrm{~cm} \mathrm{H}_{2} \mathrm{O}\right)$ and flecainide administration $(1 \mathrm{mg} / \mathrm{L})$. The degree of spatial heterageneity in conduction clearly differed during pacing from different directions. Compared to the long line of conduction delay present during pacing at site A, pacing at site B only caused some minor conduction delays close to the pacing site. The incidence of slow conduction and conduction block was most marked during pacing at sites $\mathrm{C}$ and $D$. Propagation from these sites resulted in dissociation of the main activation wave into several separated wavefronts (arrows).
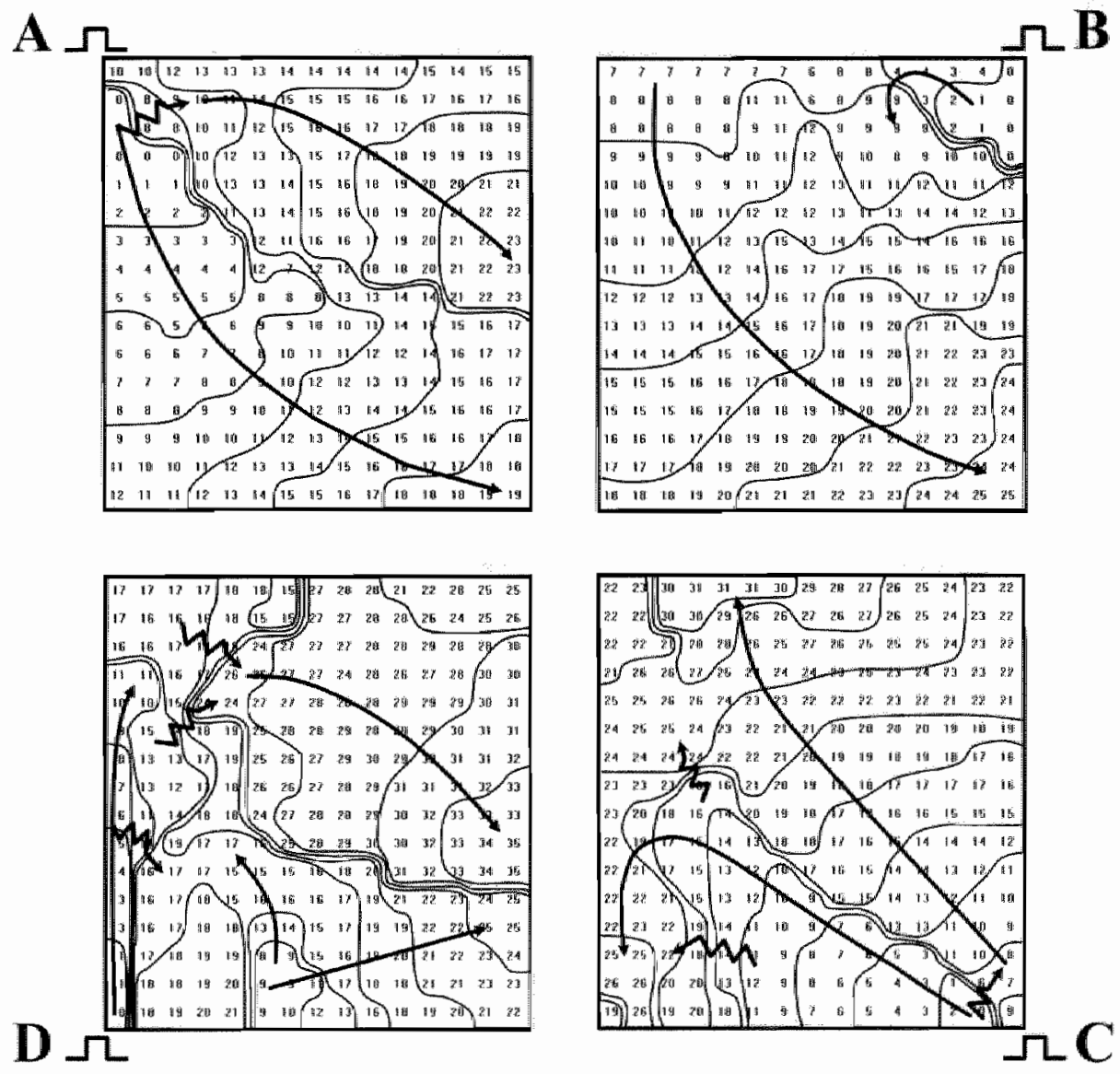

Figure 3: High density maps of the free wall of the right atrium during pacing (interval $240 \mathrm{~m} 5$ ) from 4 directions $(A, B, C$ and $D)$. Atrial pressure was $9 \mathrm{~cm} \mathrm{H}_{2} \mathrm{O}$; flecalnide concentration was $1 \mathrm{mg} / \mathrm{L}$. Activation times are given in milliseconds and isochrones are drawn at 3 ms intervals. Arrows indicate the direction of propagation of the different wavefronts. Zigzag arrows point to areas of slow conduction. The incidence of slow conduction and conduction block (crowding of isochrones) was largely dependent on the direction of activation (anisotropy). 
The macroscopic anisotropy of the right atrial wall, defined as the ratio of directional differences in TCT, was $1.4 \pm 0.2$ and was not affected either by dilatation, administration of flecainide, or both (Table 1).

Spatial heterogeneities in conduction were quantified by calculating the percentage of slow conduction and conduction block. On average, during control $6 \pm 4.6 \%$ of the right atrial wall exhibited slow conduction $(10-20 \mathrm{~cm} / \mathrm{s})$ and in less than $1 \%$ conduction block occurred $(s 10 \mathrm{~cm} / \mathrm{s})$. Acute atrial dilatation increased the incidence of sllow conduction and conduction block to respectively $8.5-9.8 \%$ and $3.9-4.6 \%(p<0.05)$. The combination of dillatation and flecainide $(1 \mathrm{mg} / \mathrm{L})$ caused even more marked heterogeneities in conduction. During pacing with an interval of $140 \mathrm{~ms}, 17.9 \pm 5.0 \%$ of the mapped area now exhibited slow conduction, whereas conduction block occurred in $21 \pm 13.4 \%$ of the atrial sites. The direction of activation was of major importance for the occurrence of conduction block and varied between $11.4 \pm 4.5 \%$ during pacing at site $A$ and $36 \pm 11.6 \%$ (pacing site $C$ ). In figure 4 the localization of lines of conduction block is mapped during administration of flecainide $(0.5$ and $1.0 \mathrm{mg} / \mathrm{L})$ both before and after dilatation $\left(9 \mathrm{~cm} \mathrm{H}_{2} \mathrm{O}\right)$. All local conduction velocities of $\leq 10 \mathrm{~cm} / \mathrm{s}$, occurring during pacing from at least one of 4 directions, are plotted. During control only at one site locall CV was $<10 \mathrm{~cm} / \mathrm{s}$. Administration of flecainide caused a moderate increase in the amount of conduction block. Also atrial dilatation resulted in only a minor increase in the incidence of local intra-atrial conduction block (lower left panel). In contrast, the combination of dilatation and flecainide caused a marked increase in heterogeneity in conduction (lower right map). Now, about one third of the atrial wall showed local conduction velocities of $<10 \mathrm{~cm} / \mathrm{s}$. Long lines of intra-atrial block appeared, which were related to the orientation of the atrial muscle bundles. The correlation between the orientation of the lines of block and the angle of the crista terminalis and pectinate muscles is shown at the bottom of figure $4(r: 0.74 ; p<0.0001)$.

The effects of dilatation and flecainide on the anisotropy in conduction are shown in figure 5. The combination of stretch and sodium blockade clearly enhanced preferential conduction of the wave front along the long axis of the crista terminalis and major pectinate muscles. The anisotropy vectors, indicating the direction of the fastest conduction and the ratio of directional differences, became longer and better aligned to the orientation of the atrial bundles. During control the median anisotropy in local conduction was $1.7 \pm 0.1$ (both during pacing with 240 and $140 \mathrm{~ms}$ ). Acute atrial stretch slightly increased the ratio to $1.8 \pm 0.1$ (NS). Administration of flecainide $(1 \mathrm{mg} / \mathrm{L}$ ) increased the anisotropy respectively to $1.9 \pm 0.2$ (NS) and $2.2 \pm 0.7$ (NS) (pacing interval 240 and $140 \mathrm{~ms}$ ). In dilated atria flecainide had a greater and statistically significant effect on anisotropy in conduction $(2.0 \pm 0.2$ and $2.2 \pm 0.4 ; p<0.05)$. The percentage of areas with an anisotropy ratio of $>4$ increased from 4.5 and $3.2 \%$ to $10.6 \%(p<0.05)$ and $7.1 \%$ (NS) during 

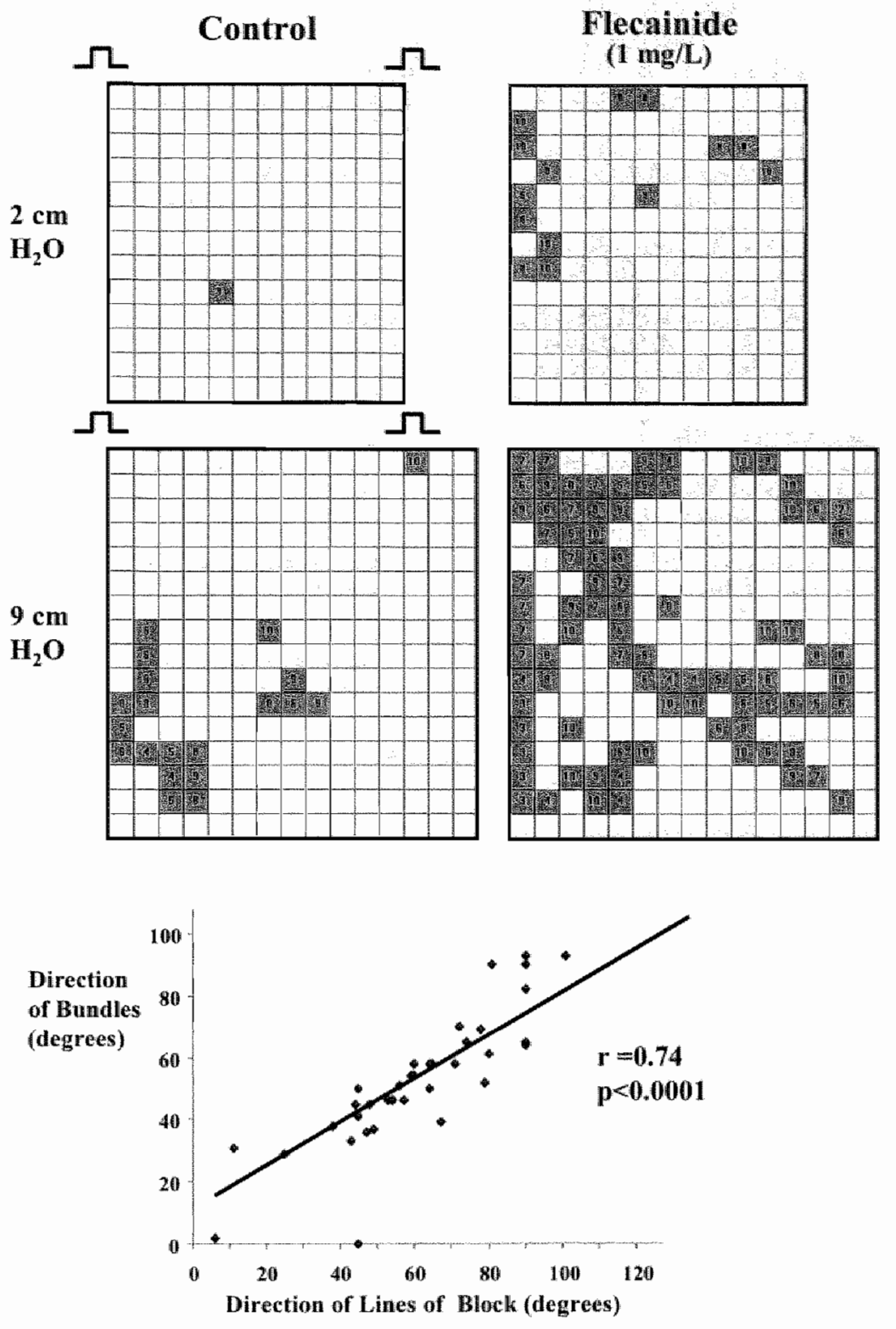

Figure 4: Top: Maps of local conduction velocities of $510 \mathrm{~cm} / \mathrm{s}$ (conduction black) during alternate pacing from the four comers of the mapping array. The local conduction velocities were derived from the conduction vectors calculated from the activation times of four neighboring electiodes $(0.5 \times 0.5 \mathrm{~mm})$. The combination of atrial diatation and flecalnide (lower right map) caused marked heterogeneities in conduction. Bottom: Coirelation between the direction of the lines of block and the direction of the underlying atrial bundle. 
dilatation, and to $8.8 \%$ (NS) and $15.8 \%$ (NS) during flecainide administration $(1 \mathrm{mg} / \mathrm{L})$. The combination of dilatation and sodium-blockade increased the number of areas with an anisotropy ratio of $>4$ to respectively $11.5 \%$ (pacing interval $240 \mathrm{~ms} ; \mathrm{p}<0.05$ ) and $16.5 \%$ (pacing interval $140 \mathrm{~ms} ; \mathrm{p}<0.05$ ).

\section{Control}
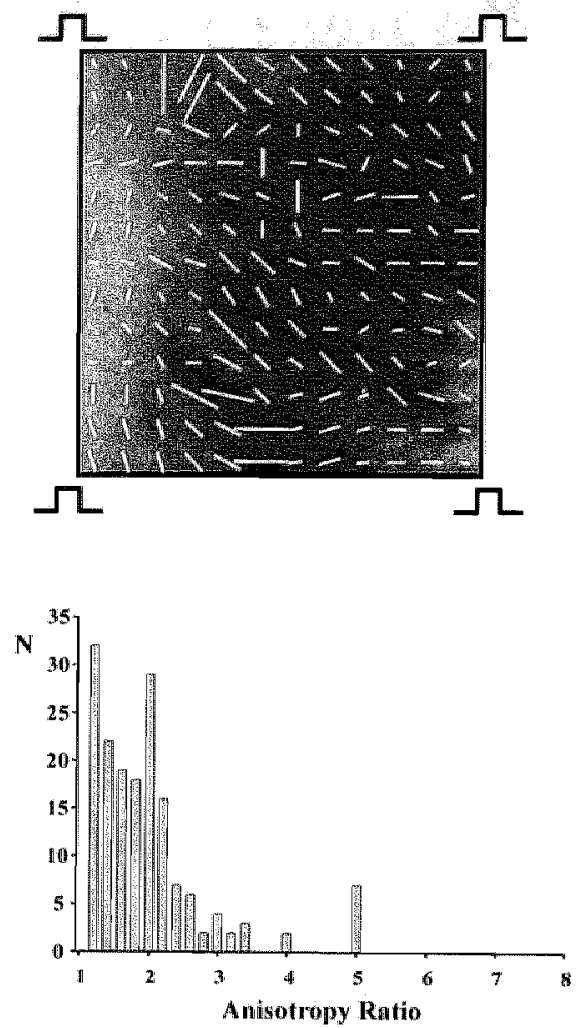

\section{Dilatation + Flecainide}
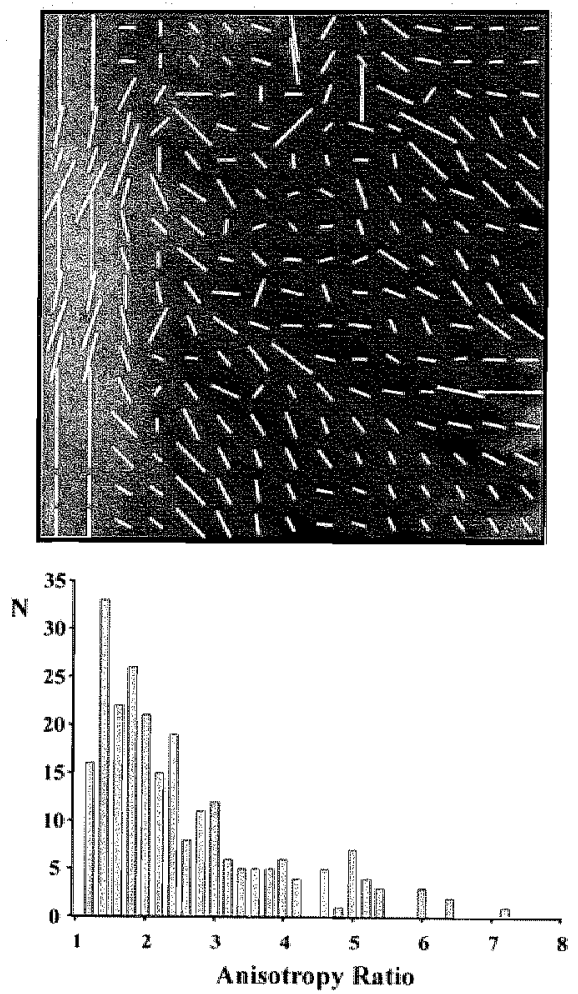

Figure 5: Top: Maps of local anisotropy in conduction during control and after the combination of dlatation and flecainide administration $(1 \mathrm{mg} / \mathrm{L})$ during pacing at an interval of $240 \mathrm{~ms}$. The arlentation of the vectors Indicates the direction with the highest conduction velocity, whereas their length expresses the degree of local anisotropy in conduction. The direction of fast conduction was closely related to the orientation of the atriat muscle bundles. Battom. The corresponding histograms of the local anisotropy ratios. The number of areas with a high degree of anisotropy increased by dilatation and flecainide. 


\section{Interaction between Atrial Dilatation and Sodium Channel Blockade}

Figure 6 shows that the effects of atrial dilatation and flecainide on conduction were highly synergistic. In the left panel the effects of flecainide on total conduction time are plotted both before and after atrial dilatation ( 8 hearts). In the right panel the incidence of intra-atrial conduction block is given. The dashed lines in each panel indicate the expected changes in TCT and conduction block in case the effects of atrial dilatation and flecainide would be additive. Since the combination of flecainide and dilatation exerted a stronger effect than the sum of the independent effects, their action was clearly synergistic $(p=0.0212$ and $p=0.0015)$. Also during pacing with an interval of $240 \mathrm{~ms}$, the effects of dilatation and flecainide on TCT and conduction block were synergistic ( $p=0.0052$ and 0.0002 ; data not shown).
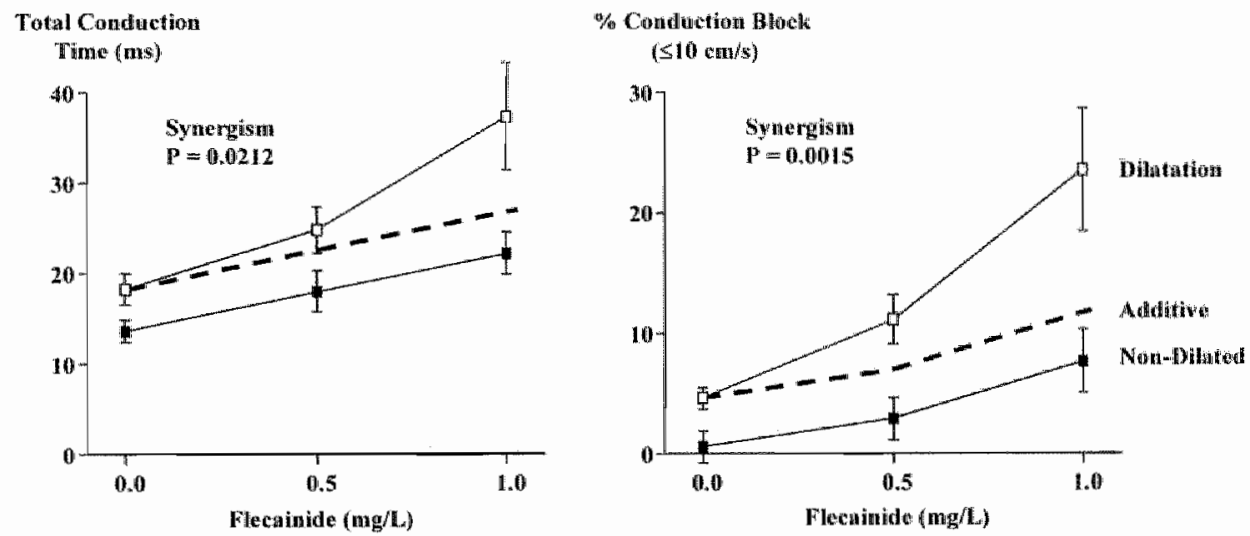

Figure 6: The effect of flecainide on TCT and percentage of conduction block in non-dilated and dilated atria (pacing interval 140ms; 8 hearts). The dashed lines indicate the sum of the separate effects of dilatation and flecainide (additive). Since the actual effect of the combination of dilatation and flecainide was higher than the sum of their separate effects, the action of flecainide and atrial dilatation were clearly synergistic.

\section{Effects on Atrial Refractory Period}

In a separate series of 6 rabbits the AERP of the right atrium was measured during pacing at 4 different sites with an interval of $240 \mathrm{~ms}$ (Table 2). In nondilated atria, flecainide ( $1 \mathrm{mg} / \mathrm{L}$ ) prolonged the AERP at all sites (mean: $81 \pm 10$ vs $71 \pm 9 \mathrm{~ms}, p<0.05)$. Acute atrial dilatation enhanced the effects of flecainide on AERP which now was prolonged from $58 \pm 13$ to $81 \pm 11 \mathrm{~ms}$. The spatial dispersion in refractory period (largest difference between 4 sites) was not significantly altered by dilatation or flecainide. 
TABLE 2. Effects of Atrial Dilatation and Fllecainide (1 mq/L) ON AERP

\begin{tabular}{|c|c|c|c|c|c|}
\hline & & \multicolumn{2}{|c|}{$2 \mathrm{~cm} \mathrm{H}_{2} \mathrm{O}$} & \multicolumn{2}{|c|}{$9 \mathrm{~cm} \mathrm{H}_{2} \mathrm{O}$} \\
\hline & & Control & Flecainllde & Control & Flecaintide \\
\hline \multirow[t]{4}{*}{ AERP(ms) } & Cranial CT & $69 \pm 2$ & $75 \pm 10$ & $53 \pm 8$. & $82 \pm 13^{*}$ \\
\hline & Cauidall CT & $82 \pm 6$ & $100+9$ & $63 \pm 8$ ․․ & $-91 \pm 5^{* 2}$ \\
\hline & Hilgh RA & $66 \pm 11$ & $73 \pm 12 *$ & $60 \pm 21$ & $79 \pm 20^{i k}$ \\
\hline & Low $\mathbf{R A}$ & $69+14$ & $80 \pm 17$ & $59 \pm 20$ & $74 \pm 14$ \\
\hline Meain & & $71 \pm 9$ & $81 \pm 10^{*}$ & $58 \pm 13 t$ & $81 \pm 11 *$ \\
\hline \multicolumn{2}{|c|}{ Spatial Dispersion (ms) } & $19 \pm 8$ & $26 \pm 15$ & $20 \pm 9$ & $24 \pm 11$ \\
\hline
\end{tabular}

Values are means \pm SD of 6 rabblts; CT: Crista Terminalis, RA: Right Atrium; * $p<0.05$ ws Control, $1 \mathrm{p}<0.0 .5 \mathrm{ws} 2 \mathrm{~cm} \mathrm{H}_{2} \mathrm{O}$.

\section{Discussion}

\section{Effects of Atrial Dilatation on the Action of Flecainide}

The present study shows that both atrial dilatation and flecainide slow the effective velocity of conduction of the depolarization wave and increase the degree of spatial heterogeneities in conduction. The effects of dilatation on conduction and refractoriness are in agreement with previous studies. ${ }^{8,12,13}$ Prolongation of the atrial refractory period by flecainide was enthanced by dilatation whereas spatial dispersion in refractoriness was not affected by dilatation or flecainide.

An important finding was that the combination of dilatation and flecainide exerted a clear synergistic effect on atrial conduction. Inoue at al. reported that in the guinea pig the reduction in $V_{\max }$ by flecainide was greater when the atrial bundles were stretched. ${ }^{14}$ Acute dilatation of the left ventricle by a balloon, also enhanced the depressive effect of flecainide on ventricular conduction. ${ }^{15}$ In contrast to acute atrial dilatation, ${ }^{8}$ dilatation of the left ventricle by increasing the diastolic pressure to as much as $30 \mathrm{mmHg}$, had no statistically significant effect on QRS duration or inter-ventricular conduction time. The synergistic effect of the combination of dilatation and sodium channel blockade was higher in the atrium than reported by Eckardt et al. in the ventricles. Apparently, important differences exist between atria and ventricles with respect to their response to stretch and sodium channel blockade.

In 1963, Penefsky and Hoffman observed that stretch of ventricular muscle bundles lowered the membrane resting potential and decreased the upstroke velocity and overshoot of the action potential. ${ }^{15}$ Depolarization of the 
membrane by stretch can be the result of activation of stretch-activated lon channels. ${ }^{17}$ It is well established that in depolarized tissue class I drugs depress conduction more than in normal myocardium. ${ }^{14,18,19}$ Thus, although not directly measured in the present study, it is likely that the enhanced effect of flecainide in dilated atria can be explained by depolarization of the membrane resting potential. There is experimental evidence that atrial dilatation stretches thinner regions of the atria more than the thicker parts. ${ }^{20}$ The enhanced heterogeneity in conduction by dilatation and flecainide as found by high density mapping in our study, thus may be the result of a heterogeneous distribution of wall stress.

\section{Anisotropy}

The synergistic effect of dilatation and flecainide on intra-atrial conduction block might be related to the anisotropic properties of the atria. The safety factor for conduction is highly dependent on the structural arrangement of cellular connections both at a microscopic and macroscopic level ${ }^{21}$ At sites where the safety factor for propagation is low, a reduction in inward sodium current by flecainide may result in local conduction block. Also the membrane uptake and kinetics of sodium channel blockers are heterogeneously distributed in anisotropic tissue. ${ }^{22}$ This will further contribute to spatial differences in depression of conduction by class IC drugs.

On a macroscopic scale, the anisotropy ratio in atrial conduction has been reported to be in the range of 1.1 and $1.8\left(\theta_{\mathrm{L} /} \theta_{T}\right) .{ }^{23,24}$ In our experiments the anisotropy in total conduction time similarly ranged between 1.3 and 1.6 and was not affected by dilatation or flecainide. At a microscopic scale, the anisotropy ratio is higher (between 4.8 and 10) than when measured more globally. ${ }^{25,26}$ In the present study, we evaluated the degree of anisotropy in conduction at a sub-macroscopic scale (areas of $1 \mathrm{~mm}^{2}$ ). At this scale, the combination of atrial stretch and flecainide increased the anisotropy ratio from 1.7 to $2.2(p<0.05)$. Our study further supports the concept that the architecture of the atrial wall is of major importance for the occurrence of preferential directions of conduction. ${ }^{23,27}$ The majority of the lines of conduction block during atrial dilatation and flecainide administration were located along the border of the crista terminalis and major pectinate muscles. In human atrial flutter, the crista terminalis is a preferential barrier for conduction as evidenced by double potentilals along its border. ${ }^{27}$ In the study of Gray et al. the orientation of lines of right atrial conduction block during AF corresponded to the direction of the major pectinate muscles. ${ }^{23}$

\section{Limitations}

A limitation of the present study is that only acute dilatation of the right atrium was studied. It is quite likely that prolonged atrial stretch may have 
different or additional effects on atrial electrophysiology and structure. The effects of atrial dilatation may also differ depending on the underlying cause (valvular disease, hypertension, heart failure, lone AF), and clinically, atrial enlargement is often more pronounced in the left than in the right atrium. However, in a previous study we showed that atrial stretch increased the heterogeneity in conduction equally in the right and left atrium. Another important limitation is that we did not investigate the (inter-)cellular mechanisms of the stretch-induced conduction disturbances and the observed synergism with sodium channel blockade. The involved cellular mechanisms need to be explored in additional studies.

It has been reported that the efficacy of class IC drugs to cardiovert AF sharply declines with the duration of AF. ${ }^{28-30}$ This loss of antifibrillatory action may partly be due to atrial dilatation. ${ }^{5,30}$ In this respect, another limitation is that we did not compare the efficacy of flecainide to cardiovert AF in dilated and nondilated atria. Because of the small size of rabbit atria AF is usually self-terminating and therefore this model is lless suitable to study pharmacological cardioversion of AF. The clinical relevance of the synergistic action of atrial dilatation and sodium channel blockade thus remains to be investigated in other experimental and clinical models.

\section{References}

1. S. M. Vaziri, M. G. Larson, E. J. Benjamin and D. Levy: Echocardiographic predictors of nonrheumatic atrial fibrillation. The Framingham Heart Study. Circulation 1994;89:724-30.

2. P. Probst, N. Goldschlager and A. Selzer: Left atrial size and atrial fibrillation in mitral stenosis: factors infliuencing their relationship. Circulation 1973;48:1282-1287.

3. G. Keren, T. Etzion, 1. Sherez, A. A. Zelcer, R. Megidish, H. I. Miller and S. Lanlado: Atrial fibrillation and atrial enlargement in patients with mitral stenosis. Am Heart $1987 ; 114: 1146$ 1155 .

4. A. J. Sanfillippo, V. M. Abascal, M. Sheehan, L. B. Dertel, P. Harrigan, R. A. Hughes and A. E. Weyman: Atrial enlargement as a consequence of atrial fibrlllation. Circulation 1990;82:792. 797 .

5. A. Bollmann, K. H. Binias, I. Toepffer, J. Molling, C. Geller and H. U. Klein: Importance of left atrial diameter and atrial fibrillatory frequency for conversion of persistent atrial fibrillation with oral flecainide. Am J Cardiol 2002;90:1011-4.

6. $M . A_{0}$ Brodsky and B. J. Allen: Factors determining maintenance of sinus rhythm after chronic atrial fibrillation with left atrial dilatation. Am J Cardial $1989 ; 63: 1065-1068$.

7. W. L. Henry, J. Morganroth, A. S. Pearlman, C. E. Clark, D. R. Redwood, S. B. Itscoitz and S. E. Epstein: Relation between echocardiographically determined left atrial size and atrial fibrillation. Circulation $1976 ; 53: 273-279$.

8. S. Eijsbouts, M. Majidi, M. van Zandvoort and M. Allessie: Effects of Acute Atrial Dilation on Heterogenelty in Conduction in the Isolated Rabbit Heart. J Cardiovasc Electrophysiol $2003 ; 14: 269 \cdot 278$.

9. M. C. Wijffels, R. Dorland, F. Mast and M. A. Allessle: Widening of the excitable gap during pharmacological cardloversion of atrial fibrillation in the goat: effects of cibenzoline, hydroquinidine, flecainide, and d-sotalol. Circulation 2000; 102:260-7. 
10. R. M. Shaw and $Y$. Rudy: Ionic mechanisms of propagation in cardiac tissue. Roles of the sodium and L-type calcium currents during reduced excitability and decreased gap junction Coupling. Circ Res 1997;81:727-41.

11. W. Gander, G. H. Golub and R. Strebel: Fitting of circles and and ellipses: least square solu. tion. BIT 1994:34:556-577.

12. F. J. Chorro, S. Egea, L. Mainar, 1. Canoves, 3. Sanchis, E. Llavador, V. Lopez Merino and L. Such: Modificaciones agudas de la longitud de onda del proceso de activacion auricular inducidas por la dilatacion. Estudio experimentall. Rev Esp Cardiol 1998;51:874-83.

13. F. Ravelli and M. Allessie: Effects of atrial dilatation on refractory period and vulnerability to atrial fibrillation in the isolated Langendorff-perfused rabbit heart. Circulation $1997,96: 1686-$ 1695.

14. D. Inoue, T. Shirayama, I. Omori, M. Inoue, R. Sakai, K. Ishibashi, H. Miyazaki, Y, Yamahara, T. Tatsumi, 3. Asayama and et al.: Electrophysiological effects of flecainide acetate on stretched guinea pig left atrial muscle fibers. Cardiovasc Drugs Ther 1993;7:373-8.

15. L. Eckardt, W. Haverkamp, U. Gottker, M. Madeja, R. Johna, M. Borggrefe and G. Breithardt: Divergent effect of acute ventricular dilatation on the electrophysiologic characteristics of of th sotalol and flecainide in the isolated rabbit heart. J Cardiovasc Electrophysiol 1998; 9:366-83.

16. Z. Penefsky and B. Hoffman: Effect of stretch on mechanical and electrical properties of car* diac muscle. Am J Physiol 1963;204:433-438.

17. H. Hu and F. Sachs: Stretch-activated ian channels in the heart. I Mol Cell Cardiol 1997; 29:1511-23.

18. L. M. Hondeghem, A. O. Grant and R. A. Jensen: Antiarrhythmic drug action: selective depression of hypoxic cardiac cells. Am Heart J 1974;87:602-5.

19. T. Anno and L. M. Hondeghem: Interactions of flecainide with guinea pig cardiac sodium channels. Importance of activation unblocking to the woltage dependence of recovery. Circ Res 1990;66:789-803.

20. T. Satoh and D. Zipes: Unequal atrial stretch in dogs increases dispersion of refractoriness conductive to developing atrial fibrilation. I Cardiovasc Electrophyslol 1996;7:833-842.

21. M. S. Spach, W. T. Miller, 3rd, P. C. Dolber, J. M. Kootsey, J. R. Sommer and C. E. Mosher, $y_{r}:$ The functional role of structural complexities in the propaigation of depolarization in the atrium of the dog Cardiac conduction disturbances due to discoritinuitles of effective axial resistivity. Circ Res 1982; 50:175-91.

22. M. Spach, P. Dolber, 1. Heidlage, 1. Kootsey and E. Johnson: Propagating depolarisation In anisotropic human and canine cardiac muscle: apparent directional differences in membrane capacitance. Circ Res 1987;60:206-219.

23. R. A. Gray, A. M. Pertsov and J. Jalife: Incomplete reentry and epicardial breakthrough patterns during atrial fibrillation in the sheep heart. Circulation $1996 ; 94: 2649-61$.

24. A. Hansson, M. Holm, P. Blomstrom, R. Johansson, C. Luhrs, J. Brandt and S. Olsson: Right atrial free wall conduction velocity and degree of anisotropy in patients with stable sinus rhythm studied during open heart surgery. Eur Heart J 1998;19:293-300.

25. M. S. Spach, W. T. Miller, 3rd, D. B. Geselowitz, R. C. Barr, J. M. Kootsey and E. A. Johnison; The discontinuous nature of propagation in normal canine cardiac muscle. Evidence for recurrent discontinuities of intracellular resistance that affect the membrane currents. Cinc-Res $1981 ; 48: 39-54$.

26. M. S. Spach, P. C. Dolber and J. F. Heidlage: Influence of the passive anisotropic properties on directional differences in propagation following modification of the sodium conductance in human atrial muscle. A model of reentry based on anisotropic discontinuous propagation. Circ-Res $1988 ; 62: 811-32$.

27. J. E. Olgin, J. M. Kalman, A. P. Fitzpatrick and M. D. Lesh: Role of right atrial endocardial structures as barriers to conduction during human type I atrial flutter. Activation and entrain" ment mapping guided by intracardiac echocardiography. Circulation 1995;92:1839-48. 
28. H. 3. Crijns, L. M. vän Wijk, W. H. van Gilst, 3. H. Kingma, I. C. van Gelder and K. I. Lie: Acute conversion of atrial fibrillation to sinus rhythm: dinical efficacy of flecaimide acetate. Comparison of two regimens. Eur Heart $\mathrm{j} 1988 ; 9: 634-8$.

29. M. J. Suttori, J. H. Kingma, E. R. Jessurun, A. H. L. Lie, N. M. van Hemel and K. I. Lie: The value of class IC antiarmythmic drugs for acute conwersion of paroxysmal atrial fibrillation or flutter to sinus rhythm. I Am Coll Cardial 1990;16:1722-7.

30. 1. J. Goy, U. Kaufmann, L. Kappenberger and U. Sigwart: Restoration of sinus rhythm with flecainide in patients with atrial fibrillation. Am J Cardiol 1988;62:38D-40D. 
Chapter 4

\section{Serial Cardioversion by Class IC Drugs during 4 Months of Persistent Atrial Fibrillation in the Goat}

Sabine Eijsbouts, MD, Jannie Ausma, PhD, Yuri Blaauw, MD, Ulrich Schotten, MD, PhD, Mattias Duytschaever, MD, PhD, Maurits A. Allessie, MD, PhD 


\section{Abstract}

\section{Introduction}

The success rate of pharmacological cardioversion of atrial fibrillation (AF) in patients depends on the duration of AF. It is unknown to what extent AFinduced structural atrial remodeling contributes to this loss of efficacy.

\section{Methods and Results}

In 10 goats persistent AF was induced by repetitive burst pacing. During a time period of 16 weeks the efficacy of flecainide (Flec) and cibenzoline (Cib) to cardiovert AF was investigated by serial cardioversion. The drugs were administered intravenously at a rate of $0.1 \mathrm{mg} / \mathrm{kg} / \mathrm{min}$. AF cycle length (AFCL) was continuously monitored. Drug infusion was continued until AF was successfully cardioverted or the QRS duration was prolonged about 2-fold. The average atrial cycle length during persistent AF was $104 \pm 10 \mathrm{~ms}$ and did not change during the 16 weeks period. The success rate of cardioversion by flecainide and cibenzoline decreased with the duration of AF from 60 to $17 \%$ and from 80 to $63 \%$. In goats that failed to cardiovert, sinus rhythm was not restored despite a 2 -fold prolongation of the AF cycle length (respectively from $96 \pm 5 \mathrm{~ms}$ to $168 \pm 30$ (Flec) and $203 \pm 26 \mathrm{~ms}$ (Cib). The sensitivity of atrial fibrillation for class I drugs was not altered with time and the dose dependent effect on AFCL remained the same (Flec: $8 \pm 5 \mathrm{vs} .7 \pm 2 \mathrm{~ms} / \mathrm{mg} / \mathrm{kg}(p=0.70)$ and Cib: $13 \pm 3$ vs. $13 \pm 5 \mathrm{~ms} / \mathrm{mg} / \mathrm{kg} \quad(p=0.95))$. In animals in which cardioversion remained possible, the critical $A F C L$ at which cardioversion occurred increased from $96 \pm 5 \mathrm{~ms}$ to $211 \mathrm{~ms}$ (Flec) and $189 \pm 24 \mathrm{~ms}$ (Cib).

\section{Conclusions}

The progressive loss of efficacy of class IC drugs to cardiovert AF of longer duration is not due to a decrease in the sensitivity of remodeled atrial myocardium for Class I drugs. Fallure of cardioversion was due to an increase in the critical AF cycle length required for pharmacological cardioversion. 


\section{Introduction}

Atrial fibrillation (AF) is a progressive arrhythmia often starting in a paroxysmal form and becoming more and more persistent with time. ${ }^{1}$ The success rate of pharmacological cardioversion by class IC drugs rapidly declines with the duration of AF. While AF of short duration ( $<24$ hours) is effectively cardioverted with a success rate between 71 and $93 \%,{ }^{2}, 3$ the conversion rate progressively decreases when AF continues for more than 10 days. ${ }^{4}, 5$ The loss of efficacy of anti-fibrillatory drugs during the first days of AF is associated with electrical and contractile atrial remodeling during the first 12-72 hours of AF. ${ }^{6-9}$ However, a further increase in AF-stability after 1 week cannot be explained on the basis of electrical remodeling. On a longer time scale also structural changes occur." ${ }^{10,11}$ Fibrillating atria become dilated and the myocytes start to increase in size, accumulate glycogen and loose part of their myofilaments (myolysis). ${ }^{11}$ Also the distribution of connexin 40 and the amount of structural proteins undergo changes. ${ }^{10}$ However "little is known about the significance of these (ultra)structure changes for the development of a substrate of persistent AF. Todd et al. showed that 3 successive one-month periods of AF in the goat, separated by one week of sinus rhythm during which electrical remodeling completely reversed, led to a progressive increase in vulnerability for atrial arrhythmias. ${ }^{12}$ This strongly suggests that apart from electrical remodeling, a second factor with a much slower time constant must be involved in the transition from paroxysmal to persistent AF.

The present study was designed to test the hypothesis that during 4 months of 'lone" persistent AF during which the atria undergo structural remodeling, the stability of AF increases. Because during persistent fibrillation the duration of AF paroxysms cannot be used to measure the stability of fibrillation, instead the amount of class IC drug required for cardioversion was used to evaluate long-term changes in the stability of AF.

\section{Methods}

\section{The Goat Model of Persistent AF}

Ten femalle goats (weight $54 \pm 9 \mathrm{~kg}$ ) were used for this study. Animal handling was carried out according to the European Directive for protection of vertebrate animals. During general anesthesia multiple electrodes (diameter $2 \mathrm{~mm}$ ) were sutured on the free wall of the right (RA) and left atrium (LA) and Bachmann's bundle (BB). Two electrodes were placed on the mid-wall of the 
left ventricle and three silver plates (diameter $10 \mathrm{~mm}$ ) were implanted subcutaneously to record a precordial ECG and to serve as indifferent electrode. In four goats, 6 piezoelectric crystals were sutured on the atria, two on Bachmann's bundle, one on the right and left atrial appendage and one in the center of the right and left atrial free wall. The distance between the crystals was measured with a sonomicrometer system (Sonometrics). ${ }^{8}$ All leads were tunneled subcutaneously to the neck and exteriorized by 30-pin connectors (Lemosa(B). After the goats had recovered from surgery persistent AF was produced by a fibrillation pacemaker. Details of the goat model have been described previously. ${ }^{6}$

\section{Serial Pharmacological Cardioversion}

Pharmacological cardioversion was performed after $1,4,8$, and 16 weeks of persistent $A F$. Flecainide $(n=7)$ or cibenzoline $(n=10)$ was infused intravenously at a rate of $0.1 \mathrm{mg} / \mathrm{kg} / \mathrm{min}$ and at these dosages the two drugs exerted an equal effect on the duration of the QRS complex. Flecainide was chosen because it is commonly used in the clinic and Cibenzoline because of its dose dependent effect on the atrial fibrillation cycle length (AFCL) in the goat. ${ }^{13}$ In case AF did not terminate within one hour, the infusion rate was doubled to $0.2 \mathrm{mg} / \mathrm{kg} / \mathrm{min}$. The two class IC drugs were used in random order. Sufficient time was allowed between experiments for complete washout of the drugs (at least five half-lifes). During the cardioversion protocol all atrial electrograms were recorded simultaneously (gain 500, bandwidth $1-500 \mathrm{~Hz}$, sampling rate $1 \mathrm{kHz}$ ). The median AFCL was measured on-line from 300 consecutive cycles. The R-R interval, QRS duration and QTtime were monitored from a precordial electrocardiogram or a unipolar ventricular electrogram. Measurements were started 15 minutes before infusion. Drug infusion was interrupted when: 1) AF was cardioverted, 2) the QRS duration was prolonged by about 2-fold, or 3) ventricular arrhythmias occurred (Flgure 1).

\section{Statistical Analysis}

Data are given as mean \pm SD. For statistical analysis a one -way ANOVA or a paired student t-test was used. A $p<0.05$ was comsidered statistically significant.

\section{Results}

The median AFCL did not change significantly during 4 months of persistent AF. In 10 goats the average of the median AFCL after $1,4,8$ and 16 weeks of AF was respectively $104 \pm 10,101 \pm 11,101 \pm 9$ and $96 \pm 5 \mathrm{~ms}(p=0.38)$. Also the 
median RR-interval did not change with time $(386 \pm 55,419 \pm 77,402 \pm 46$ and $434 \pm 79 \mathrm{~ms} ; \mathrm{p}=0.44)$. After 1,4 and 8 weeks of Af the diameter of the let atrum increased by $13 \pm 9 \%, 21 \pm 14 \%$ and $22 \pm 19 \%$. (one way ANOVA: $p=0.02)$. At 16 weeks the atrial diameter could not be measured because in most animals the thin crystal wires were broken.

\section{Hersistent $\mathrm{AF}$}

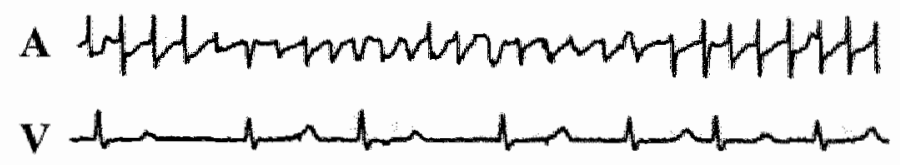

Successfut

Cardioversion

A

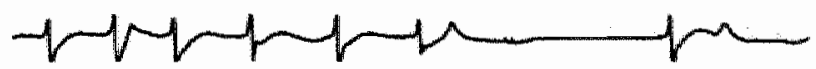

V

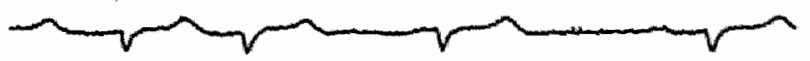

Failure:

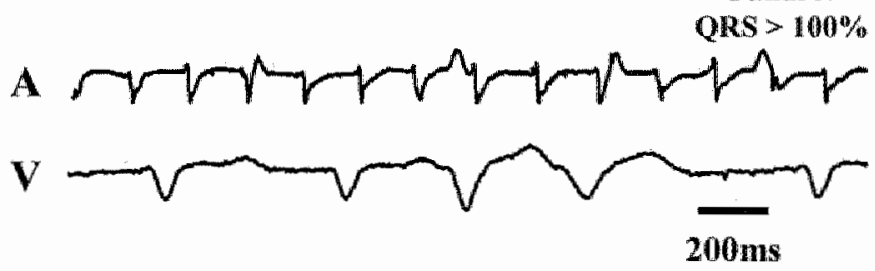

Figure 1: Cardioversion of atrial fibrillation by class IC drugs after 16 weeks of persistent AF. The upper panel shows an atrial (A) and ventricular (W) electrogram after 16 weeks of persistent AF. In the middle panel flecalnide had prolonged the AFCL to $210 \mathrm{~ms}$ when AF was converted to sinus rhythm. In the lower panel cardioversion of AF failed and infusion of flecalnide was interrupted because the QRS complex was prolonged by $>100 \%$.

\section{Effects of Flecainide and Cibenzoline on AFCL}

Figure 2 shows an example of the prolongation of AFCL by 60 minutes infusion of cibenzoline $(0.1 \mathrm{mg} / \mathrm{kg} / \mathrm{min})$ after 16 weeks of persistent AF. At increasing dosages the median $\mathrm{AFCL}$ prolonged from 91 to $162 \mathrm{~ms}$. The absolute variation in AFCL (difference between $p_{5}$ and $P_{95}$ value of the AFCL histogram) remained the same. Linear regression analysis yielded a correlation coefficient of 0.98 and an increase in AFCL of $13 \mathrm{~ms} / \mathrm{mg} / \mathrm{kg}$. Figure 3 shows the average dose dependent changes by flecainide $(n=7)$ and cibenzoline $(n=10)$ after 1,8 and 16 weeks of AF. Cibenzoline exerted a larger dose dependent effect on AFCL than flecainide (13æ3 vs. $8 \pm 5$ $\mathrm{ms} / \mathrm{mg} / \mathrm{kg} ; p<0.01$ ). The sensitivity of the atria for both class IC drugs did not change with time, and after 16 weeks of AF they still exerted the same effect on AFCL as after 1 week ( $7 \pm 2$ vs. $8 \pm 5 \mathrm{~ms} / \mathrm{mg} / \mathrm{kg} ; p=0.70$ and $13 \pm 5 \mathrm{vs}$. $13 \pm 3 \mathrm{~ms} / \mathrm{mg} / \mathrm{kg} ; p=0.95)$. The duration of the QRS complex was equally 
prolonged by flecainide and cibenzoline ( $9 \pm 3 \mathrm{vs}, 10 \pm 8 \mathrm{~ms} / \mathrm{mg} / \mathrm{kg}, \mathrm{p}=0.72)$. The dose dependent widening of the QRS complex did not change during the 4 months of AF (see also Table 1).

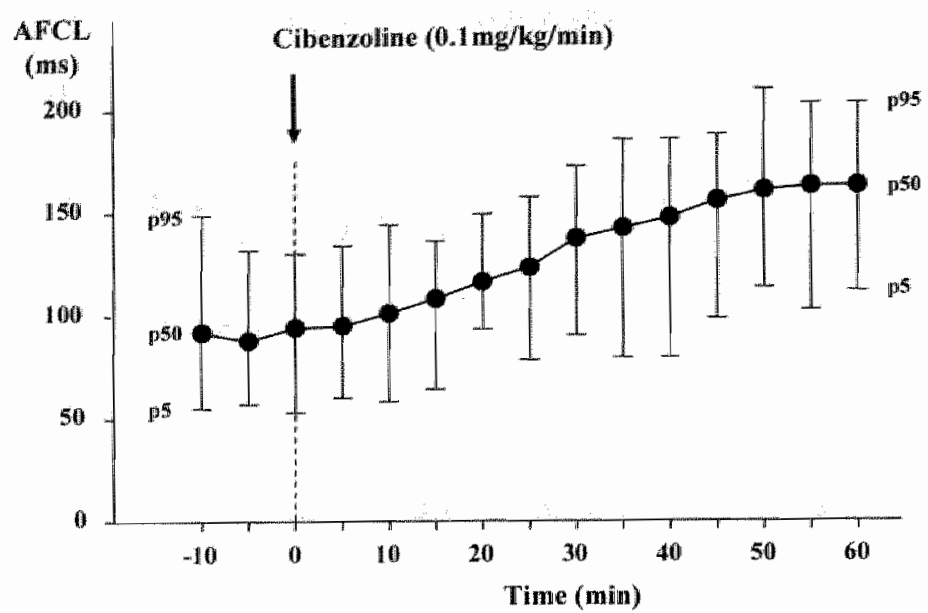

Figure 2: An example of the cumulative dose-dependent increase in median AFCL during infusion of cibenzoiline after 16 weeks of persistent AF $(0.1 \mathrm{mg} / \mathrm{kg} / \mathrm{min})$. The bars indicate the difference between the $5^{\text {th }}$ and $95^{\text {th }}$ percentile of the AF cycle length (temporal variation in AFCL). In this example cibenzoline caused an average dose-dependent prolongation of $A F C L$ of $13 \mathrm{~ms} / \mathrm{mg} / \mathrm{kg}$ (inear regresslon: $R^{2}=0.98$ ).

\section{1 week $A F$}

$\triangle \mathrm{AFCL}$

(ms)

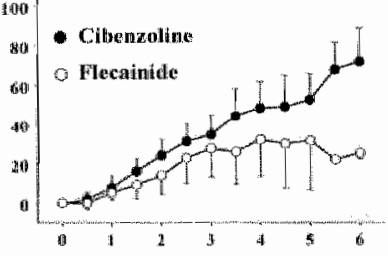

$\triangle$ QRS

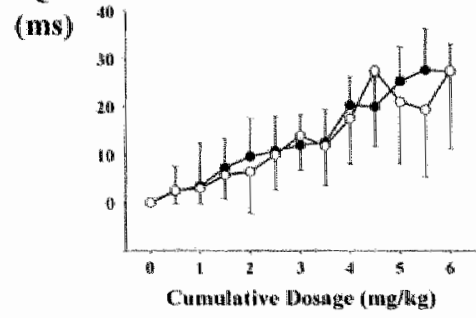

8 weeks AF
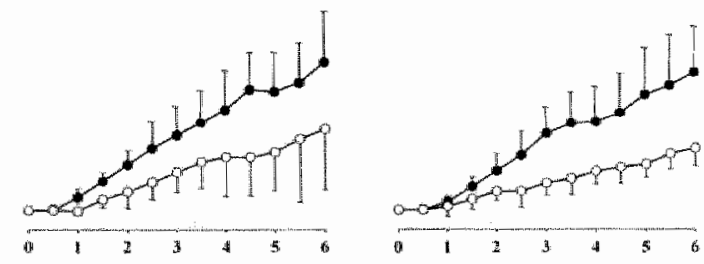

Figure 3: Cumulative dose-dependent increase in AFCL and QRS duration by flecainide $(n=7)$ and cibenzoline $(n=10)$ after 1,8 and 16 weeks of AF. During 16 weeks of persistent AF the effects of flecainide and cibenzoline on AFCL and QRS did not change. 


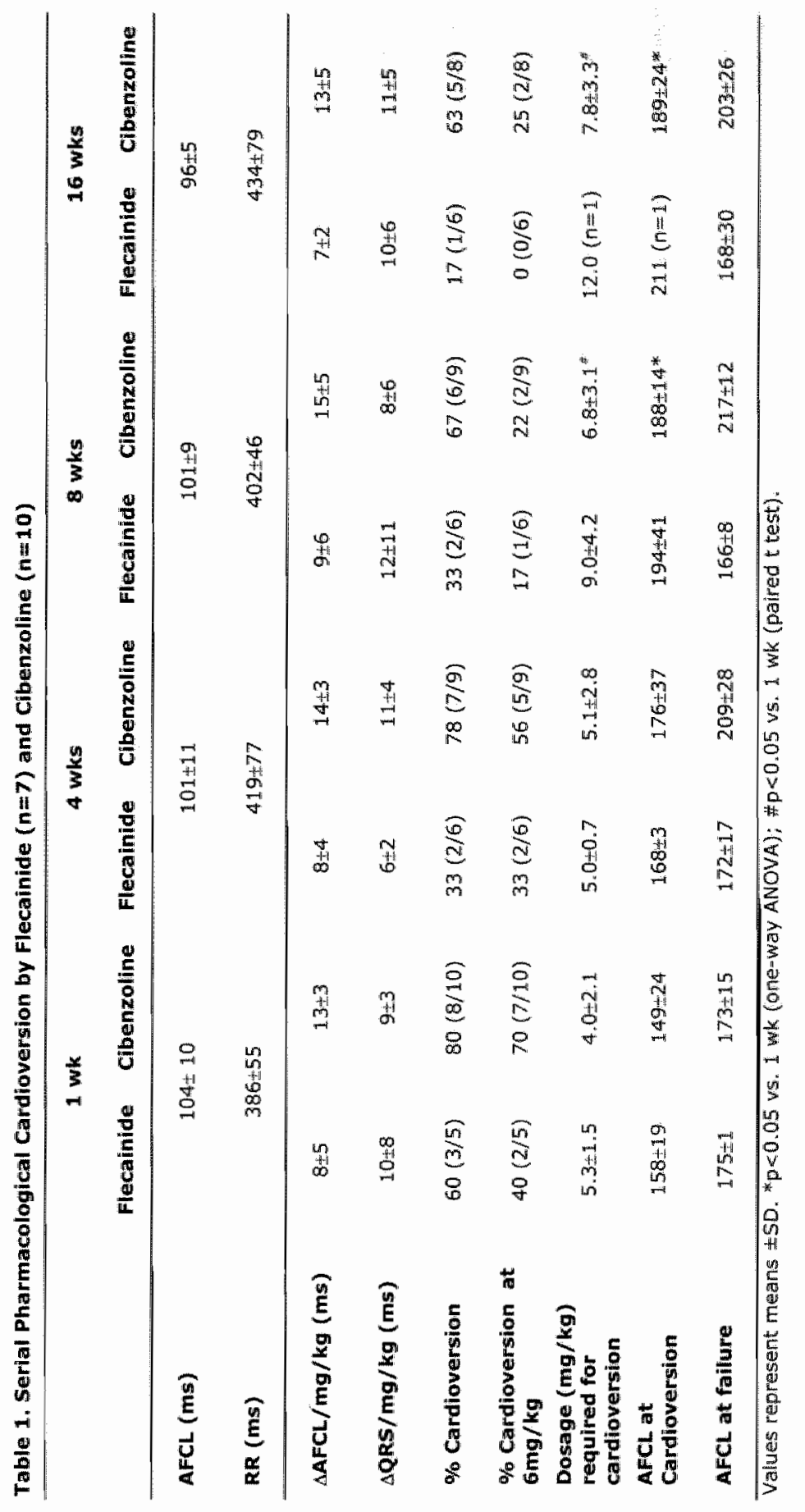




\section{Serial Pharmacological Cardioversion of Persistent AF}

Figure 4 shows the success rate of serial cardioversion and the required dosages of flecainide and cibenzoline during 16 weeks of persistent AF. After 1 week the success rate of cardioversion by a maximal dosage of flecainide was $60 \%$. Cibenzoline cardioverted AF in 8 of 10 goats $(80 \%)$. In the course of 16 weeks the success rate of pharmacological cardioversion progressively declined. Flecainide cardioverted AF of 4 and 8 weeks duration in only $33 \%$ of the animals and after 16 weeks the success rate was dropped to $17 \%$. Also cibenzoline became less effective with time and after 16 weeks cardioversion occurred in $63 \%$ of the cases (Table 1). At a sub-maximal but still high dosage of $6 \mathrm{mg} / \mathrm{kg}$, flecainide was completely unsuccessful to cardiovert AF of 16 weeks, whereas cibenzoline still cardioverted 2 of 8 goats $(25 \%)$. Clinically dosages of flecainide $(150 \mathrm{mg})$ and cibenzoline $(1.2 \mathrm{mg} / \mathrm{kg})$ were completely unable to cardiovert AF already after 1 week duration. The minimal dosages of flecainide and cibenzoline required for successful cardioversion of AF are given in the lower panels of figure 4.

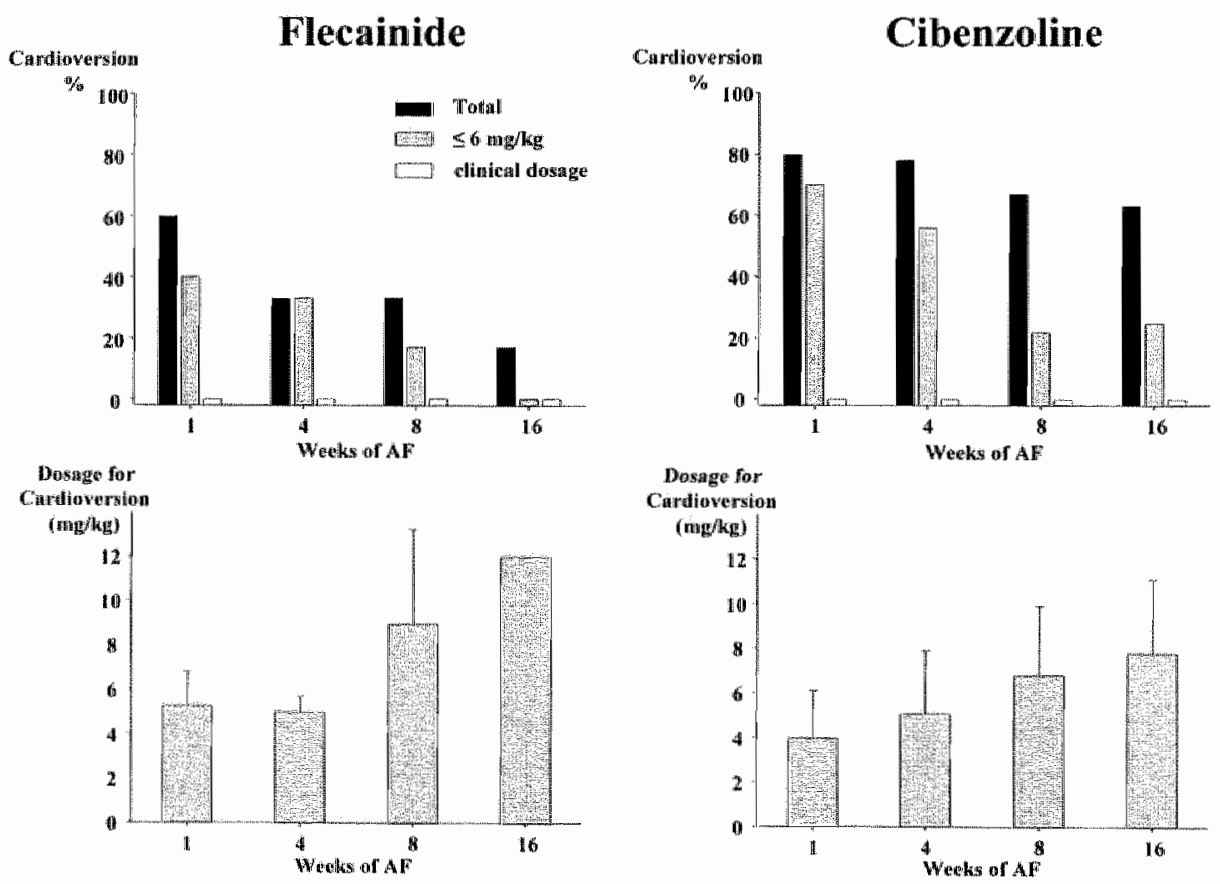

Figure 4: Upper panels: The success rate of serial cardioversion by flecainide and cibenzoline during 16. weeks of persistent AF. The black bars represent cardioversion at all dosages, the gray bars at a dosage of $\leq 6 \mathrm{mg} / \mathrm{kg}$ and the white bars at clinically used dosages (flecainide: 150mg, cibenzoline: $1.2 \mathrm{mg} / \mathrm{kg}$ ). The success rate decreased progressively in the course of 16 weeks of AF. Lower panels: The dosages of flecalnide and cibenzoline required for cardioversion of AF. The amount of class IC drugs needed for restoration of simus rhythm increased progressively during 16 weeks of AF. 
During 16 weeks of persistent AF the amount of class IC drugs required for restoration of sinus thythm progressively increased (Table 1). The number of goats that could be cardioverted by flecainide after $>4$ weeks of AF was too small for statistical analysis. The higher dosages of cibenzoline required for cardioversion after 8 and 16 weeks were statistically significant using a paired test $(p<0.05)$ but were not statistically significant when tested with ANOVA.

\section{Threshold for Pharmacological Cardioversion of AF}

In figure 5 the critical AF cycle length associated with termination of AF is plotted after $1,4,8$ and 16 weeks of AF. In case cardioversion falled because drug infusion had to be interrupted due to adverse effects (prolongation of QRS complex or ventricular arrhythmias) the longest attained AF lengths are plotted. After 1 week of AF, the critical AFCL associated with cardioversion was $158 \pm 19 \mathrm{~ms}$ (flecainide) and $149 \pm 24 \mathrm{~ms}$ (cibenzoline). After 4,8 and 16 weeks, cardioversion by flecainide occurred at an AFCL of $168 \pm 3,194 \pm 41$ and $211 \mathrm{~ms}$ and by cibenzoline at $176 \pm 37$ (NS), $188 \pm 14(\mathrm{p}<0.05)$ and $189 \pm 24 \mathrm{~ms}$ $(p<0.05)$. In the lower panels of figure 5 the widening of the QRS-complex by flecainide and cibenzoline are plotted for each goat. The majority of failures (open bars) were due to a widening of the QRS complex and in 4 cases because of runs of ventricular tachycardia (asterisks).

\section{Discussion}

\section{Efficacy of Pharmacological Cardioversion of AF}

The present study shows that the efficacy of cardioversion by flecainide and cibenzoline gradually declined during 16 weeks of persistent atrial fibrillation. The success rate decreased from 60-80\% after 1 week to 17-63\% after 4 months of AF. This was true despite the fact that both drugs were administered in very high dosages. Clinicall atrial fibrillation of short duration ( $<24$ hours) can be cardioverted by class IC drugs with a success rate of 71 $93 \%,{ }^{2}, 3$ In contrast, after AF has persisted for more than 10 days the conversion rate is less than $38 \% .4,5$ This reduction in efficacy of class IC drugs to cardiovert AF can be due either to a loss of the electrophysiological action of the drugs or by an increase in stability of the fibrillatory process. In our present series the sensitivity of the atria for class IC drugs was not reduced after 4 months of AF. In particular no reduction in the dosedependent effect on AF cycle length was found. In dosages exerting a similar effect on QRS duration, cibenzoline had a stronger effect on AFCL than flecainide. Besides blocking the rapid sodium channels, cibenzolin to some degree- also blocks the $\mathrm{k}$-type calcium current. This may explain the stronger 
Flecainide

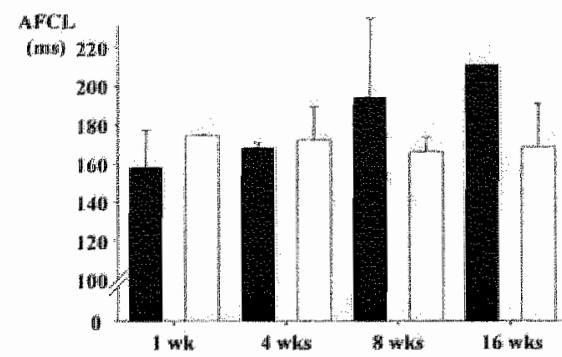

Whatening
of Qns

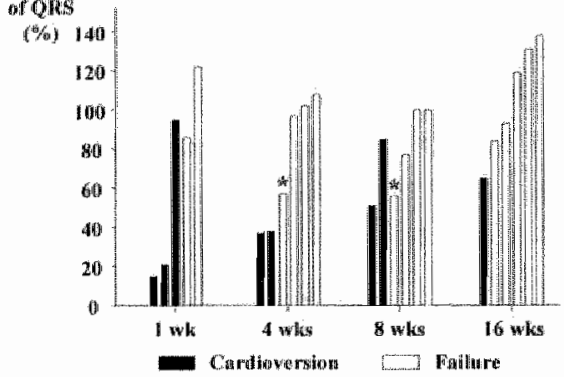

Cibenzoline

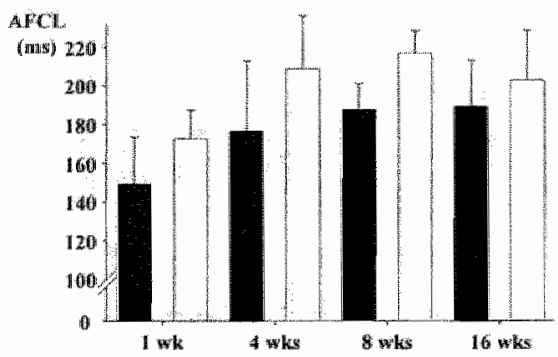

Widening
of ORRS

(\%) 140

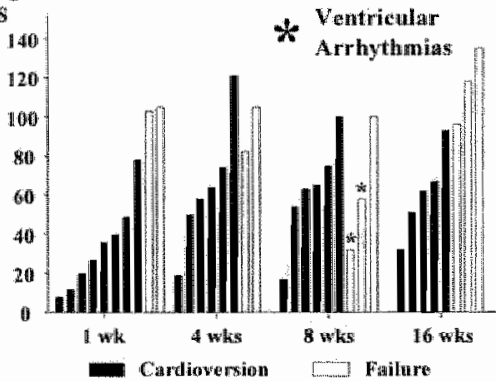

Figure 5: Upper panels: the critical AFCL for successful termination of AF (black bars). The apen bars indicate the AFCL when flecainide or cibenzoline infusion was stopped because of adverse effects. The AFCL, for successful cardioversion became progressiwely longer during 16 weeks of AF. Lower panels: widening of the QRS-complex by flecainide and cibenzoline (open bars: failures). In the 4 cases indicated by an asterisk, cardioversion was abonted because of the occulrence of ventriculai arrhythmias.

effect of cibenzoline on AFCL, because the calcium current plays a role in conduction under circumstances where the safety factor for conduction is low (for example at pivot points). ${ }^{14}$

The lower success rate of cardioversion with time thus must be ascribed to an increase in the stability of atrial fibrillation. When AF persisted for a longer period of time, the critical AF cycle length at which AF terminated increased from $149 \pm 15$ (cibenzoline) and $158 \pm 19 \mathrm{~ms}$ (flecainide) to respectively $189 \pm 24$ and $211 \mathrm{~ms}$. It should be stressed that in our experimental studies we used much higher dosages than applied clinically. At clinical dosages also in the goat flecainide and cibenzoline were completely unsuccessful to cardiovert AF after one week.

\section{The Role of Electrical, Contractile and Structural Remodeling}

Electrical remodeling occurs during the first days of atrial fibrillation. ${ }^{6,7}$ Due to a shortening in atrial refractoriness and wavelength, paroxysms of AF progressively prolong in duration from less than 10 seconds to several minutes or hours. However, the time course of electrical remodeling and the 
prolongation of AF duration do not run in parallel. Whereas electrical remodeling reaches a steady state within $3-4$ days, the stability of $\overline{A F}$ continues to increase thereafter. On average it takes $1-2$ weeks until AF becomes persistent and spontaneous conversion to sinus rhythm no longer occurs. "We do not know exactly which factors are responsible for the further increase in AF duration after electrical remodeling is completed. As a result of atrial fibrillation the down-regulation of the L-type $\mathrm{Ca}^{+4+}$ current not only shortens the atrial action potential but also causes a decrease in atrial contractility. ${ }^{15-17}$ As a result the fibrillatory contractions get weaker with time and the atria become dilated. ${ }^{18}$ Another possible factor contributing to the transition from paroxysmal to persistent AF is a down regulation and heterogeneous distribution of connexin 40 during the first weeks of AF. 19,20 The possible involvement of a "second factor" in the development of persistent AF was recently evaluated by Todd et al. ${ }^{12}$ In the goat model of AF, three consecutive 1-month periods of AF were induced, separated by one week of sinus rhythm during which electrical remodeling of the atria was completely reversed. It was found that the time course of development of persistent AF became shorter during each 1 month period of AF. Such a cumulative effect was earlier shown to be absent after successive periods of 5 days of AF. ${ }^{21}$ This observation provides indirect evidence that a slow 'second factor' must be involved in the remodeling process during the transition from paroxysmal to persistent AF.

\section{Possible Candidates of a 'Second Factor'}

The time course by which AF became refractory to pharmacological cardioversion by class IC drugs coincided with the time course of structural atrial remodeling as has been reported by Ausma et al. "1 The first signs of structural remodeling occurred after 1 week of AF and consisted of a more homogeneous distribution of nuclear chromatin and a decrease in cardiotin. With longer duration of AF the size of the atrial myocytes gradually increased and a loss of myofilaments and perinuclear accumulation of glycogen was observed (myolysis). ${ }^{11}$ Also the gap-junctions underwent remodeling. Whereas Cx43 was unchanged the amount of Cx40 decreased and became more heterogeneously distributed. ${ }^{10}$ After 16 weeks of AF in the left atrium the diameter of the myocytes was increased from $12.3 \pm 1.3 \mu \mathrm{m}$ to $21.2 \pm 2.3 \mu \mathrm{m}$. At that time $42 \%$ of the cells showed mill or severe myolysis. The total amount of connective tissue per surface area was not changed by 16 weeks of AF. However, because the atrial cells were increased in size, the relative amount of interstitial collagen per myocyte was increased from $13.2 \pm 5.1$ to $37.0 \pm 17.0 \mu \mathrm{m}^{2}{ }^{22}$ The reversibility of AF-induced structural remodeling was studied after 2 and 4 months of restored sinus rhythm. ${ }^{22}$ After 2 months the remodeling of gap-junctions was completely reversed. In contrast, after 4 months of sinus rhythm $27 \%$ of the myocytes still showed 
myolysis and the extracellular matrix fraction and the expression of structural proteins were only partially restored. Also the duration of AF-episodes was still prolonged after 4 months of sinus rhythm (minutes vs. seconds). ${ }^{22}$ Although the time course of these structural changes coincide with the lass of efficacy of class IC drugs to cardiovert AF, it is not clear whether and how they are involved in the development of persistent AF. Cellullar hypertrophy slows atrial conduction transverse to the cell orientation and the heterogeneous cellular and gap-junctional changes will result in enhanced nonuniform tissue anisotropy. ${ }^{23}$ This may lead to more heterogeneous conduction and intra-atrial conduction block, promoting the stability of atrial rotors and multiple wandering wavelets. Acute atrial dilatation has been shown to cause heterogeneities in conduction $^{24}$ and in canine atria subjected to long-term rapid ventricular pacing resulting in chronic atrial dilatation, discrete regions of slow atrial conduction were found. ${ }^{25}$ In the goat, no depression of atrial conduction was found during sinus thythm or atrial pacing after conversion of 2-4 months of AF. $6,19,26$ However, the conduction patterns during atrial fibrillation became more complex with time and local conduction delays and intra-atrial conduction block became more frequent during persistent AF. The increased wall stress and the resulting atrial dilatation during atrial fibrillation may also be of importance. In the present study the left atrial diameter was increased by $13 \pm 9 \%$ after 1 week of AF. In another series of goats the right atrial diameter was reported to be $12 \%$ higher after 5 days. ${ }^{27}$ In patients with persistent 'lome' AF, Sanfilippo et al. found an increase in right and left atrial diameter of respectively 13 and $14 \%$ after a follow-up of 20 months. ${ }^{26}$ It is well known that the success rate of cardioversion and maintenance of sinus rhythm is negatively correlated with left atrial enlargement. ${ }^{4,29}$ The electroanatomical substrate for persistent and permanent AF thus may be based both on macroscopic and microscopic structural changes of the atria. The larger size provides more room for

fibrillatory conduction, whereas microscopic barriers may create areas of discontinuous conduction and local conduction delays, promoting zig-zag conduction and enhancing the stability of wandering fibrillation waves and atrial rotors.

\section{Conclusions}

During the first 4 months of lone AF, during which the atria are structurally remodeled, the dosage of class IC drugs required for pharmacological cardioversion progressively increased. This reduction in anti-fibrillatory effect was not due to a decrease in sensitivity of the atrial myocardium for sodium channel blockade, since the slowing of the rate of atrial fibrillation by class IC drugs remained the same. In stead, the stability of the fibrillatory proces slowly increased with time and successful pharmacological cardioversion required a prolongation of the AF cycle length to a higher 'threshold' value. 


\section{Limitations}

An important limitation of this experimental study is that the goat model of "lone' AF does not represent the pathological substrate encountered in clinical AF. Depending on the etiology of atrlall fibrillation, in human atria the mechanisms responsible for perpetuation of AF may be different. A second caviat is that the dosages we used for cardioversion of AF are much higher than can be applied in humans. A major limitation of this study is that the experiments were not designed to provide data on the mechanisms underlying the loss of efficacy.

\section{References}

1. Kopecky SL, Gersh BJ, McGoon MD, Whisnant JP, Holmes DR, Jr, Jistrup DM, Frye RL. The natural history of lone atrial fibrillation. A population-based study over three decades. $N$ Engl J Med $1987 ; 317(11): 669-674$

2. Crijns HJ, van Wijk LM, van Gilst WH, Kingma JH, van Gelder IC, Lie KI. Acute conversian of atrial fibrillation to sinus rhythm: clinical efficacy of flecainide acetate. Comparison of two regimens. Eur Heart J 1988;9(6):634-638.

3. Suttorp MJ, Kingma JH, Jessurun ER, Lie AHL, wan Hemel NM, Lie KI. The value of class IC antiarrhythmic drugs for acute conversion of paroxysmal atrial fibrillation or fitter to sinus rhythm. J Am Coll Cardiol 1990;16(7):1722-1727.

4. Goy y3, Kaufmann U, Kappenberger L, Sigwart U. Restoration of sinus thythm with flecainide in patients with atrial fibrillation. Am J Cardiol 1988;62(6):38D-40D.

5. Mary-Rabine $L_{r}$ Kulbertus HE. Clinical efficacy of flecainide acetate in atrial fibrillation. Cardiology $1990 ; 77(6): 443-449$.

6. Wijffels MCEF, Kirchhof $\mathrm{CJH}$, Dorland R, Allessie MA. Atrial fibrillation begets atrial fibrillation. A study in awake chronically instrumented goats. Circulation $1995 ; 92: 1954-1968$.

7. Daoud EG, Bogun F, Goyal R, Harvey M, Man KC, Strickberger SA, Morady F. Effect of atrial fibrilation on atrial refractoriness in humans. Circulation 1996;94:1600.1606.

8. Schotten U, Duytschaever M, Ausma J, Eijsbouts S, Newberger HR, Aliesstè M. Electrical and contractile remodeling during the first days of atrial fibrillation go hand in hand. Circulation $2003 ; 107(10): 1433-1439$.

9. Allessie M, Ausma 3, Schotten U. Electrical, contractile and structural remodeling during atrial fibrillation. Cardiovascular Research 2002;54(2):230-246.

10. van der Velden HM, Ausma J, Rook MB, Hellemons AJ, wan Veen TA, Allessie MA, Jongsma HJ. Gap junctional remodeling in relation to stabilization of atrial fibrillation in the goat. Cardio. vase Res $2000 ; 46(3): 476-486$.

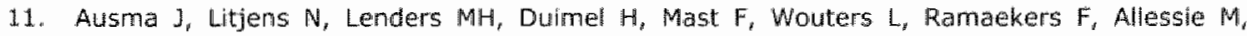
Borgers M. Time course of atrial fibrillation-induced cellular structurall remodeling in atria of the goat. J Mol Cell Cardiol 2001;33(12):2083-2094.

12. Todd DM, Fynn SP, Walden AP, Hobbs WJ, Arya 5, Garratt CJ. Repetitive 4-week periods of atrial electrical remodeling promote stability of atrial fibrillation: time course of a second factor inwolved in the self-perpetuation of atrial fibrillation. Circulation 2004; 109(11): 1434-1439.

13. Wijffels $M C_{*}$ Dorland $R_{x}$ Allessie MA. Pharmacologic cardioversion of chronic atrial fibrillation in the goat by class IA, IC, and III drugs: a comparison between hydroquinidine, cibenzoline, flecainide, and d-sotalol. J-Cardiovasc-Electrophysiol 1999;10(2):178-193. 
14. Kleber $A G$, Rudy $Y$. Basic mechanisms of cardiac impulse propagation and associated arrhythimias. Physiof Rev $2004 ; 84(2): 431-488$.

15. Bosch RF, Zeng X, Grammer JB, Popiowic K, Mewis C, Kuhlkamp $V$. Ionic mechanisms of electrical remodeling in human atrial fibrillation. Cardiovasc Res 1999;44(1):121-131.

16. Van Wagoner DR, Pond AL, Lamorgese M, Rossie SS, McCarthy PM, Nerbonne JM. Atrial L-type Ca2+ currents and human atrial fibrillation. Circ Res 1999;85(5):428-436.

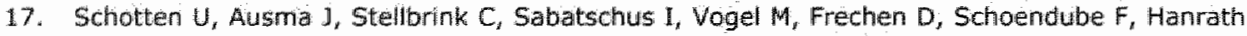
$P_{*}$ Allessie MA. Cellular mechanisms of depressed atrial contractility in patients with chronic atrial fibrillation. Circulation 2001;103(5):691-698.

18. Schotten $U_{f}$ Neuberger $H R_{,}$Allessie MA. The role of atrial dilatation in the domestication of atrial fibrillation. Prog Biophys Mol Biol 2003;82(1-3):151-162.

19. van der Velden $H M$, van Kempen $M$, Wijffels $M C_{\text {, }}$, van Zijverden $M$, Groenewegen WA, Allessie $M A$, Jongsma HJ. Altered pattern of connexin 40 distribution in persistent atrial fibrillation in the goat. I Cardiovasc Electrophysiol 1998;9(6):596-6i07.

20. Kanagaratnam $P_{i}$ Cherian $A$, Stanbridge RD, Glenville $B_{z}$ Severs NJ, Peters NS. Relationship between connexins and atrial activation diuring human atrial fibrillation. I Cardiovasc Electrophysiol 2004;15(2):206-216.

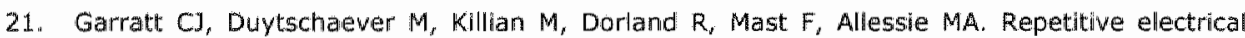
remodeling by paraxysms of atrial fibrillation in the goat: no cumulative effect on inducibility or stability of atrial fibrillation. J Cardiovasc Electrophysiol 1999;10;8):1101-1108.

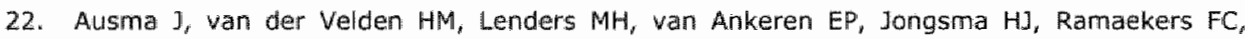
Borgers $M$, Allessie MA. Reverse structural and gap-junctional remodeling after prolonged atrial fibrillation in the goat. Circulation 2003;107(15):2051-2058.

23. Spach MS, Heidlage JF, Dolber PC, Barr RC. Changes in anisotropic conduction caused by remodeling cell size and the cellular distribution of gap junctions and $\mathrm{Na}(+)$ channels. $J$ Electrocardiol 2001;34 Suppl:69-76.

24. Eijsbouts $S$, Majidi $M_{4}$ wan Zandvoort Mn Allessie M. Effects of Acute Atrial Dilation on Heterogeneity in Conduction in the Isolated Rabbit Heart. J Cardiovasc Electrophysiol $2003 ; 14(3): 269-278$.

25. LI D, Fareh S, Leung TK, Nattel S. Promotion of atrial fibrillation by heart failure in dogs: atrial remodeling of a different sort. Circulation 1999;100(1):87-95.

26. Konings KTS. Mapping of electrically induced atrial fibrillation in humans. Maastricht: Department of Physiology, University of Maastricht; 1999(Thesis).

27. Schotten U. Mechanisms of Atrial Paralysis due to Atrial Fibrillation. An Integrative study in man and goat. Maastricht, Maastricht University; 2003(Thesis).

28. Sanfilippo AJ, Abascal WM, Sheehan M, Oertel LB, Harrigan $P_{r}$ Hughes RA, Wewman AE. Atrial enlargement as a consequence of atrial fibrillation. Circulation 1990;82:792-797.

29. Bollmamn A, Binias KH, Toepffer I, Molling J, Geller $C_{\text {, }}$ Kiein HU. Importance of left atrial diameter and atrial fibrillatory frequency for conversion of persistent atrial fibrillation with oral flecainide. Am J Cardiol 2002;90(9):1011-1014. 


\section{Chapter 5}

\section{Effects of 6 Weeks of Atrial Volume Overload on the Substrate of AF in the Goat}

Sabine Eijsbouts, Jannie Ausma, Ted Elebaas, Hans-Ruprecht Neuberger, Fons Verheyen, Arne van Hunnik, Ulrich Schotten, Maurits Allessie 


\section{Introduction}

Atrial dilatation is an important risk factor for the development of $\mathrm{AF}^{1-3}$ "The size of the atria is also an important determinant for successful pharmacological cardioversion of AF and the chance that sinus rhythm is maintained. "46 From experimental data it is known that acute atrial dilatation slows conduction and creates spatial heterogeneities in propagation of the depolarization wave. ${ }^{7-10}$ Studies of the effects on atrial refractoriness have provided conflicting results. An acute increase in atriall pressure was reported to produce either a shortening, ${ }^{711-13}$ a prolongation, $8,14,15$ or no change ${ }^{16,17}$ of the atrial refractory period. It is quite likely that chronic atrial dilatation exerts different effects on atrial electrophysiology than acute stretch. Animal models of atrial dilatation include tricuspid or mitral regurgitation ${ }^{18,}{ }^{19}$ rapid ventricular pacing ${ }^{20,21}$ and total $A V$-block with slow idioventricular rhythm. ${ }^{22}$ In these animal models, the electrophysiological properties of the atria are not only affected by stretch, but also by other concomitant changes like an increase in heart rate and varying degrees of congestive heart failure.

In the present study we attempted to create an animal model of 'pure' atrial dilatation without other confounding factors. Chronic atrial volume overload was produced by making a shunt between the carotid artery and the jugular vein. After 6 weeks the effects on the electrophysiological properties of the atria and the duration of AF episodes were evaluated.

\section{Methods}

\section{The Animal Model}

Twelve female goats (weight $55 \pm 8 \mathrm{~kg}$ ) were used for this study. Animal handling was carried out according to the Dutch law and the European Directive for protection of vertebrate animals. Two groups of goats were studied. In one group $(n=7)$ an AV-shunt was created to induce cardiac volume overload during a period of 6 weeks. Another group $(n=5)$ without an AV-shunt served as control. The carotid-jugular shunt was produced during general anesthesia induced by Thiopental ( $10 \mathrm{mg} / \mathrm{kg}$ i.v.) and maintained by ventilation with a mixture of $30 \% \mathrm{O}_{2}$ and $70 \% \mathrm{~N}_{2} \mathrm{O}$ and intravenous infusion of Dormicum (Midazolam $0.4 \mathrm{mg} / \mathrm{kg} / \mathrm{hr} \mathrm{i}_{\text {. }} \mathrm{v}_{\text {. }}$ ) and Sufenta Forte (3 $\mathrm{\mu g} / \mathrm{kg} / \mathrm{hr}$ I.v.). A single dose of 5000 IU of heparin was administered intravenously. A Swan-Ganz catheter was introduced in the proximal left jugular vein to measure the pressure in the right atrium, right ventricle, pulmonary artery and the pulmonary capillary wedge pressure before and after creation of the 
AV-shunt. Cardiac output was measured by the thermodilution technique (cardiac output computer; Baxter Healthcare Corporation, Santa Ana, CA). Because of the short recirculation time the thermodilution technique may underestimate the increase in cardiac output by the shunt.

Through a cervical incision, the left carotid artery and jugular vein were mobilized over a length of approximately $5 \mathrm{~cm}$ and ligated distally. The jugular vein was cut proximal to the ligation and connected to the carotid artery by an end-to-side anastomosis of approximately $1 \mathrm{~cm}$ diameter, using a 6-0 polypropylene nonabsorbable running suture (Figure 1). After opening of the shunt, the jugular vein extended 2-3 fold and a strong thrill and loud murmur along the jugular vein confirmed a high flow through the shunt. As a result of the arterio-venous shunt, the maximal right atrial pressure increased from $4.7 \pm 3.2$ to $7.6 \pm 3.4 \mathrm{mmHg}$. During the period of 6 weeks of the AV-shunt, none of the goats developed signs of heart failure or distress. The body weight of the goats slightly increased from $55 \pm 5$ to $60 \pm 6 \mathrm{~kg}$ (NS).

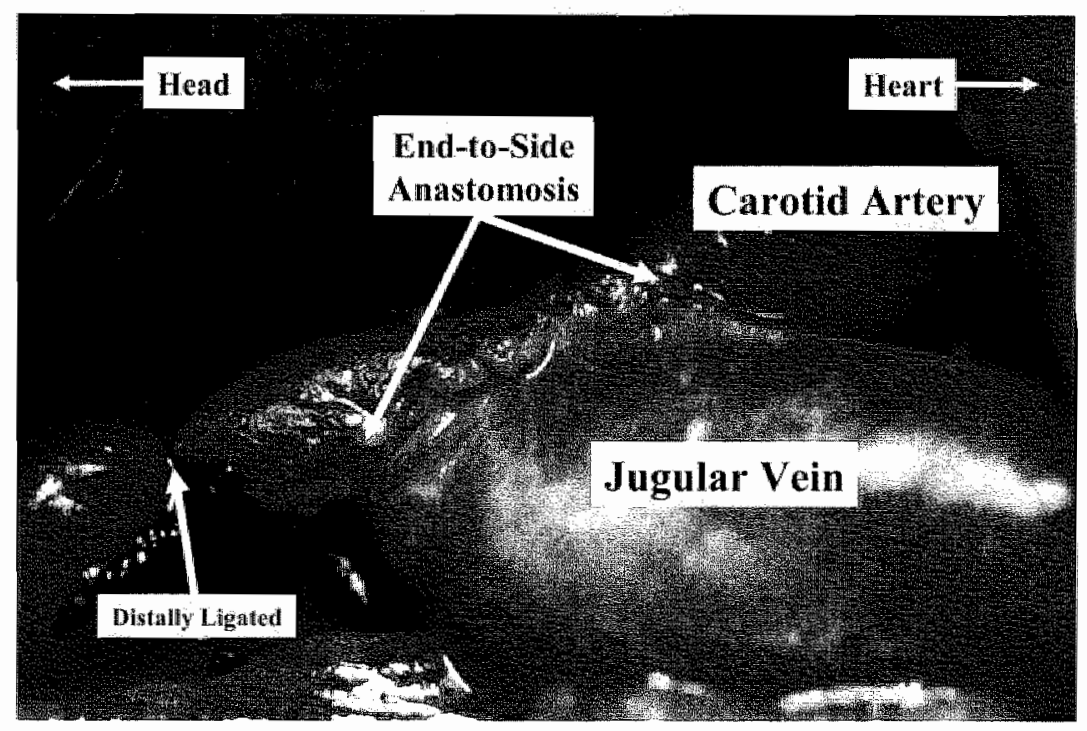

Figure 1: Surgicall procedure to create an arterio-venous-shunt between the jugular wein and the carotid artery. Through a cervical incision, the left carotid artery and jugular win are mobilized and ligated distally. The jugular vein is cut proximal to the ligation and connected with an end-to side anastomosis (diameter approximately $1 \mathrm{~cm}$ ) to the side of the artery.

\section{Electrophysiological and Hemodynamic Measurements}

Hemodynamic measurements were made under general anesthesia both before and 30 minutes after creation of the AV-shunt as well as during sacrifice of the animals 6 weeks later. Electrophysiological measurements were performed 6 weeks after creation of the arterio-venous shunt and compared with a separate control group. A left intercostal thoracotomy was 
made and the pericardium was opened to expose the heart. Eight bipolar silver pacing electrodes (diameter $1.6 \mathrm{~mm}$, interelectrode distance $4.0 \mathrm{~mm}$ ) were sutured on the right and left atrium. At the right atrium they were positioned on the cranial and caudal part of the crista terminalis (CT), the right atrial appendage and in the middle of the free atrial wall close to the AV-ring. The left atrium was paced lateral to the left superior and inferior pulmonary veins, the left atrial appendage and the mild AV-ring area. The AERP was measured at all 8 pacing sites during pacing at 400,300 and $200 \mathrm{~ms}$ interval. A custom made computer-controlled stimulator was used to deliver constant-current pulses of $1 \mathrm{~ms}$ duration. A single premature stimulus of $4 x$ threshold was interpolated after every 8 basic stimuli. Starting well within the refractory period, the S1-S2 interval was incremented in steps of 2 ms until the atria were captured. The shortest coupling interval resulting in an atrial response was taken as the AERP.

Spatial dispersion in AERP was measured as the largest difference in AERP between the four pacing sites within each atrium and between both atria. AF was induced by burst pacing $(50 \mathrm{~Hz}, 4 x$ threshold) from the right atriall appendage. The duration of 20 successive AF paroxysms was measured to determine the stability of atrial fibrillation. In case AF lasted longer than 10 minutes, the atria were electrically cardioverted and after 10 minutes of sinus rhythm the measurements were resumed. The median atrial fibrillation cycle length (AFCL) of the right and left atrium was measured from 300 consecutive AF-intervals recorded by an unipolar electrode at the free wall of the right and left atrium.

\section{Mapping of Conduction}

The free wall of the right and left atrium was mapped with a slightly concave octagonal array of 240 silver electrodes (diameter $0.3 \mathrm{~mm}$ ). The diameter of the mapping electrode was $3.6 \mathrm{~cm}$ and the inter-electrode distance $2.25 \mathrm{~mm}$. A silver plate in the thoracic cavity was used as indifferent electrode. The unipolar electrograms were amplified $(1000 \mathrm{x})$, band-pass filtered $(0.5-500$ $\mathrm{Hz}$ ) and analog to digital converted with a sampling rate of $1 \mathrm{kHz}$. The local activation times were determined automatically by an algorithm detecting the steepest negative deflections in the electrograms and edited manually if necessary. Color-coded activation maps were generated by the computer. Local conduction velocities (CV) in the mapping area was calculated from the activation times of an array of $3 \times 3$ electrodes $(4.5 \times 4.5 \mathrm{~mm})$ as reported earlier. 23,24 Slow conduction was defined as a local conduction velocity of $<40 \mathrm{~cm} / \mathrm{s}$. Intra-atrial conduction block, defined as an apparent local conduction velocity of $<20 \mathrm{~cm} / \mathrm{s}$, was detected by a conduction delay between neighboring electrodes of $>11 \mathrm{~ms}$ (i.e. $>5 \mathrm{~ms} / \mathrm{mm}$ ). Each atrium was paced from 4 different sites at two frequencies (400 and $200 \mathrm{~ms}$ ). After every 10-15 
stimuli the pacing site was automatically shifted to another site. The last of each series of 10-15 beats was used for analysis.

\section{Histology}

After the electrophysiological measurements the heart was removed and fixed in buffered formalin. Samples from the high and low free wall of the right and left atrium were embedded in paraffin. Sections of $4 \mu \mathrm{m}$ were stained with Sirius red (collagen) or a modified Azan staining (myocyte dimensions). The size of myocytes was measured in cells showing a nucleus in the center and intercalated discs at the both ends of the cell. For each group 5 goats were analyzed (total amount of myocytes; control goats: right atrium $=161$, left atrium $=81$, 6 weeks goats: right atrium $=146$, left atrium $=128$ ).

\section{Statistical Analysis}

Data are given as mean $\pm 5 D$. For statistical analysis a paired or unpaired Student's $t$-test was used or a two-way ANOVA. A $p<0.05$ was considered statistically significant.

\section{Results}

\section{Hemodynamic Effects of the Arterio-Venous Shunt}

The carotid-jugular AV-shunt induced immediate and long-term hemodynamic changes (Figure 2). The right atrial (left upper panel), right ventricular (left lower panel) and pulmonary artery pressure (not shown) increased slightly immediately after creation of the AV-shunt. The mean and maximal right atrial pressure increased from respectively $2.8 \pm 2.2$ and $4.7 \pm 3.2$ to $4.7 \pm 2.8$ and $7.6 \pm 3.4 \quad(p=0.22$ and $p=0.14)$. The mean and maximal right ventricular pressure increased from respectively $8.6 \pm 3.3$ and $22.9 \pm 3.8$ to $13.7 \pm 3.7$ and $32.1 \pm 5.5 \quad(p<0.05$ and $p<0.05)$. The mean pulmonary artery pressure increased from $10.0 \pm 3.2$ to $16.1 \pm 6.8(p=0.05)$. The wedge pressure was not increased 30 minutes after the AV-shunt (right upper panel). After 6 weeks of the AV-shunt, the mean right atrial pressure had increased from $2.8 \pm 2.2$ to $11.9 \pm 4.8 \mathrm{mmHg}(p<0.05)$. Also the mean wedge pressure, mean right ventricular pressure and mean pulmonary artery pressure were raised about $3-4$ times (from respectively $3.2 \pm 2.7,8.6 \pm 3.3$ and $10.0 \pm 3.2$ to $14.3 \pm 3.8,25.7 \pm 9.7$ and $36.4 \pm 18 ; p<0.05$ ). The mean cardiac output increased from $4.8 \pm 0.9$ to $5.7 \pm 0.8 \mathrm{~L} / \mathrm{min}$ after 30 minutes and to $6.0 \pm 1.6 \mathrm{~L} / \mathrm{min}$ after 6 weeks (right lower panel). 


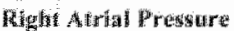

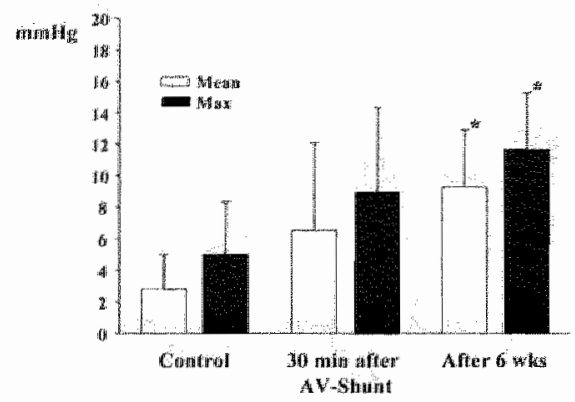

Right Ventricular Pressure

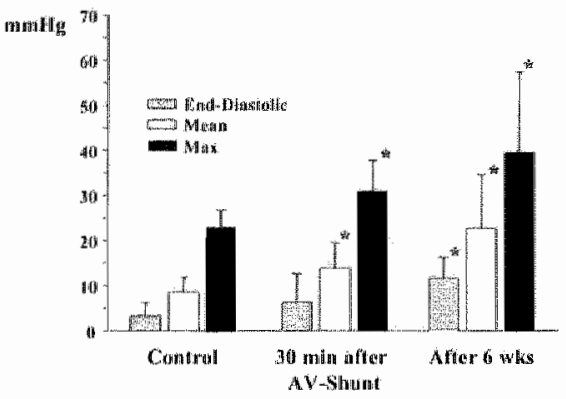

Wedgre Pressure

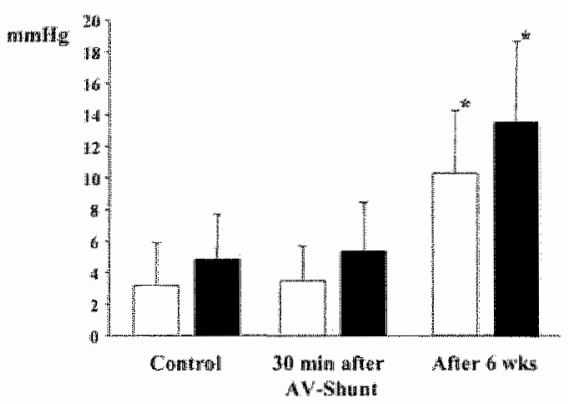

Cardine Output

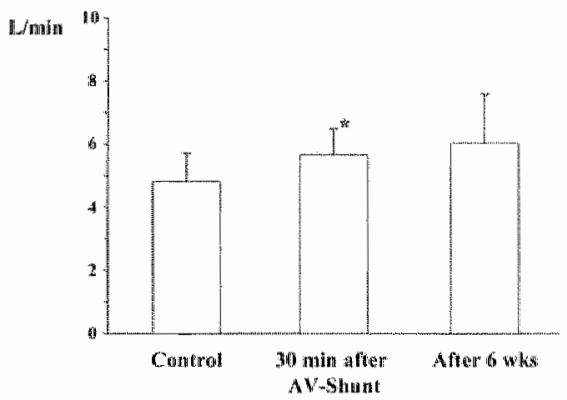

Figure 2: Immediate (30 min) and Iong-term (6 weeks) effects of a carotid-jugular shunt on right atrial pressure (left upper panel), right ventricular pressure (left lower panel), wedge pressure (right upper panel) and cardiac output (right lower panel). Right atrial and ventricular pressures increased immediately after opening of the shunt. The wedge pressure did not change acutely but. was increased 3-4 times 6 weeks after creation of the shunt.

\section{Effects on Atrial Refractory Period}

The effects of 6 weeks of volume overload on right and left atrial refractory period are shown in figure 3. During control the mean AERP of four left atrial sites was $151 \pm 24 \mathrm{~ms}$ (pacing interval $400 \mathrm{~ms}$ ) and was not statistically significant different from the mean AERP at the four right atrial sites (136 132 ms) $(p=0.43)$. After 6 weeks of AV-shunt, the AERP of the left atrium was significantly different from the control group (164115 vs $151 \pm 24 \mathrm{~ms}$ $(p<0,05))$. The AERP of the right atrium was not different from control, but was now statistically different from the left atrium $(p<0.001)$. The AV-shunt had no effect on the spatial dispersion in AERP either within the right or left atrium, or between both atria (upper right panel). Also the rate adaptation of the AERP measured at the left and right atrial appendages was not different between control and AV-shunt goats (lower panels). 

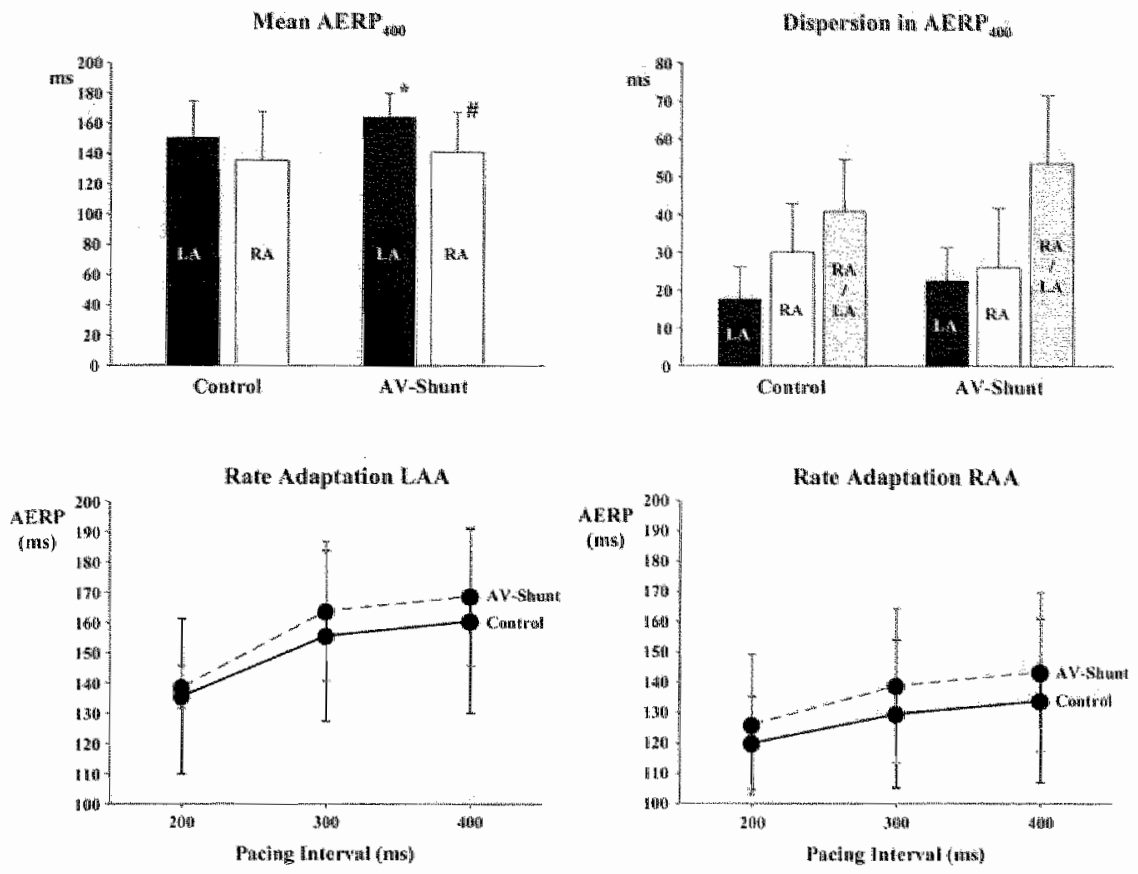

Figure 3: Effects of chronic atrial dilatation on the refractory period of the right and left atrium. In the upper left panel the mean AERP of the left (black bars) and right (white bars) atrlum during pacing with an interval of $400 \mathrm{~ms}$ are plotted. In the AV-shunt group the let atrial AERP was significantlly longer than in the control group $\left({ }^{*} p<0.05\right.$ ). The AERP of the right atrium was not different form control. In AV-shunt goats the AERP of the right atrium was significantly shorter than in the left atrium ( $\$ p<0.001$ ). The right upper panel shows the effects of an AV-shunt on the spetial dispersion in AERP. The black and white bars represent respectively the spatial dispersion within the left and right atrium and the gray bars represent the difference in AERP between both atria. In the lower panels the effects on the rate adaptation of the AERP in the right and left atrial appendage are plotted. No effect of the AV-shunt on the spatial dispersion or the rate adaptation of the AERP was abserved.

\section{Effects on Stability of AF}

The effects of 6 weeks of atrial volume overload on the duration and cycle length of paroxysms of AF are shown in Figure 4 (20 paroxysms in each goat). In the control group, the median duration of induced AF paroxysms in 5 goats was 8 seconds. In the AV-shunt group the median AF duration was 27 seconds $(p=0.16)$. In control goats only $2 \%$ of the induced AF episodes lasted longer than 1 minute compared to $11 \%$ in AV-shunt goats. In 2 of 7 AV-shunt goats an AF episode of $>10$ minutes was induced, which was never the case in control goats. The median of the longest AF duration in control goats was 93 seconds compared to 270 seconds in AV-shunt goats $(p=0.11$ ). This increased stability of AF was not accompanied by a change in AF cycle length. In the $A V$-shunt group the $A F C L$ in the right and left atrium was respectively $111 \pm 15$ and $126 \pm 8 \mathrm{~ms}$ compared to $103 \pm 14$ and $121 \pm 5 \mathrm{~ms}$ in the control group (NS). 
AF Duration

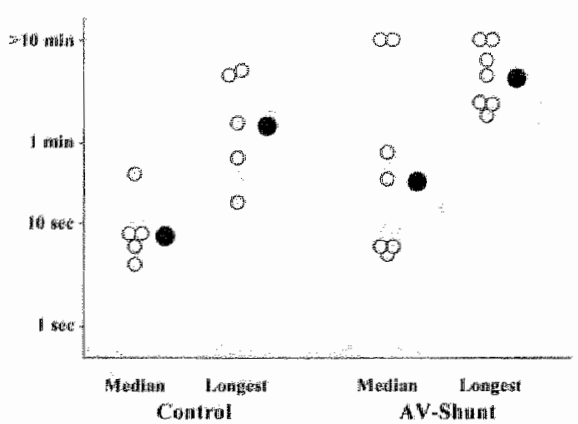

AF Cycle Length

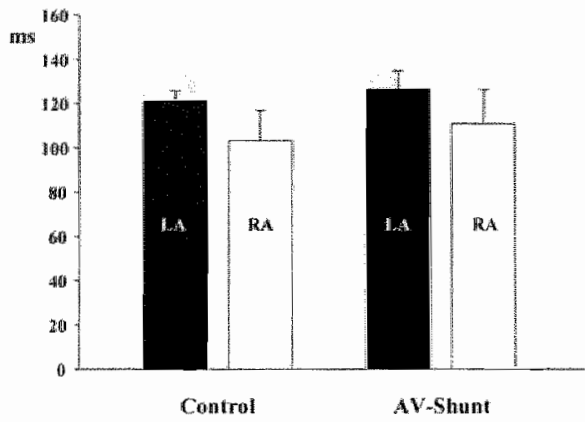

Figure 4: Effects of 6 weeks of AW-shunt on AF duration and AF cycle length. The left panel shows the median AF duration in all control $(n=5)$ and AV-shunt goats $(n=7)$ as well as the longest AF duration (black spots represent the median of the mediain and longest AF duration). In the right panel the mean AFCL in the left (black bars) and right atrium (white bars) are plotted. Both the median and longest AF duration showed an increase after 6 weeks of AV-shunt (NS). The increase in stabillty of AF was not accompanied by a change in AF cycle length.

\section{Left Atrium}

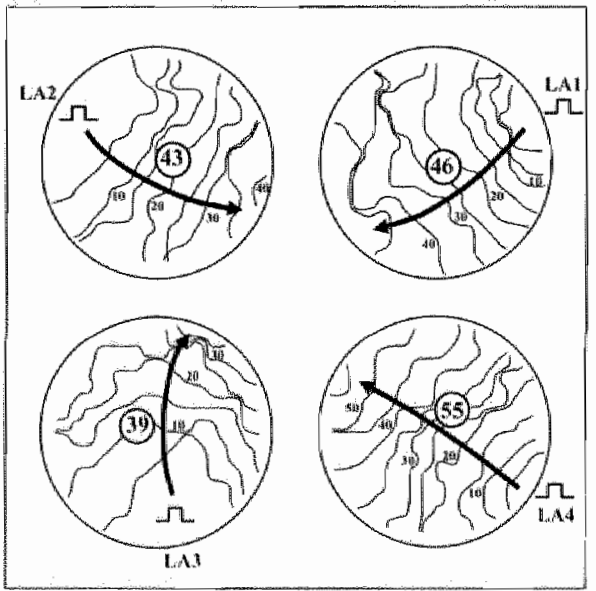

Right Atrium

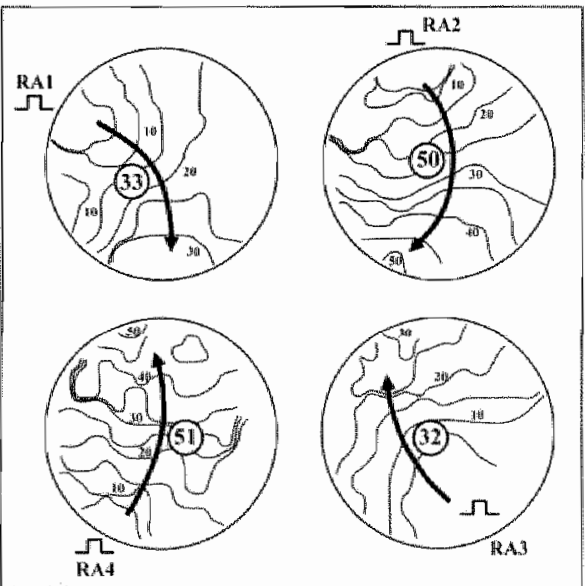

Figule 5: Isochronal maps of the electrical activation of the left and right atrium in an AV-shiunt goat during pacing from four different directions (pacing interval 400ms). Isochrones are drawn every $5 \mathrm{~ms}$ and the arrows indicate the main pathway of activation. The total conduction time (ms) of the tissue under the mapping electrode is plotted in the white circies. In both atria, only minor conduction delays were observed and conduction was uniform in all 4 directions.

\section{Effects on Atrial Conduction}

Figure 5 shows an example of isochrone maps of the free wall of the left and right atrium after 6 weeks of atrial volume overload during pacing from 4 different sites with an interval of $400 \mathrm{~ms}$. The arrows indicate the main 
directions of activation together with the total conduction time of the mapping area. The pacing site RA1 was located at the cranial part of the crista terminalis and resulted in a similar spread of activation as during sinus rhythm. Pacing sites RA2, RA3 and RA4 were located at the right atrial appendage, the mid $A V$-ring and the caudal part of the crista terminalis. The left atrium was activated respectively from the left superior pulmonary vein (LA1), left atrial appendage (LA2), mid AV-ring (LA3) and the left inferior pulmonary vein (LA4). Activation of the left and right atrium was uniform in all directions and showed only minor local conduction delays. The total conduction time of the mapping area ranged between 32 and $55 \mathrm{~ms}$.

\section{Left Atrium}

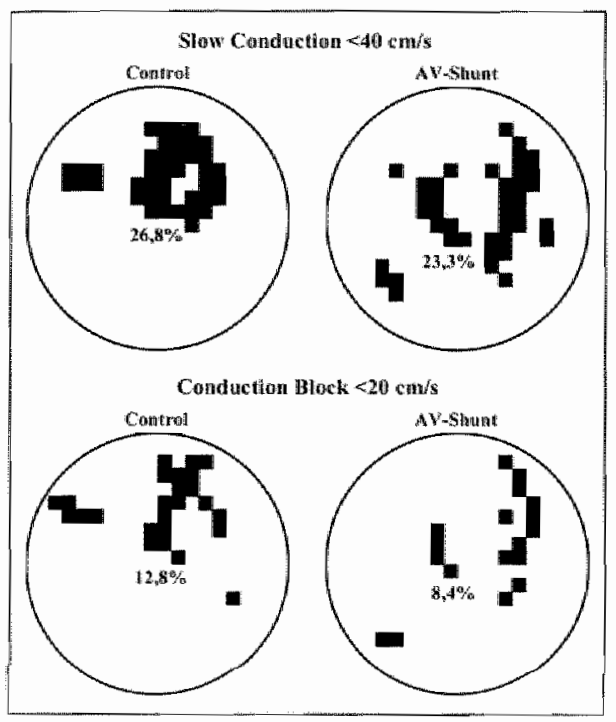

Right Atrium

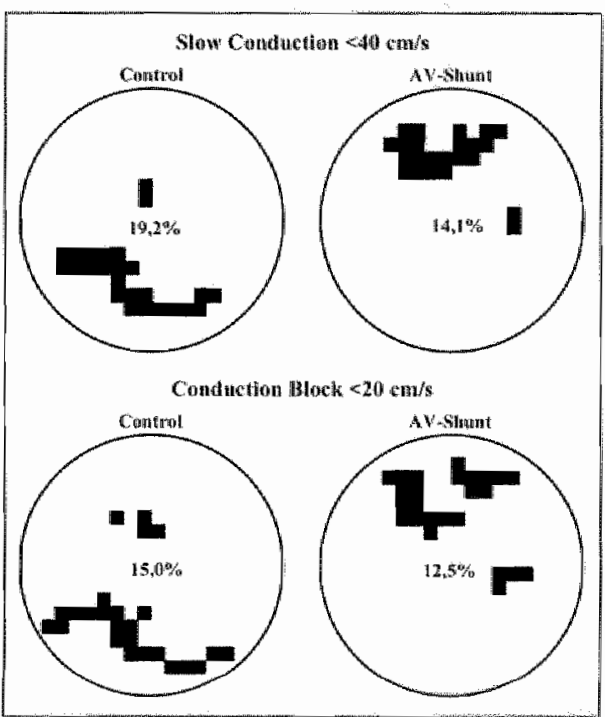

Figure 6: Example of the spatial distribution of areas with slow conduction (upper panels) and intraatrial conduction block (lower panels) during pacing from four different directions in a control anc: $A V$-shunt goat. The amount of intra-atrial conduction disturbances was not different in the AV-shuint goat.

Figure 6 shows an example of the spatial distribution of areas with slow conduction (upper panels) and conduction block (lower panels) during pacing from four different directions in a control goat and after 6 weeks of volume overload. In this example the percentage of tissue area exhibiting slow conduction (14-27\%) and conduction block (8-15\%) after 6 weeks of AVshunt was not different from control. In Table 1 the effects of 6 weeks of AVshunt on atrial conduction are given for all goats. On average, no effect on total conduction time, conduction velocity, or heterogeneity in conduction could be demonstrated. The total conduction time (TCT) in control goats during pacing with an interval of $400 \mathrm{~ms}$, ranged between $36-42 \mathrm{~ms}$, 
compared to $41 \mathrm{~ms}$ in AV-shunt goats $(p>0.09)$. There was no statistically significant difference in total conduction time between the 4 directions of activation. During rapid pacing (interval 200ms), the TCT of the right atrium in AV-shunt goats was prolonged compared to control goats ( $43 \pm 5 \mathrm{~ms}$ Vs. $37 \pm 9 \mathrm{~ms} ; \mathrm{p}<0.05)$. The mean atrial conduction velocity was $76-80 \mathrm{~cm} / \mathrm{s}$ in the control group and $80-86 \mathrm{~cm} / \mathrm{s}$ in AV-shunt goats $(p>0.15)$. In control goats the incidence of slow conduction was less than $12 \%$ and intra-atrial conduction block occurred in only 1.9-2.5\%. The percentage of tissue area exhibiting slow conduction was $23-26 \%$ and conduction block was present in $11-15 \%$. No effect of the $A V$-shunt on the incidence of slow conduction and intra-atrial conduction block could be demonstrated.

\begin{tabular}{|c|c|c|c|c|c|c|c|c|c|}
\hline & \multirow[b]{3}{*}{ Oirection } & \multicolumn{4}{|c|}{ Contral } & \multicolumn{4}{|c|}{6 Whis AV-Sthant } \\
\hline & & \multicolumn{2}{|c|}{$400 \mathrm{~ms}$} & \multicolumn{2}{|c|}{$200 \mathrm{~ms}$} & \multicolumn{2}{|c|}{4000 mos } & \multicolumn{2}{|c|}{$200 \mathrm{~ms}$} \\
\hline & & LA & RA & LA & $\mathbf{R A}$ & LA & RA & LA & $\mathbf{R A}$ \\
\hline \multirow{5}{*}{$\begin{array}{l}\text { Total Conduction } \\
\text { Time (mis) }\end{array}$} & 1. & $44,4=7$ & $37+14$ & $4+4$ & $38 \div 1.2$ & $41 \pm 5$ & $40 \pm 5$ & $43=3$ & $42 \pm 3$ \\
\hline & 2 & $44 x^{3}$ & $39+9$ & 5128 & $40 \div 9$ & $42 \pm 7$ & $44+4.5$ & 446 & $49 \pm 4$ \\
\hline & $\$$ & $36 \mathrm{~s} 7$ & $33 \pm 0$ & $40 \pm 8$ & $34 \pm 8$ & $37 \pm 7$ & 3629 & at:2:9 & $40 \mathrm{~s}$ \\
\hline & 4 & $47 \pm 5$ & $36 \pm 7$ & $51: 5$ & $36 \pm 7$ & $46 \pm 5$ & $43 \pm 1$ & $47>5$ & $42 \div 3$ \\
\hline & Mein & $42 \pm 7$ & $35 \pm 9$ & $46: 8$ & $37 \times 5$ & 4146 & $41 \pm 8$ & 4446 & 475 \\
\hline $\begin{array}{l}\text { Conducton Valocity } \\
\text { (cm/sec) }\end{array}$ & & $60 \div 7$ & $79 \pm 10$ & $76: 7$ & $78 * 28$ & 85.4 & $86 \pm 6$ & $90 \div 5$ & 84.56 \\
\hline \multirow{2}{*}{$\begin{array}{l}\text { Slow Condutetion }(\%) \\
440 \mathrm{cr} / \mathrm{s}\end{array}$} & Iricidence & $0.5 \pm 2.4$ & $10.6 \pm 5.3$ & 9.5 .3 .11 & $11.9 \pm 5.8$ & $5.8 \pm 5.3$ & 7.3 .55 .3 & 6.7 政 4.8 & $8.4 \pm 6.4 .3$ \\
\hline & Tissiue Area & $24: 3$ & $23 \pm 14$ & $24 \pm 6$ & $26 \pm 13$ & $1.5 \pm 19$ & $15 \pm 9$ & $16 \div 9$ & $19: 8$ \\
\hline \multirow{2}{*}{$\begin{array}{l}\text { Conduction plock } \\
(\% \%)<20 \mathrm{~cm} / \mathrm{s}\end{array}$} & Inclidencel & 1.90 .7 & $2.1 \pm 1.2$ & $2.0 \pm 0.0$ & $2.5+1.5$ & $1.2 \pm 1.1$ & $2.1 \pm 1.6$ & 1.9. 1.9 & $2,6 \pm 1,3$ \\
\hline & Thesue Area & 11.2 & $12+8$ & $11+3$ & $14 \pm 6$ & 7 出 & $1.0) \pm 6$ & $3 \pm 3$ & $13 \pm 6$ \\
\hline
\end{tabular}

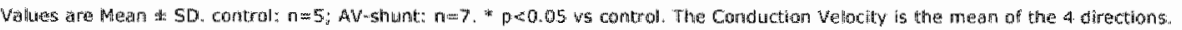

\section{Structural Changes}

Figure 7 shows histological sections of the left atrium of a control and an AVshunt goat stained with modified azan and sirius red. The cardiomyocytes of the AV-shunt goat showed moderate hypertrophy which was more pronounced in the left than in the right atrium. After 6 weeks of AV-shumt no change in the amount of collagen was observed in the right or left atria. The effect of the AV-shunt on the size of the cardiamyocytes is shown in figure 8. The surface area of the cardiomyocytes of the right and left atrium was increased after 6 weeks of AV-shunt (RA: $1462 \pm 356 \mu \mathrm{m}^{2}$ vs. $1097 \pm 288 \mu \mathrm{m}^{2}$ $(p=0.11) ; \quad L A: 1739 \pm 270$ vs. $1156 \pm 379 \mu m^{2}(p=0.02)$. The increase in surface area was mainly due to an increase in myocyte length, which increased in the left atrium from $76 \pm 12$ to $100 \pm 9 \mu m(p=0.008)$ and in the right atrium from $78 \pm 14$ to $90 \pm 9 \mu \mathrm{m}(p=0.13)$. The diameter of the cardiomyocytes increased by about $18 \%$ from respectively $15 \pm 3$ to $17 \pm 2 \mu \mathrm{m}$ $(p=0.11)$ and from $14 \pm 2$ to $16 \pm 3 \mu m(p=0.17)$. 
Control

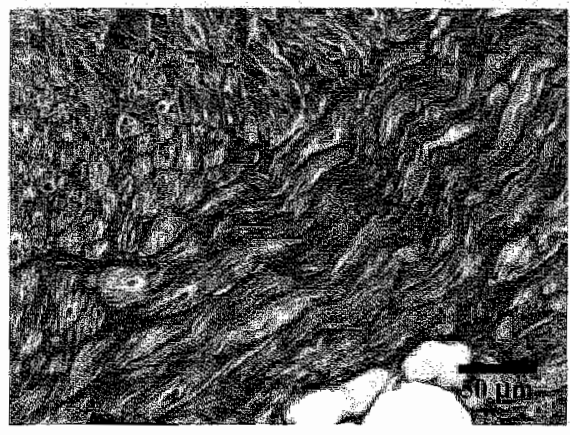

Axan

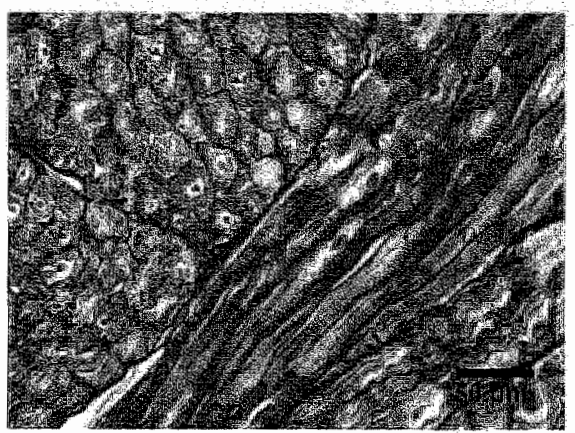

Sirius Red
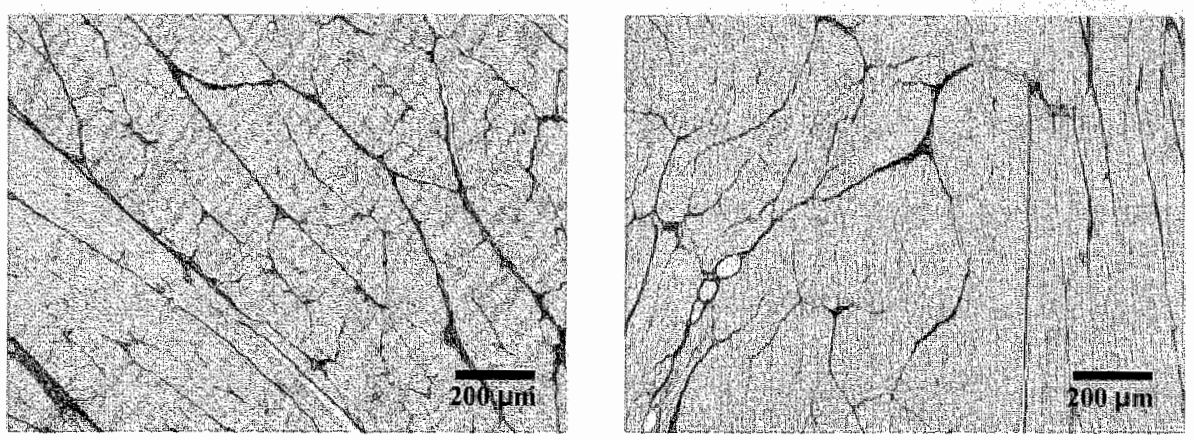

Figure 7: Histological sections of the left atrium of a control (left) and an AV-shunt goat (right) stained with modified azan and sirius red. After 6 weeks of atrial volume overlosd the atrial myocytes were moderately hypertrophied. No change in the amount of collagien was observed.

Myocyte Surface

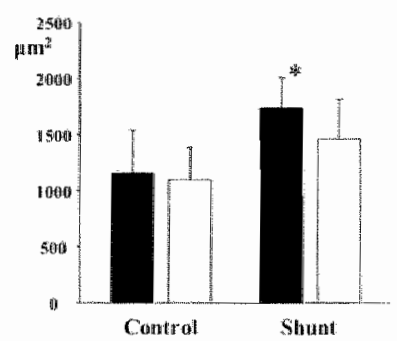

Myocy he Lengh

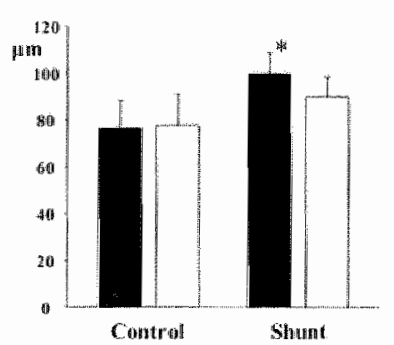

Myocyte Dithrintes

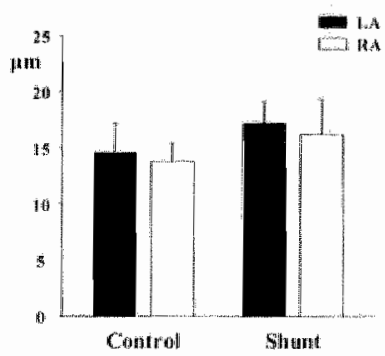

Figure 8: Surface area, length and diameter of myocytes of the left (biack bars) and right atrium (white bars) in 5 control and 5 AV-shunt goats. After 6 weeks of AV-shunt the atrial myocytes were enlarged about 1.5 -fold. 


\section{Discussion}

\section{The AV-Shunt Model}

In the present study we created a carotid-jugular shunt to produce chronic atrial volume overload. ${ }^{25 ;} 26$ Six weeks of AV-shunt increased the right and left atrial pressure about 3-4 fold. The atrial cardiomyocytes became enlarged, but there were no signs of atrial fibrosis. Due to a chronically increased wall stress the atria gradually dilate, but because in the present series we did not monitor atrial size, the exact degree of atrial dilatation remains unknown. In a similar model of 8 weeks of AV-shunt Bolotin et al. showed no hemodynamic or clinical signs of heart failure. ${ }^{25,}{ }^{27}$ Also in the present study the goats showed no clinical signs of heart failure and after 6 weeks of AV-shunt the cardiac output was still higher than during control. The observed electrophysiological and histological changes after 6 weeks of $A V$-shunt thus are due to the direct effects of chronic atrial volume overload without concomitant heart failure. The first experiments on chronic atrial dilatation were performed in the early 1980 s by Boyden et al. ${ }^{18}$ Right atrial dilatation ( $40 \%$ increase in RA volume) was produced in dogs by surgical creation of tricuspid insufficiency and pulmonary artery stenosis. Verheule et al. created a dog model of left atrial dillatation by mitral regurgitation ( $26 \%$ increase in LA diameter after 6 weeks). Recently, Neuberger et al. studied a goat model of atrial dilatation resulting from 4 weeks of total AV-block and slow idioventricular rhythm, causing a two-fold increase in right and left atrial pressure and a $14 \%$ increase in RA diameter. ${ }^{22}$ Chronic rapid ventricular pacing induces congestive heart failure and a 3-4 fold increase in atrial pressure, resulting in progressive left and right atrial dilatation. ${ }^{20,21}$ In all these models, chronic atrial dilatation is either one-sided and/or associated with heart failure.

The Role of Chronic Atrial Stretch on the Development of a Substrate of AF

In the present study we observed an increase in duration of AF paroxysms after 6 weeks of AV-shunt. Compared to other models of chronic atrial dilatation the magnitude of this effect was relatively small. The increased stability of AF could not be attributed to a change in AERP, spatial dispersion in refractoriness or rate adaptation of the refractory period. Boyden et al. and Neuberger et al. found no changes in action potential duration or atrial effective refiractory period during atrial dilatation. ${ }^{10,22}$ In dilated left atria due to mitral regurgitation the AERP was prolonged, ${ }^{19}$ whereas in rapid pacing induced heart failure the left atrial refractory period was either increased ${ }^{20}$ or unchanged. ${ }^{21}$ 
No changes in atrial conduction velocity or incidence of slow conduction of conduction block accurred in response to 6 weeks of moderate atrial dilatation. Also in dilated atria due to heart failure or mitral valve regurgitation, the overall atrial conduction velocity was not changed. 19,20 In the canine model of congestive heart fallure with increased atrial pressure and extensive atria fibrosis, atrial conduction was more heterogeneous with locallized regions of slow conduction. ${ }^{21}$ In the study of Neuberger et al. the incidence of areas with slow atrial conduction during rapid pacing was increased in goats with chronic AV-block. ${ }^{22}$ Like in the study of Neuberger et al. we also observed an increase in atrial cell size without a change in the amount of collagen. Thus, after 6 weeks of atrial volume overload only minimal electrophysiological and structural changes were found in the dilated atria. This is in agreement with the slow time course of the development of a substrate of AF by atrial dilatation in humans. It usually takes years before hypertension or valvular disease leads to persistent atrial fibrillation. The pericardial sac may also delay the time course of atrial dilatation as a result of an increased atrilal pressure. ${ }^{28}$

\section{References}

1. Vaziri SM, Larson $M G$, Benjamin EJ, Levy D. Echocardiographic predictors of nonrheumatic atrial fibrillation. The Framingham Heart Study. Circulation 1994;89(2):724-730.

2. Psaty BM, Manolio TA, Kuller LH, Kronmal RA, Cushman M, Fried LP, White R, Furberg CD, Rautaharju PM. Incidence of and risk factors for atrial fibrillation in older adults. Circulation $1997 ; 96(7): 2455-2461$.

3. Vasan RS, Larson MG, Levy D, Evans JC, Benjamin EJ. Distribution and cakegorization of echocardiographic measurements in relation to reference limits: the Framingham Heart Study: formulation of a height-and sex-specific classification and its prospective validation. Circulation $1997 ; 96(6): 1863-1873$.

4. Bollmann $\mathrm{A}_{1}$ Binias $\mathrm{KH}_{x}$ Toepffer $\mathrm{I}_{v}$ Molling $\mathrm{J}$, Geller $\mathrm{C}$, Klein HU. Importance of left atrial di. ameter and atrial fibrillatory frequency for conversion of persistent atrial fibrilation with oral flecainide. Am J Cardiol 2002;90(9): 1011-1014.

5. Bradsky MA, Allen B]. Factors determining maintenance of sinus rhythm after chronic atrial fibrillation with left atrial dilatation. Am J Cardiol 1989:63:1065-1068.

6. Henry WL, Morganroth J, Pearlman AS, Clark CE, Redwood DR, Itscollz SB, Epstein SE. Relation between echocardiographically determined left atrial size and atrial fibrillation. Circullation $1975 ; 53: 273-279$.

7. Solti $F$, Vecsey $T$, Kekési $V$, Juhász-Nagy A. The effect of atrial dilatation on the genesis of atrial arrhythmias. Cardiovasc Res $1989 ; 23: 882-886$.

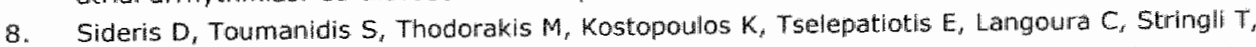
Moulopoulos $S$. Some observations on the mechanism of pressure related atrial fibrillation. Eur Heart J 1994;15:1585-1589.

9. Chorro FJ, Egea S, Mainar L, Canoves J, Sanchis J, Llavador E, Lopez Merino V, Such L. Modificaciones agudas de la longitud de ondia del proceso de activacion auricular inducidas por la dilatacion. Estudio experimental. Rev Esp Cardiol 1998;51(11):874-883. 
10. Eijebouts 5, Majdi wan Zandwoort M. Alessie M. Effects of Acute Atrial Dilation on Heterogendty in Conduetion in the Isolated Rabbit Heart. I Cardiovasc Electrophysiol $2003 ; 4(3): 269-278$

11. Nazh $S$, Lab M. Mechanoelectrical feedback in the atrim of the isolated guineampig heart: Cardiovase Res $1996 ; 32: 112-119$.

12. Ravefl F, Allessie M. Effects of atrial dilatation on refractory period and vulnerability to atrial fibriliation in the solated Langendorfipertused pabbit heart. Crculation 1997:96:1686-1695.

13. Tse HA, Pelosi F, Oral H, Knight BP, Strickberger SA, Morady F. Effects of simultaneous atrioventricular pacing on atrial refractoriness and atrial fibrillation inducibility: role of atrial mechandelectrical feedback. J Cardiovasc Electrophysiol $2001 ; 12(1): 43-50$.

14. Kaseda $S$, Zipes DP. Contracton-excitation feedback in the atria: a cause of changes in refractoriness, J Am Coll Cardiol 1988; 11(6):1327-1336.

15. Klein $L S$, Milles WM, Zipes DP. Effect of atrioventricular interval during pacing or reciprocating lachycardia on atrial size, pressure, and refractory period. Contraction-excitation feedback in human atrium. Circulation 1990;82:60-68.

16. Calkins $H$, el-Atassi $R_{y}$ Leon $A$, Kalbfleisch $S$, Borganelli $M$, Langbeng $\mathbb{J}$, Morady $F$. Effect of the atriowentricular relationship on atrial refractoriness in humans. Pacing Cin Electrophwsial $1992 ; 15(5) ; 771-778$

17. Wijfels $M C$, Kirchthof $C J$, Dorland $R$, Power J, Allessie MA. Ellectrical remodeling due to atrial fibrillation in chronically instrumented conscious goats: roles of neurohumoral changes, ischemia, atrial stretch, and high rate of electrical actiwation. Circulation 1997;96(10):37103720 .

18. Boyden PA, Hoffman BF. The effects on atrial electrophysiology and structure of surgically induced right atrial erilargement in dogs. Circ Res 1981;49:1319-1331.

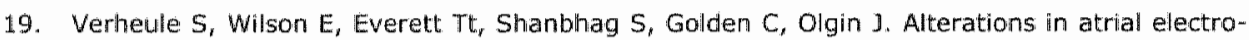
physiology and thissue structure in a canine model of chronic atrial dilatation due to mitral regurgitation. Circulation 2003; 107(20):2615-2622.

20. Power $\mathbf{M}$, Beecom GA, Alferness CA, Ramain J, Wijffels M, Farish SJ, Burrell LM, Tonkin AM. Susceptiblity to atrial fibrillation: A study un an ovine madel of parcing-induced early heart fallure. J Cardliowasc Electrophysiol 1998; $9(4): 423$; 435 .

21. Li D. Fareh S, Leung TK, Nattel S. Promotion of atrial fibrillation by heart fallure in dogs: atrial remodeling of a different sort. Circulation 1999;100(1):87-95.

22. Neuberger HR, Schotten U, Verheule S, Eijsbouts S, Blaauw $Y_{,}$van Hunnik A, Allessie $M$. Development of a substrate of atrial fibillation during chronic atrioventricular block in the goat. Firculation 2005;111(1):30-37.

23. Eijsbouts SC, Houten RP, Bladuw $Y$, Schotten U, Allessie MA. Synergistic action of atrial dilation and sodium channel blockade on conduction in rabbit atria. 1 Cardiovasc Electrophysio $2004: 15(12): 1453-1461$.

24. Houben RP, de Groot NM, Smeets $M_{4}$, Becker AE, Lindemans FW, Allessie MA. S-wave predominance of eplicardial electrograms during atrial fibriliation in humans: Indirect evidence for a role of the thin subepicardial layer. Heart Rhythm 2004;1(6):639-647.

25. Bolotin G. Surgical options to treat heart failure patients. Maastricht: Cardiothoracic Department, Maastricht University; 2001(Thesis).

26. Kaulbach $H G$, Lorusso $R$, Bolotin $G$, Schreuder 13 , van der Veen FH. Effects of chrontic cardiomyoplasty on ventricular remodeling in a gat model of chronic cardiac dilatation: part 2 . Amn Tharac Surg 2002; 74(2):514-521.

27. Bolotin $G$, Lorusso $R$, Schreuder JJ, Kaulbach $H G$, Uretzky $G$, van der Veen FH. Effects of acute dynamic cardiomyoplasty in a goat model of chronic ventricular dilatation: part 1 . Ann Thorac Surg $2002: 74(2): 507-513$.

28. Gilbent JC, Glantz SA. Determinants of lleft ventricular filling and of the diastolic pressurevolume ralation. Circ Res 1989;64(5):827-852. 
Chapter 6

\section{Effects of 20 Weeks of Atrial Volume Overload on the Substrate of AF in the Goat}

Sabine Eijsbouts, Arne van Hunnik, Hans Degens, Jack Cleutjens, Ted Elebaas, Ulrich Schotten, Maurits Allessie 


\section{Introduction}

In the previous chapter we have described the effects of 6 weeks of volume overload on the development of a substrate of AF. Although the atrial cells were clearly hypertrophied and the stability of induced paroxysms of AF was slightly increased, no clear changles in atrial refractory period or conduction velocity were seen. To investigate whether 6 weeks of an AV-shunt were not long enough to induce electrophysiological changes in the atria, in the present study the duration of atrial volume overload was extended to 20 weeks.

\section{Methods}

\section{The Animal Model}

Twenty-eight female goats (weight $55 \pm 8 \mathrm{~kg}$ ) were used for this study. Animal handling was carried out according to the Dutch law and the European Directive for protection of vertebrate animals. In 11 goats an AV-shunt was created to induce cardiac volume overload during a period of 20 weeks. The goats were anaesthetized with Thiopental $(10 \mathrm{mg} / \mathrm{kg} \mathrm{i.v.)}$ and ventilated by a $1: 2$ mixture of $\mathrm{O}_{2}$ and $\mathrm{N}_{2} \mathrm{O}$. Anesthesia was maintained with Isoflurane. $A$ single dose of 5000 IU of heparin was administered intravenously. Through a cervical incision, the left carotid artery and jugular vein were mobilized over a llength of approximately $5 \mathrm{~cm}$ and ligated distally. The jugular vein was cut proximal to the ligation and connected to the carotid artery by an end-to-side anastomosis of approximately $1 \mathrm{~cm}$ diameter, using a 6-0 polypropylene nonabsorbable running suture. After opening of the shunt, the jugular vein extended 2-3 fold and a strong thrill and loud murmur along the jugular vein confirmed a high flow through the shunt. As a result of the arterio-venous shunt, the maximal right atrial pressure acutely increased from $6.1 \pm 4.5$ to $8.0 \pm 4.3 \mathrm{mmHg}(\mathrm{p}<0.05)$. During the period of 20 weeks of the AV-shunt, none of the goats developed signs of heart failure or distress. The body weight of the goats increased from $41 \pm 5$ to $48 \pm 5 \mathrm{~kg}(p=0.002)$. One goat died 1 week after the operation due to a lung infection and one goat after 19 weeks during atrial burst pacing. In two goats the AV-shunt closed within the first days after the operation. In one case the shunt could be reopened successfully. The effects of 20 weeks of an open AV-shunt thus could be followed in 8 goats. Two other groups of respectively 7 and 10 goats served as controls for the atrial mapping and remodeling studies. 


\section{Hemodynamic Measurements}

Figure 1 shows the flow chart of the study design. At time 0 , the carotidjugular AV-shunt was created and hemodynamic measurements were made during general anesthesia, both before and 30 minutes after opening of the AV-shunt. During sacrifice of the animals after 20 weeks of AV-shunt, the hemodynamic measurements were repeated. A Swan-Ganz catheter was introduced through the left femoral vein to measure the pressures in the right atrium, right ventricle, and pulmonary artery and to record the pulmonary capillary wedge pressure. Left ventricular hemadynamics were measured using a 12-electrode conductance catheter (Sentron, The Netherlands) inserted through the left or right carotid artery into the left ventricle (LV). The correct position was confirmed by fluoroscopy and by inspection of the segmental conductance signals. A leycom Sigma-5DF signal conditionerprocessor (Cardiodynamics, Zoetermeer, the Netherlands) was used to compute the volume of the left ventricle. To correct the volume for parallell conductance of the tissue surrounding the LV cavity, $7.5 \mathrm{ml}$ of hypertonic saline solution ( $8 \%$ ) was injected into the pulmonary artery to calculate the parallel conductance offset term (Vc). Blood resistance was measured by 5 $\mathrm{ml}$ of blood in a four-electrode cuvette to correct for blood conductance. The pressure and volume signals were analyzed with CONDUCT-PC software (Cardiodynamics). Cardiac output was measured by the thermodilution technique (cardiac output computer; Baxter Healthcare Corporation, Santa Ana, CA).

\section{Electrophysiological Measurements}

Eighteen weeks after creation of the AV-shunt a bipolar screw-in J-lead (Medtronic) was implanted through the right jugular vein in the right atrial appendage. Two additional silver electrodes were attached next to the tip of the lead to record a bipolar atrial electrogram. One week later (week 19) AF was induced during 48 hours by burst pacing $(50 \mathrm{~Hz})$. Electrophysiological measurements were made before and after 8,24 and 48 hours of AF. The atrial effective refractory period (AERP) was measured during regular pacing (S1-S1) at 400, 300 and 200ms intervals. Single premature stimuli ( $4 x$ threshold) were interpolated after every 8 basic stimuli. The coupling interval was incremented in steps of $2 \mathrm{~ms}$, starting well within the refractory period. The shortest S1-S2 interval that resulted in a propagated atrial response was taken as the AERP. The atrial fibrillation cycle length (AFCL) and AF duration were measured after 5 minutes and 8,24 and 48 hours of AF. The median AFCL was determined by an automatic algorithm detecting the moments of activation during 500 consecutive AF intervals in a bipolar fibrillation electrogram. The longest duration of the AF paroxysms induced during a period of 1 hour was taken as an estimation of the stability of AF. 


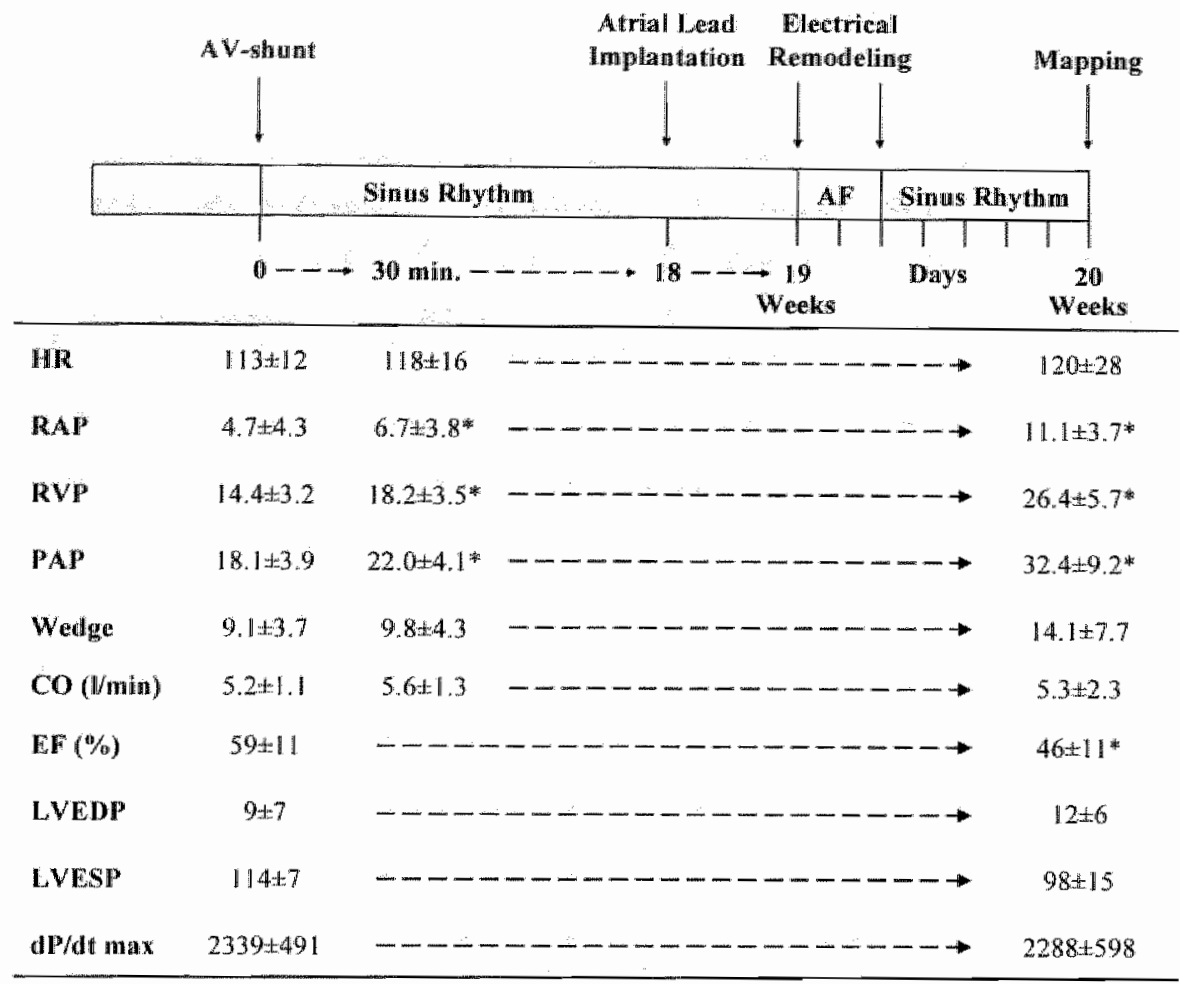

Figure 1: Flow chart of the study design together with the effects of the AV-shunt on hemodynamic parameters. After 19 weeks of volume overload, AF was induced during 48 hours by burst pacing. The goats were then kept in sinus rhythm during at least 5 days before they were sacrificed. Before sacrifice atrial conduction was mapped under general anesthesia and the hemodynamic measurements were repeated. Data are mean values \pm SD of 8 goats. $* p<0.05$ vs before $A V$ shunt. $H R=$ heart rate (beats $/ \mathrm{min})$, $R A P=$ right atrial pressure $(\mathrm{mmHg}), R V P=$ right ventricular pressure $(\mathrm{mmHg})$, PAP=pulmonary artery pressure $(\mathrm{mmHg}), \mathrm{CO}=$ Cardiac Output, $E F=$ ejection fraction, LVEDP =left ventricular end-diastolic pressure (mmHg), LVESP=left ventricular end-systolic pressire $(\mathrm{mmHg}), \mathrm{dP} / \mathrm{dt}$ max $=$ first derivative of left ventricular pressure.

\section{Mapping}

After the $48 \mathrm{~h}$ period of $\mathrm{AF}$-induced electrical remodeling the goats were kept in sinus rhythm for at least 5 days, before the atria were mapped. Under general anesthesia a left intercostal thoracotomy was made and the pericardium was opened to expose the heart. The free wall of the right and left atrium was mapped with a slightly concave octagonal array of 240 silver electrodes (diameter $0.3 \mathrm{~mm}$; inter-electrode distance $2.5 \mathrm{~mm}$ ). The total diameter of the mapping electrode was $3.6 \mathrm{~cm}$. Unipolar electrograms were recorded with a silver plate in the thoracic cavity as indifferent electrode. After individual amplification (1000x), band-pass filtering $(0.5-500 \mathrm{~Hz})$ and digitization ( 12 bits, sampling rate $1 \mathrm{kHz}$ ) all signals were recorded simultaneously on hard disc. Local activation times were determined 
automatically by an algorithm detecting the steepest negative deflections in the ellectrograms and edited manually if necessary. Color-coded activation maps were generated by the computer. Local conduction velocities (CV) were calculated from the activation times of $3 \times 3$ electrodes $(5 \times 5 \mathrm{~mm})$ as reported earlier. ${ }^{1,2}$ Slow conduction was defined as a local conduction velocity of $<40 \mathrm{~cm} / \mathrm{s}$. Intra-atrial conduction block was detected by a conduction delay between neighboring electrodes of $>12 \mathrm{~ms}$ (apparent conduction velocity $<20 \mathrm{~cm} / \mathrm{s}$ ). The atria were paced at two frequencies (interval 400 and $200 \mathrm{~ms}$ ) by bipolar electrodes at the 4 borders of the mapping array. After every 10-15 stimuli the pacing site was automatically shifted to another site. The last of each series of 10-15 beats was used for analysis. Four seconds of AF induced by burst pacing from one of the pacing sites were analyzed. In case AF lasted longer than 10 minutes, the atria were electrically cardioverted and after 10 minutes of sinus rhythm the measurements were resumed.

\section{Histology}

After the atria were mapped, the hearts were removed and fixed in buffered formalin. Samples were taken from the high and low free wall of the right and left atrium and embedded in paraffin. $4 \mu \mathrm{m}$ sections were cut and stained with a modified Azan staining. The size of the atrial myocytes was measured in cells with a nucleus in the center and an intercalated disc on either side. The contour of these cells was traced with custom made software and the surface area, the long axis and 3 diameters (center and halfway between nucleus and each intercalated disc) were calculated. In 5 control and 5 AVshunt goats the dimensions of a total of 161 right and 81 left atrial cells and 11 right and 45 left atrial cells were measured. Because these numbers are relatively small, these data must still be regarded as preliminary.

\section{Statistical Analysis}

Data are given as mean $\pm S D$. For statistical analysis a paired or unpaired Student"s t-test was used or a two-way ANOVA. A $p<0.05$ was considered statistically significant.

\section{Results}

\section{Hemodynamic Effects of the Arterio-Venous Shunt}

The short - and long-term hemodynamic effects of a carotid-jugular AV-shunt are shown in figure 1 . The heart rate of the goats was $113 \pm 12$ before creation of the AV-shunt and increased slightly to $118 \pm 16 \quad(p=0.34)$ immediately after opening of the shunt. After 20 weeks of volume overload 
the heart rate was not changed $(120 \pm 28 ; p=0.54)$. Immediately ( 30 min) after creation of the shunt, the right atrial, right ventricular and pulmonary artery pressures increased from respectively $4.7 \pm 4.3,14.4 \pm 3.2$ and $18.1 \pm 3.9 \mathrm{mmHg}$ to $6.7 \pm 3.8,18.2 \pm 3.5$ and $22.0 \pm 4.1 \mathrm{mmHg}(\mathrm{p}<0.05)$. After 20 weeks these pressures had further increased to respectively $11.1 \pm 3.7$, $26.4 \pm 5.7$ and $32.4 \pm 9.2 \mathrm{mmHg}(p<0.05)$. The wedge pressure increased from $9.1 \pm 3.7$ to $14.1 \pm 7.7 \mathrm{mmHg} \quad(p=0.05)$. The cardiac output (CO) initially increased from $5.2 \pm 1.1$ to $5.6 \pm 1.3 \mathrm{~L} / \mathrm{min}$, but was decreased again to $5.3 \pm 2.3 \mathrm{~L} / \mathrm{min} 20$ weeks after the AV-shunt. The ejection fraction (EF) decreased from $59 \pm 11$ to $46 \pm 11 \%(p<0.05)$. Left ventricular end-diastolic pressure (LVEDP) increased from $9 \pm 7$ to $12 \pm 6(p=0.26)$ whereas the LV endsystolic pressure (LVESP) decreased from $114 \pm 7$ to $98 \pm 15(p=0.08)$. The contractile force of the left ventricle, expressed by its dP/dt max was unchanged after 20 weeks of AV-shunt, and also no clinical signs of heart failure were present.

\section{Changes in Dimensions of Atrial Myocytes}

Figure 2 shows the effects of respectively 6 weeks (see Chapter 5) and 20 weeks of atrial pressure and volume overload on the size of atrial myocytes. In control goats the width of right and left atrial myocytes was $14 \pm 2$ and $15 \pm 3 \mu \mathrm{m}$ compared to respectively $16 \pm 3$ and $17 \pm 2$ and $12 \pm 3$ and $13 \pm 2 \mu \mathrm{m}$ after 6 and 20 weeks of AV-shunt. The difference between 6 and 20 weeks was statistically significant $(p<0.05)$. The length of the atrial myocytes after 6 and 20 weeks of AV-shunt, increased respectively from $78 \pm 14$ to $90 \pm 9$ and $108 \pm 23 \mu \mathrm{m}$ in the right atrium $(p=0.13$ 6weeks; $p<0.0520$ weeks $)$ and from $76 \pm 12$ to $100 \pm 9$ and $119 \pm 27 \mu \mathrm{m}$ in the left atrium $(p<0.0016$ and 20 weeks)
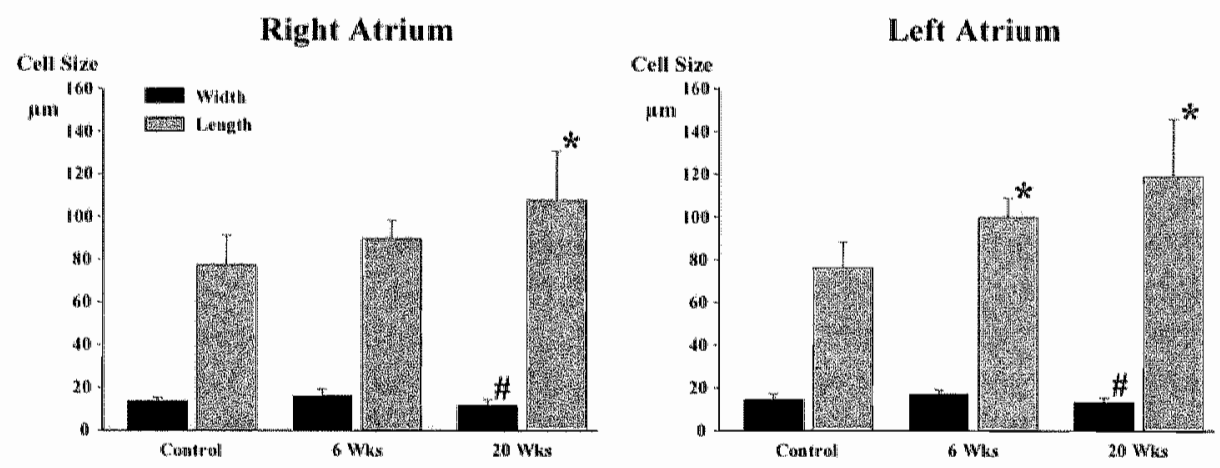

Flgure 2: Effects of 6 and 20 weeks of Av-shunt on width (black bars) and llength (gray bars) of atrial myocytes * $p<0.05$ vs control, \#p<0.05 vs 6 weeks. The length of left atrial myocytes was increased after 6 weeks and in both atria after 20 weeks of AV-shunt. The width of the atrial myocytes did not differ between 20 weeks of AV-shunt and controll, but was significantly decreased compared to 5 weeks of AV-shunt $(p<0.05)$. 


\section{Atrial Refractoriness}

Figure 3 (left panel) shows the effects of 48 hours of AF on the AERP in control and AV-shunt goats. Before electrical remodeling, the AERP 400 , $A_{E R P_{300}}$ and $A E R P_{200}$ were not significantly different in control and $A V$-shunt goats (respectively $180 \pm 22 \mathrm{~ms}$ vs. $165 \pm 25 \mathrm{~ms}(p=0.19), 178 \pm 21$ vs. $169 \pm 28$ $(p=0.48)$ and $147 \pm 8$ vs. $150 \pm 22(p=0.74))$. During 48 hours of $A F$ the $A{ }^{2} P_{400}$ and $A E R P_{300}$ shortened significantly in both groups, but this effect was more pronounced in AV-shunt goats $(p<0.01$ for AERP 400 and $p<0.001$ for $A E R P_{300}$ ). The right panel of figure 3 shows the rate adaptation curves during sinus rhythm and after 48 hours of AF. Also the change in rate adaptation in dilated atria was more marked. Whereas after 48 hours of AF in the control group the rate adaptation was lost (flat curve), in dilated atria the normal physiological rate adaptation became even slightly inversed $(p=0.09)$.
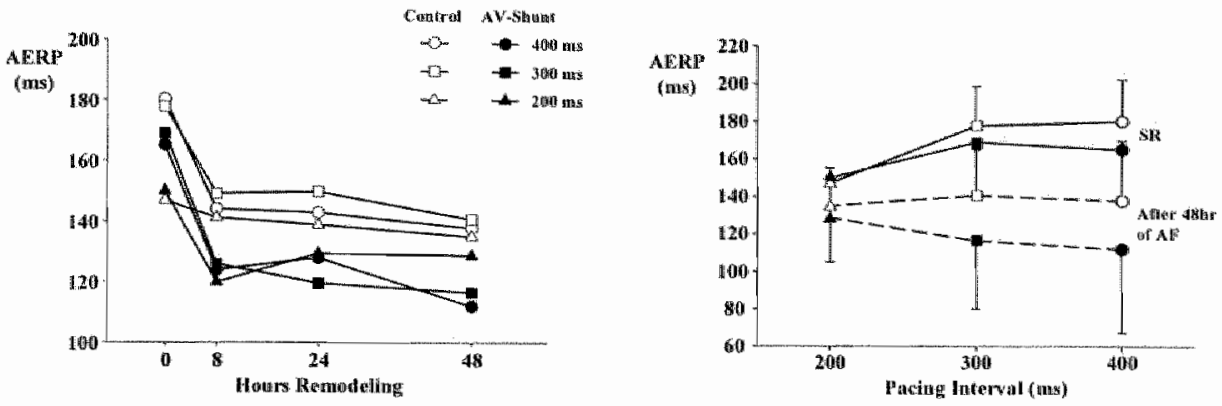

Figure 3: The left panel shows the effects of 48 hours of AF induced remodeling on AERP in control and AV-shunt gaats. During 48 hours of AF the AERP 400 and AERP $P_{300}$ significantly shortened in both groups, but the effect was mare pronounced in the AV-shunt goats $(p<0.01$ for AERPan and $p<0.001$ for $\left.A E R P_{300}\right)$. In the right panel the rate adaptation curves during baseline and after 48 hours of AF are platted.

\section{Atrial Fibrillation}

Figure 4 shows the effects of 48 hours of atrial electrical remodeling on the characteristics of atrial fibrillation, both in a control and the AV-shunt group. There was no difference in either degree or time course of electrical remodeling on the AFCL (upper left panel). During the first 48 hours of AF, in the two groups the median AFCL shortened from $150 \pm 26$ and $149 \pm 17 \mathrm{~ms}$ to respectively $118 \pm 9$ and $123 \pm 33 \mathrm{~ms} \quad(p=0.94)$. The longest durations of induced paroxysms of AF after $0,8,24$ and 48 hours of atrial electrical remodeling in control and $A V$-shunt goats are plotted in the right upper panel. At baseline, in AV-shunt goats the longest AF duration was longer than in control goats ( \pm 3 minutes vs. $16 \mathrm{sec}$.). In dilated atria, the longest AF duration was greatly enhanced after 48 hours of AF to $>25$ minutes (compared to 2 minutes in the control group; $p<0.05$ ). In the lower panels of 
figure 4 the longest AF episodes after $0,8,24$ and 48 hours of electrical atrial remodeling are plotted in the control (left) and AV-shunt groups (right).
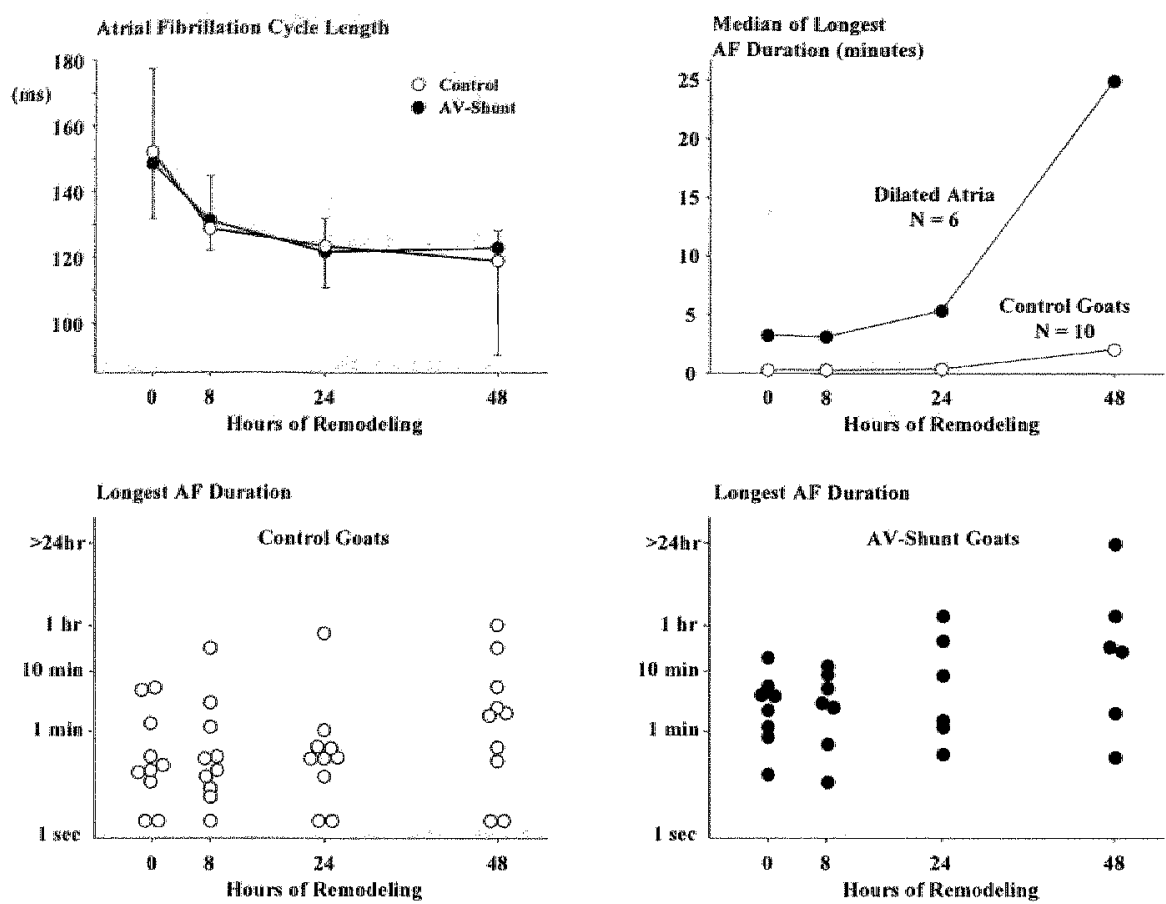

Figure 4: In the left upper panel the effects of 48 hours of electrical remodeting on AFCL are platted in control and AV-shunt goats. In both groups, 48 hours of atrial fibrillation shortened the median $A F C L$ to the same extent. There was also no difference th the time course of AF-induced electrical remodeling. In the right upper panel the median longest AF duration is plotted during 48 hours of ellectrical remodeling in control and AV-shunt goats. After electrical remodeling . AF lasted longer in the AV-shumt than in the control group $(>25 \mathrm{~mm}$ vs. $2 \mathrm{~min})$. In the lower panels the duration of the longest AF episode in ach individual animal is plotted, as abserved after $0,8,24$ and 48 hours of AF.

\section{Mapping of Atrial Conduction}

Table 1 shows the effects of 20 weeks of atrial dilatation on the conduction properties of the left and right atrium during pacing with an interval of 400 and $200 \mathrm{~ms}$. In the AV-shunt goats, the total conduction time (TCT) under the mapping electrode ranged between 41 and $47 \mathrm{~ms}$ and was not different from control $(44-5.2 \mathrm{~ms} ; p=0.25)$. The conduction velocity in the free wall of the right and left atrium was not different from control $(92 \pm 11$ and $87 \pm 12 \mathrm{~cm} / \mathrm{s}$ during slow pacing and $85 \pm 14$ and $80 \pm 7 \mathrm{~cm} / \mathrm{s}$ during rapid pacing). The incidence of slow conduction and intra-atrial conduction block in chronically dilated atria was also not different from control (respectively $1.8-3.0$ and $0.3-$ $0.5 \%$ versus $1.9-5.2$ and $0.2-0.8 \%$ ). Also ${ }_{r}$ the percentage of tissue area exhibiting slow conduction and intra-atrial conduction block was not different between control and AV-shunt. 


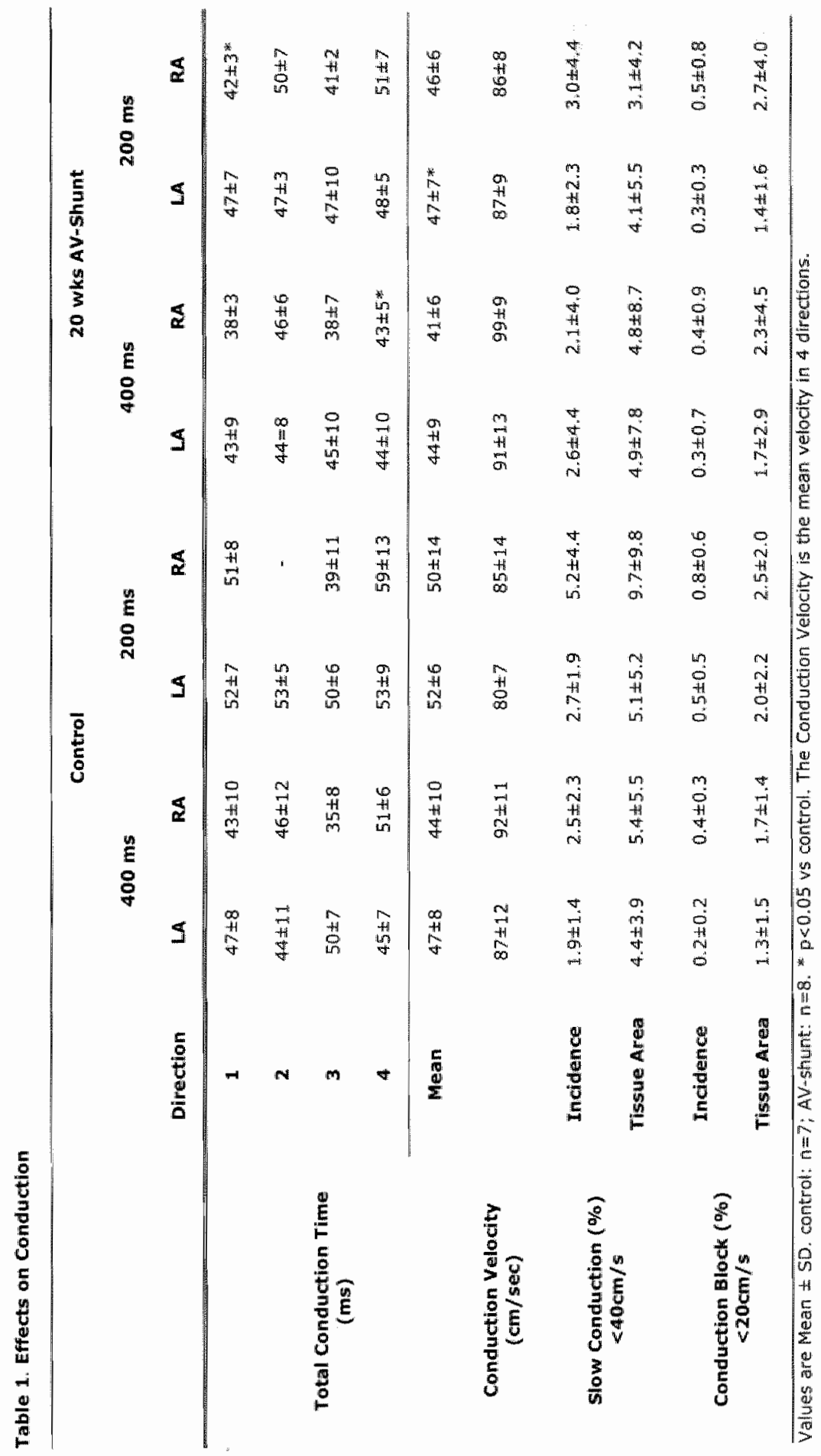


Figure 5 shows a representative example of isochronal maps of 24 consecuthe AF beats in the right atrium of an AV-shunt goat. Isochrones are drawn every $10 \mathrm{~ms}$ and the arrows indicates the main directions of activation. During most AF cycles, one or two fibrillation waves propagated under the mapping electrode (type I-II AF). Type III AF ( $>=3$ fibrillation waves) occurred more rarely. Fibrillation waves were frequently linked (i.e. followed more or less the same direction). In Table 2 the effects of 20 weeks AV-shunt on the characteristics of atrial fibrillation are given. In control goats, the conduction velocity during AF was $85 \pm 15 \mathrm{~cm} / \mathrm{s}$ in the left and $72 \pm 20 \mathrm{~cm} / \mathrm{s}$ in the right atrium, compared to respectively $87 \pm 20$ and $67 \pm 14 \mathrm{~cm} / \mathrm{s}$ in the AVshunt group $(p=0.82$ and $p=0.57)$. The incidence of slow conduction and intra atrial conduction block was higher in the right (respectively $20.8 \pm 10.8$ and $7.2 \pm 2.5 \%)$ than in the left atrium $(7.5 \pm 9.1 \% ;(p=0.07)$ and $2.1 \pm 2.4 \%$; $p<0.05)$. In AV-shunt goats the incidence of slow conduction and intra-atrial conduction block was $13.3 \pm 12.5$ and $4.3 \pm 4.0 \%$ in the left and $22.9 \pm 14.7$ and $7.8 \pm 5.1$ in the right atrium and was not significantly different from control. In the control group, the median AFCL was $166 \pm 11 \mathrm{~ms}$ in the left and $150 \pm 20 \mathrm{~ms}$ in the right atrium, compared to respectively $159 \pm 24$ and $152 \pm 25 \mathrm{~ms}$ in the AV-shunt goats (NS). Also the variation in AFCL was not different in dilated and non-dilated atria.

Table 2. Effects on Characteristics of Atrial Fibrillation

\begin{tabular}{|c|c|c|c|c|c|}
\hline & & \multicolumn{2}{|c|}{ Control } & \multicolumn{2}{|c|}{20 wks AV-Shunt } \\
\hline & & LA & RA. & LA & $\mathbf{R A}$ \\
\hline $\begin{array}{l}\text { Conduction Velocity } \\
(\mathrm{cm} / \mathrm{sec})\end{array}$ & & $85 \pm 15$ & $72 \pm 20$ & $87 \pm 20$ & $67 \pm 14$ \\
\hline \multirow{2}{*}{$\begin{array}{l}\text { Slow Conduction }(\% / \%) \\
40 \mathrm{~cm} / \mathrm{s}\end{array}$} & Incidence & $7.5 \pm 9.1$ & $20.8 \pm 10.8$ & $1.3 .3 \pm 12.5$ & $22.9 \pm 14.7$ \\
\hline & Tissue Area & $44 * 30$ & $75 \pm 23$ & $54 \pm 28$ & $75 \pm 21$ \\
\hline $\begin{array}{l}\text { Condiuction Bilock } \\
(0 / 6)\end{array}$ & Incidence & $2.1 \pm 2.4$ & $7.2 \pm 2.5$ & $4.3 \pm 4.0$ & $7.8 \pm 15.1$ \\
\hline$<20 \mathrm{~cm} / \mathrm{s}$ & Tissue Area & $26 \pm 25$ & $58 \pm 28$ & $32 \pm 24$ & $52+24$ \\
\hline Median AFCL (ms) & & $166 \pm 11$ & $150 \pm 20$ & $159 \pm 24$ & $152 \pm 25$ \\
\hline $\begin{array}{l}\text { Varlation in AFCL } \\
\text { ( } \mathrm{ms} \text { ) }\end{array}$ & & $13 * 5$ & $17 \pm 5$ & $14 \pm 6$ & 15 尘 4 \\
\hline
\end{tabular}

Walues are Mean $\pm 5 D$, control: $n=7 ; A V-$ shunt: $n=8$, $* 0<0,05$ vs control. Variation in $A F C L=p 50-p 5 / p 50$ 


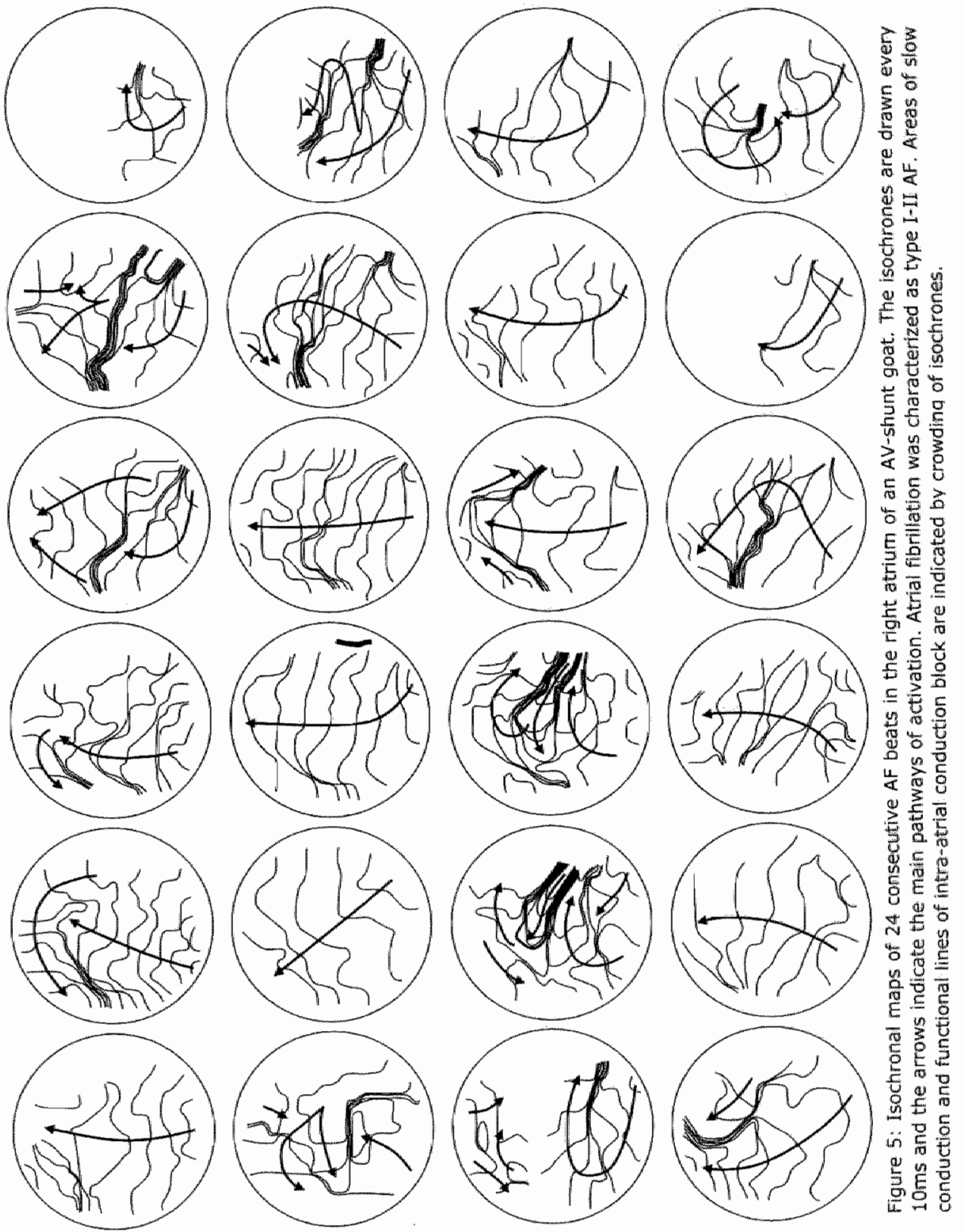




\section{Discussion}

The purpose of this study was to create an experimental model of atrial dilatation without concomitant heart fallure. The hemodynamic measurements showed that after 20 weeks of cardiac volume overload the diastolic function of the heart was not impaired as demonstrated by an LVEDP of $12 \pm 6 \mathrm{mmHg}$. However, the left ventricular systolic function was slightly decreased as shown by a lowered LVESP, ejection fraction and cardiac output (Fig. 1). None of the goats showed clinical signs of heart failure like tachypnoe, pulmonary edema or ascites. The decline in systolic function must have occurred between 6 and 20 weeks of volume overload, since after 6 weeks the cardiac output was still higher than before creation of the shunt. Our present model thus can be considered as a model of atrial dilatation with still compensated ventricular function.

\section{Long-Term Effects of Atrial Stretch on the Substrate of AF}

In the present study we evaluated the effects of 20 weeks of atrial volume overload on the substrate of AF in the goat. The duration of the longest episodes of electrically induced AF stability of AF was clearly increased in goats with an AV-shunt. This difference was markedly amplified after 48 hours of electrical atrial remodeling, when the median duration of the longest AF paroxysm was prolonged to more than 25 minutes, compared to 2 minutes in the control group. No effect of chronic volume overload on the AFCL or AERP was observed. In dilated atria, electrical remodeling still resulted in shortening of the AFCL and $A E R P$, indicating a predominant role of functional reentry during $\mathrm{AF}^{3}$ This is in contrast with observations of Shinagawa et al. in a dog model of rapid atrial pacing and heart failure, in which the shortening of the AERP during electrical remodeling was significantly less in dogs with atrial enlargement. ${ }^{4}$ In our present study intraatrial conduction velocity and the incidence of slow conduction and conduction block was not different in AV-shunt goats compared to controls. This was true during slow and rapid atrial pacing as well as during paroxysms of AF. Mapping of AF demonstrated multiple lines of intra-atrial conduction block which were functional in nature. No structural lines of conduction block were found. Other experimental atrial dilatation models also demonstrated an increase in intra-atrial conduction delays together with an increase in the amount of atrial fibrosis. 4.5 The increase in atrial size and structural changes in the extracellular matrix are probably both important for the creation of a substrate of AF. 20 Weeks of atrial stretch increased the stability of AF without apparent changes in atrial refractoriness, conduction velocity, or fibrosis. The effect on electrical remodeling on the $\mathrm{AERP}_{400}$ and $\mathrm{AERP}_{300}$ was more pronounced in AV-shunt goats. In this situation, the higher propensity 
of AF may simply be the result of the increase in size of the atria, which will allow more re-entrant circuits to co-exist. However, when the atria dilate as a result of congestive heart failure, structural atrial remodeling occurs by activation of various intracellular signaling pathways. ${ }^{6}, 7$ Changes in atrial structure and architecture, at a microscopic or macroscopic level, may alter the electrophysiological properties of the atria. The electroanatomical substrate is characterized by increased non-uniform anisotropy in conduction, enabling reentrant circuits of small size in the atria. ${ }^{8}$ An experimental study on chronic atrial dilatation and extensive atria fibrosis, due to heart failure, demonstrated major heterogeneities in conduction and a significant increase in inducibility and duration of $\mathrm{AF}^{5}$ In a model of chronic atrial dilatation due to total AV-block (no concomitant heart failure), only a minor increase in local atrial conduction delays occurred during rapid pacing. ${ }^{9}$ As in our present study, a marked increase in length and width of the atrial myocytes was observed (concentric hypertrophy) without any sign of an increased deposition of collagen. In our study, after 20 weeks of AV-shunt the atrial myocytes appeared to be stretched rather than concentrically hypertrophied. Concentric hypertrophy has been attributed to pressure overload, whereas volume overload causes an increase in length of the myocytes. Gerdes et al. showed that, during the progression to heart failure the myocytes became lengthened without a further increase in cross-sectional area. ${ }^{10}$ This occurred long before the development of symptomatic heart failure. Both hypertrophy of atrial myocytes and atrial fibrosis are important determinants of tissule anisotropy at the cellular level and can lead to slow, heterogeneous conduction, unidirectional conduction block and reentry. $11_{s} 12$

In contrast to what was expected, our study showed that 'pure' atrial dilatation by as long as 20 weeks of atrial volume overload, is a rather 'weak' stimulus for the development of a substrate of AF.

\section{References}

1. Eijsbouts SC, Houben RP, Blaauw Y, Schotten U, Allessle MA. Synergistic action of atmial diliation and sodium channel blockade on conduction in rabbit atria. I Cardiovasc Electrophyslol $2004 ; 15(12): 1453-1461$.

2. Houben RP, de Groot NM, Smeets IL, Becker AE, Lindemans FW, Allessle MA. S-wave pledominanice of epicardial electrograms during atrial fibrillation in humans: Indirect ewdence for a role of the thin subepicandial layer. Heart Rhythm 2004; $1(6): 639-647$.

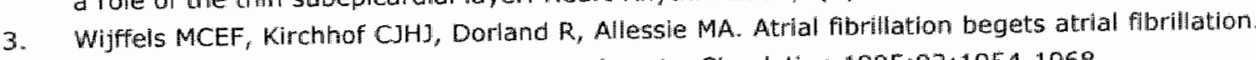
A study in awake chronically instrumented goats. Circulation 1995;92:1954-1968.

4. Shlinagawa K, Shil YF, Tardif JC, Leung TK, Nattel S. Dynamic nature of atrial fibrillation substrate during development and reversal of heart failure in dogs. Circulation $2002 ; 105(22): 2672-2678$.

5. Li D, Fareh S, Leung TK, Nattel S. Promotion of atrial fibrillation by heart failure in dogs: atrial remodeling of a different sort. Circulation $1999 ; 100(1): 87-95$. 
6. Ruwhof C, van der Laarse A. Mechanical stress-induced cardiac hypertrophy: mechanisms and signal transduction pathways. Cardlovasc Res 2000;47(1):23-37.

7. Goette A, Lendeckel U, Klein HU. Signal transduction systems and atrial fibrillation. Cardiovasc Res $2002 ; 54(2): 247-258$.

8. Spach MS, Josephson ME. Initiating reentry: the role of nonuniform anisotropy in small circults. J Cardiowase Electrophysiol 1994;5(2):182-209.

9. Neuberger $H R$, Schotten U, Verheule $S$, Eljsbouts $S$, Blaauw $Y$, van Hunnik A, Allessie M. Development of a substrate of atrial fibrillation during chronic atrioventricular block in the goat. Circulation 2005;111(1):30-37.

10. Gerdes AM. Cardiac myocyte remodeling in hypertrophy and progression to fallure. I Card Fail $2002 ; 8(6$ Suppi):5264-268.

11. Spach MS, Dolber PC. Relating extracellular potentials and their derivatives to anisatropic propagation at a microscopic level in human cardiac muscle. Evidence for electricall uncoupling of side-to -side fiber connections with increasing age. Circ Res 1986;58:356-371.

12. Spach MS, Heldlage JF, Dolber PC, Barr RC. Electrophysiological effects of remodeling cardiac gap junctions and cell size: experimental and model studies of normal cardiac growth. Circ Res $2000 ; 86(3): 302-311$. 
Chapter 7

\section{General Discussion:}

\section{Role of Atrial Dilatation in the Stability of AF}

Sabine Eijsbouts 


\section{Role of Acute Atrial Dilatation in the Stability of AF}

Acute atrial stretch can cause premature beats or runs of rapid responses which trigger a paroxysm of AF. In response to the hemodynamic load during acute stretch electrophysiological changes occur (mechanoelectrical feedback). These changes include shortening of the action potential duration, a decrease in resting membrane potential, accurrence of early afterdepolarizations and the generation of ectopic beats. ${ }^{1}$ When stretch is applied during the plateau phase of the action potential, a repolarizing current is induced which shortens the action potential. When stretch is applied a little later, an inward current is activated which lengthens the action potential and may generate either early or delayed afterdepolarizations. Mechanoelectrical feedback can partially be explained by activation of stretch-activated ion channels (SACS). ${ }^{2}$ In this thesis we showed that acute atrial dilatation results in slowing of conduction and increases the incidence of intra-atrial conduction block. This increase in spatial heterogeneity in conduction was related to the anisotropic properties of the atriall wall. Lines of intra-atrial conduction block predominantly occurred along the border of the crista terminalis and larger atrial trabecullae. Due to the heterogeneous distribution of wall stress during increased atrial pressure, the thin parts of the atrium will be stretched more than the thicker bundles. ${ }^{3}$ This may explain lines of conduction block in the thin parts between atrial trabeculae. The architecture of the atrial myocardium thus may play an important role in the conduction disturbances due to dilatation. Shortening of the refractory period and slowing of conduction by acute stretch decreases the atrial wavelength. When the wavelength is long, a large area of unidirectional block is required to make the impulse re-enter itself, but when the wavelength is shortened, only a small area of block may set up a re-entry circuit. ${ }^{4}$ Also increased heterogeneity and discontinuity in local conduction may facilitate the initiation and perpetuation of AF, because it will allow reentry of smaller dimensions. As shown by Spach et al., in nonuniform anisotropic tissue reentry can already occur within an area as small as $1-2 \mathrm{~mm}^{2}$ (microreentry). Apart from providing triggers for AF, atrial dilatation thus may also create a substrate for perpetuation of AF.

Although acute atrial stretch may be important in making the atria more vulnerable to $A F$, chronic atrial stretch may be even more important for the perpetuation of AF. It is likely that during chronic atrial dilatation other mechanisms play a role in the creation of a substrate for AF than during acute atrial dilatation. 


\section{Role of Chronic Atrial Dilatation in the Development of a Substrate of AF}

In this thesis we showed that after 6 and 20 weeks of chronic atrial dilatation the duration of AF paroxysms became progressively increased. After 48 hours of remodeling the duration of AF paroxysms became markedly prolonged compared to a control group. This was not accompanied by changes in atrial fibrillation cycle length, atrial refractoriness or conduction. Electrical remodeling in dilated atria still resulted in shortening of AFCL and AERP, indicating an important role for functional reentry during AF. The effect of remadeling on the AERP during slow pacing was more pronounced in dilated atria than in normal atria. In contrast, no increase in discontinuities in conduction were found during mapping of atrial fibrillation in the free wall of the left and right atrium. It has been shown that in patients with paroxysmal AF, initiation of AF is caused by ectopic foci located in the myocardial "sleeves" of the pulmonary veins. ${ }^{6}$. In our study we did not map the pulmonary vein area. However, we have no indications for atrial ectopy in the goat. We never observed spontaneous paroxysms of AF, or ectopic premature atrial beats.

In this thesis, we showed that 20 weeks of 'pure' atrial dilatation in the goat is still a relatively "weak" stimulus for the development of a substrate of AF, and it may probably take years before atrial dillatation alone will lead to a substrate of persistent AF. Other animal models of a combination of atrial dilatation and heart failure showed a much stronger increase in the duration of AF, already after 5-6 weeks of atrial dilatation. ${ }^{7-9}$. The 3-4 fold increase in atrial pressure in these models was similar as in our present AV-shunt model. Thus, in heart failure models other factors than atrial dilatation may be the primary cause of the increased stability of AF. During chronic cardiac overload, stress-induced cardiac hypertrophy develops and structural remodeling occurs by activation of various intracellular signaling pathways in cardiomyocytes and fibroblasts. ${ }^{10}, 11$ Chronic myocardial stretch induces angiotensin expression and promotes angiotensin II release from secretory granules. Due to activation of MAP kinases in cardiac fibroblasts, angiotensin II induces interstitial accumulation of collagen and proliferation of fibroblasts which results in interstitial fibrosis. Li et al. have shown in a pacing induced heart failure model that atrial fibrosis increases heterogeneity in conduction favoring the inducibility and stability of $\mathrm{AF}^{8}$ The development of atrial fibrosis in their model was associated with increased levels of angiotensin II. ${ }^{12}$ Although enalapril (ACE-inhibitor) reduced the increase in tissue angiotensin II, atrial fibrosis, conduction abnormalities and AF stability, it failed to protect the atrium completely against structural remodeling and AF. Probably, atrial stretch also activates other signaling pathways such as, endothelin-1, growth promoting factors (VEGF and TGF- $\beta$ ) and cytokines, which also lead to 
structural remodeling. Release of growth-promoting factors, such as angiotensin 11, endothelin-1, and transforming growth factor- $\beta$, may stimulate cardiac hypertrophy. ${ }^{10}$ Both experimentally and clinically, it has been shown that chronic atrial dilatation causes structural changes. ${ }^{13-15}$ Boyden et al. showed that right and left atrial enlargement caused interstitial fibrosis and cellular hypertrophy. ${ }^{13}, 14$ Also in patients with atrial dilatation and atrial fibrillation accumulation of collagen and elastic fibers was found together with an increase in atrial cell size. ${ }^{15}$ Isolated atrial tissue of a $62-$ year-old patient with right atrial enlargement, showed a high degree of nonuniform anisotropy in conduction. ${ }^{16}$ Histologically, this was associated with hypertrophy and collageneous septa surrounding virtually all muscle fibers. Extra-cellular potentials were highly fractionated, and micro re-entry was demonstrated within a single atrial muscle bundle. More recently, Spach et al. demonstrated that in a two-dimensional cellular model, cell size was an important determinant of anisotropic properties at the cellular level. ${ }^{1.7}$ As the cells were enlarged, both the mean $V_{\max }$ during transverse propagation and lateral cell-to-cell delays increased. Cellular hypertrophy thus may alter anisotropic conduction properties and can lead to slow, inhomogeneous conduction, unidirectional block and re-entry. In fibrotic myocardium conduction is slowed by a zigzag course of propagation. ${ }^{5,18} \mathrm{~A}$ change from uniform to nonuniform anisotropic conduction allows reentry to occur in progressively smaller regions. ${ }^{19}$ Given the micro-architecture of the atrium, with its high variation in the amount of collagen, it is likely that atrial stretch affects certain areas of the atria differently than others. Tissue fibrosis may also increase spatiall dispersion in electrophysiological properties. ${ }^{20}$ Unequal atrial stretch has been shown to cause heterogeneity in refractory periods. ${ }^{3}$ Apart from the increased atrial tissue mass itself, such electroanatomical changes will allow multiple small reentrant circuits in the atrium which will stabilize AF.

\section{Clinical Relevance of Atrial Dilatation in AF}

Atrial dilatation is common in the population aged $\geq 45$ years. The prevalence of left atrial enlargement has been reported to be $12-18 \%$ in a study of 2042 people older than 45 years in the United States. ${ }^{21}$ Atrial dilatation frequently occurs in patients with hypertension, coronary artery disease, valvular disease, heart failure and in elderly people. Depending on the severity of the underlying heart disease, up to $50 \%$ of these patients may develop AF. Congestive theart failure is a strong predictor of $A F .^{22}$ The prevalence of AF in heart failure is dependent on the New York Heart Association Functional Class (NYHA functional class). ${ }^{23}$ Patients with NYHA functional class I (asymptomatic) have an AF prevalence of $\leq 5 \%$, while patients with NYHA 
functional class IV (symptoms at rest) have a prevalence of AF approaching $50 \%,{ }^{24,25}$ It may often take years before patients in NYHA class I will develop NYHA class IV heart failure. Also, in hypertensive patients and patients with mitral regurgitation it may take a long time before atrial fibrillation develops. With increasing age structural changes occur in the heart. There is a decrease in number and an increase in size of the cardiac myocytes. Also the amount of fibrosis increases and there is loss of elastic element. Due to geometric changes of the heart chambers and some associated valvular dysfunction, the atria become gradually enlarged in the elderly. Age-related structural changes may thus create a substrate of AF in the absence of overt heart failure. Thus, although an increase in atrial dimension is an important risk factor for the development of atrial fibrillation, 22,25 it may develop very slowly and it may take years before it leads to atrial arrhythmias.

\section{References}

1. Nazir S, Lab M. Mechanoelectric feedback and atrial arrhythmias. Cardiovasc Res 1996;32:5261.

2. Hu H, Sachs F. Stretch-activated ion channels in the heart, J Moll Cell Candlol $1997 ; 29(6): 1511-1523$.

3. Satoh $T$, Zipes D. Unequal atrial stretch in dogs increases dispersion of refractoriness conductive to developing atrial fibrillation. I Cardiovasc Electrophysiol 1996;7:833-842.

4. Allessie MA, Lammers WJEP, Rensma PL, Schallij MJ, Kinchhof CJHJ. Determinamts of reentry In cardiac muscle. Progress Cardiol 1988;1/2:3-15.

5. Spach MS, Dolber PC. Relating extracellular potentials and their derivatives to anisotroplic propagation at a micrascopic level in human cardiac muscle. Evidence for electrical uncoupling of side-to -side fiber connections with increasing age. Circ Res 1986;58:356 -371.

6. Haissaguerre $M$, Jais $P$, Shah DC, Takahashi A, Hocini M, Quiniou $G$, Garrigue S, Le Mouroux A, Le Metayer P, Chementy J. Spontaneous Initiation of atrial fibrillation by ectoplic beats origlnating in the puimonary veins. N Engl J Med 1998;339(10):659-666.

7. Power JM, Beacom GA, Alferness CA, Raman J, Wigffels M, Farish SiJ, Bumell LM, Tonkin AM. Susceptibilty to atrial fibrilation: A study in an ovine model of pacing induced early heart fallume. I Cardiovasc Electiophysiol 1998;9(4):423-435.

8. Li D, Fareh 5 , Leung TK, Nattel S. Promotion of atial fibrillation by heart failuire in dogs: atrial remodeling of a different sort. Circulation 1999;100(1):87-95.

9. Shinagawa $K$, Shi YF, Tardif JC, Leung TK. Nattel S. Dynamic nature of atrial fibrillation substrate during development and reversal of heat failulre in dogs. Circulation $2002 ; 105(22): 2672-2678$.

10. Ruwhof $C$, van der Laarse $A$. Mechanical stress-induced cardiac hypertrophy: mechanisms and signal transduction pathways. Candiovase Res 2000;47(1):23-37.

11. Goette $A$, Lendeckel $U_{i}$ Klein HU. Slgnal transduction systems and atrial fibrillation. Cardiovasc Res $2002 ; 54(2): 247-258$.

12. Li $D$, Shinagawa $K$, Pang $L$, Leung TK, Cardin $S$, Wang $Z$, Nattel $S$. Effects of anglotensin converting enzyme intubition on the development of the atrial fibrillation substrate in dogs with ventricular tachypacing-induced congestive heart failure. Circulation 2001; 104(21):26082614. 
13. Boyden PA, Hoffrian BF. The effects on atrial electrophysiology and structure of surgically induced right atrial enlargement in dogs. Circ Res 1981;49:1319-1331.

14. Boyden PA, Tilley $L P$, Pham TD, Liu SK, Fenoglic $33_{n} \mathrm{Jr}$, Wit AL. Effects of left atrial enlargement on atrial transmembrane potentials and structure in dogs with mitral valve fibrosis. Am J Cardiol 1982;49(8):1896-1908.

15. Aime-Sempe $C$, Folliguet $T$, Rucker-Martin $C$, Krajewska M, Krajewska $S_{r}$ Heimburger $M_{r}$ Aubleir M, Mercadier 11 , Reed JC; Hatem SN. Myocardiall cell death in fibrillating and dilated human right atria. J Am Coll Cardiol 1999;34(5):1577-1586.

16. Spach MS, Dolber $P C_{*}$ Heidlage JF. Influence of the passive anisatropic properties on directional differences in propagation following modification of the sodium conductance in thuman atrial muscle. A model of reentry based on anisotropic discontinuous propagation. Circ-Res $1988 ; 62(4): 8111-832$.

17. Spach MS, Heidlage JF, Dolber PC, Barr RC. Electrophysiological effects of remodeling cardiac gap junctions and cell size: experimental and model studies of normal cardiac growth. Circ Res 2000;86(3):302-311.

18. de Bakker JM, wan Capelle FJ, Janse MJ, Tasseron S, Vermeulen JT, de Jonge $\mathbb{N}$, Lahpor JR. Slow conduction in the infarcted human heart. 'Zigzag' course of activation. Crrculation $1993 ; 88(3): 915-926$.

19. Spach MS, Josephson ME. Initiating reentry: the role of nonuniform anisotiopy in small circuits. J Cardliovase Electrophysiol 1994;5(2):182-209.

20. Allessie MA, Boyden PA, Camm AJ, Kleber AG, Lab MJ, Legato MJ, Rosen MR, Schwartz PJ, Spooner $\mathrm{PM}_{\text {. }}$ Van Wagoner DR, Waldo AL. Pathophysiology and prevention of atrial fibrillation. Crculation 2001:103(5):769-777.

21. Pritchett AM, Jacobsen SJ, Mahoney DW, Rodeheffer $\mathbb{R}_{r}$ Bailey $K R_{x}$ Redfield MM. Left atrial volume as an index of left atrial size: a population-based study. $\mathrm{J}$ Am Coll Cardiol 2003;41(6):1036-1043.

22. Vaziri SM, Larson MG, Benjamin E], Levy D. Echocardiographic predictors of nonrheumatic atrial fibrillation. The Framingham Heart Study. Circulation 1994;89(2):724-730.

23. Maisel WH, Stevenson LW. Atrial fibrillation in heart failure: epidemiology, pathophysiology, and rationale for therapy. Am J Cardiol 2003;91(6A):2D-8D.

24. Dries DL, Exner DV, Gersh BJ, Domanskl MJ, Waclawiw MA, Stevenson LW. Atrial fibrillation is associated with an increased risk for mortality and heart failure progression in patients with asymptomatic and symptomatic left ventricular systolic dysfunction: a retrospective analysis of the SOLVD trials. Studies of Left Ventricular Dysfunction. I Am Coll Cardiol $1998 ; 32(3): 695-703$.

25. Group CTS. Effects of enalapril on mortality in severe congestive heart failure. Results of the Cooperative Nortt Scandinavlan Enalapril Survival Study (CONSENSUS). The CONSENSUS Trlal Study Group. N Engl J Med 1987;316(23):1429-1435.

26. Benjamin EJ, D'Agostino R.B, Belanger AJ, Wolf PA, Levy D. Left atrial size and the risk of stroke and death. The Framingham Heart Study. Circulation 1995;92(4):835-841. 


\section{Summary}

Atrial dilatation is common in the population aged $\geq 45$ years and is an important independent risk factor for atrial fibrillation (AF). Depending on the severity of the underlying heart disease up to $50 \%$ of these patients will develop AF. For more than 100 years, experimental and clinical investigations have tried to demonstrate and unravel the relation between atrial size and occurrence and perpetuation of atrial fibrillation. Several clinical studies have shown a causal relationship between increased left atrial size and the development of AF. Atrial size is also a predictor of successful cardioversion and maintenance of sinus rhythm. In animal studies both acute and chronic atrial dilatation have been shown to increase the vulnerability to AF. On the other hand, dilatation of the atria can also be a consequence of AF. This is supported by the observation that AF induced electrical remodeling is accompanied by a loss of atrial contractility (contractile remodeling). The resulting increase in compliance of fibrillating atria will lead to atrial dilatation. Thus, apart from being a cause of AF, atrial dilatation can also be a consequence of AF. In this way atrial dilatation may play a role in the perpetual cycle leading to persistent AF.

The aim of the thesis was to investigate the effects of acute and chronic atrial dilatation on the development of a substrate for AF. The main question to be studied was whether atrial dilatation causes heterogeneities in conduction which play an important role in the initiation and perpetuation of re-entrant arrhythmias. The effect of acute atrial dilatation on atrial conduction was studied in isolated Langendorff perfused rabbit hearts (Chapter 2 and 3). In chapter 2, spatial heterogeneities in atrial conduction were quantified during acute dilatation of the right and left atrium using high-density mapping (resolution: $0.5 \mathrm{~mm}$ ). Acute atrial dilatation resulted in slowing of conduction and an increase of the amount of intra-atrial conduction block. The increase in spatial heterogeneity in conduction was related to the anisotropic properties of the atrial wall. Lines of intra-atrial conduction block predominantlly occur along the border of the crista terminalis and larger atrial trabeculae.

Class Ic drugs, which are often used to cardiovert AF in patients, slow conduction by blockade of the rapid sodium channels. In chapter 3 we investigated the combination of acute atrial dilatation and a class IC drug (flecainide) on the degree of atrial anisotropy and conduction. The study showed that both atrial dilatation and flecainide slowed the effective velocity of conduction of the depolarization wave and increased the degree of spatial heterogeneities in conduction. An important finding was that the combination of dilatation and flecainide exerted a clear synergistic effect on atrial conduction. 
In chapter 4 we tested the hypothesis that during 4 months of "lone" persistent AF during which the atria undergo structural remodeling, the stability of AF increases. Because during persistent fibrillation the duration of AF paroxysms can not be used to measure the stability of fibrillation, instead the amount of class IC drug required for cardioversion was used to evaluate long-term changes in the stability of AF. In goats persistent AF was induced by repetitive burst pacing. During a time period of 16 weeks the efficacy of flecainide and cibenzoline to cardiovert AF was investigated by serial cardioversion. The reduction in efficacy of pharmacological cardioversion by class I drugs can be due either to a loss of the electrophysiological action of the drugs or by an increase in stability of the fibrillatory process. In our present series the sensitivity of the atria for class IC drugs was not reduced after 4 months of AF. In particular no reduction in the dose-dependent effect on AF cycle length was found. The lower success rate of cardioversion with time thus must be ascribed to an increase in the stability of atrial fibrillation.

The effects of chronic atrial dilatation on the substrate of AF were studied in a goat model of chronic atrial volume overload. Chronic volume overload was produced by making a shunt between the carotid artery and the jugular vein (AV-shunt). In chapter 5 the effects on the electrophysiological properties of the atria and the duration of AF episodes were evaluated after 6 weeks of AVshunt. The effects of chronic atrial volume overload on atrial conduction was evaluated by high-density mapping (resolution: $2.25 \mathrm{~mm}$ ) of the free wall of the left and right atrium. Six weeks of AV-shunt increased the right and left atrial pressure about 3-4 fold. We observed a small increase in duration of AF paroxysms after 6 weeks of AV-shunt. The increased stability of AF could not be attributed to a change in AERP, spatial dispersion in refractoriness or rate adaptation of the refractory period. Also, no changes in atrial conduction velocity or incidence of slow conduction or conduction block occurred. To investigate whether 6 weeks of an AV-shunt were not long enough to induce electrophysiological changes in the atria, we performed an additional study in which the duration of atrial volume overload was extended to 20 weeks (chapter 6). We showed that 20 weeks of chronic atrial dilatation the duration of AF paroxysms became progressively increased. After 48 hours of remodeling the duration of AF paroxysms became markedly prolonged compared to a control group. This was not accompanied by changes in atrial fibrillation cycle length, atrial refractoriness or conduction. Electrical remodeling in dilated atria still resulted in shortening of AFCL and AERP, indicating an important role for functional reentry during AF. The effect of remodeling on the AERP during slow pacing was more pronounced in dilated atria than in normal atria. In contrast, no increase in discontinuities in conduction were found during mapping of atrial fibrillation in the free wall of the left and right atrium. 
In chapter 7 the role of acute and chronic atrial dilatation in the stability of AF is discussed. Acute atrial stretch may be important in making the atria more vulnerable to $A F$, chronic atrial stretch may be even more important for the perpetuation of AF. However, we showed that 20 weeks of 'pure' atrial dilatation in the goat is still a relatively 'weak" stimulus for the development of a substrate of AF, and it may probably take years before atrial dilatation alone will lead to a substrate of persistent AF. 


\section{Samenvatting}

Dilatatie van de boezems komt veel voor bij mensen boven de 45 jaar en is een belangrijke risicofactor voor het ontstaan van boezemfibrilleren. Afhankelijk van de onderliggende hartziekte krijgt bijna $50 \%$ van deze mensen boezemfibrilleren. Al meer dan 100 jaar wordt er experimenteel en klinisch onderzoek gedaan naar de relatie tussen de grootte van de boezem en het ontstaan van boezemfibrilleren. Enkele klinische studies hebben een causaal verband aangetoond tussen dilatatie van de boezem en het ontstaan van boezemfibrilleren. De grootte van de boezem heeft ook een voorspellende waarde voor het succes van cardioversie en het behoudt van sinus ritme. Dier-experimenteel onderzoek heeft aangetoond dat zowel acute als chronische atriale dilatatie de gevoeligheid voor boezemfibrilleren verhoogd, Dilatatie van de boezem kan ook een gevolg zijn van boezemfibrilleren. Dit komt doordat de electrische remodellering (verkorting van de refractaire periode) door boezemfibrilleren gepaard gaat met verlies van contractiliteit van de boezem (contractiele remodellering). De rekbaarheid van de boezem neemt door verlies van de contractiliteit toe en de boezems dilateren. Dus, dilatatie van de boezem kan zowel een aorzaak als een gevolg van boezemfibrilleren zijn. Op deze manier speelt atriale dilatatie een rol in de vicieuze cirkel welke tot persisterend boezemfibrilleren leidt.

Deze studie is bedoeld om de effecten van acute en chronische atriale dilatatie op het ontstaan van een substraat voor boezemfibrilleren te onderzoeken. De belangrijkste vraag die we wilden beantwoorden was of atriale dilatatie de electrische gelleiding heterogeen maakt. We weten namelijk dat heterogene geleiding een belangrijke rol speelt bij het ontstaan en in stand houden van boezemfibrilleren. Het effect van acute atriale dilatatie is bestudeerd in Langendorff-geperfundeerde konijnen harten (Hoofdstuk 2 and 3). In hoofdstuk 2 hebben we de spatiële heterogeniteit in geleiding van de boezem gekwantificeerd door middel van een hoge-resolutie mapping electrode (resolutie: $0,5 \mathrm{~mm}$ ). Acute dilatatie veroorzaakte vertraging van de geleidingssnelheid en een toename van de incidentie van geleidingsblok. De toename van de spatiële heterogeniteit in geleiding was gerelateerd aan de anisotropie van het atriale weefsel. Lijnen van geleidingsblok traden bij voorkeur op langs de rand van de crista terminalis en de grote atriale spierbundiels.

Klasse IC anti-aritmica worden vaak gebruikt in patiënten om boezemfibrilleren te cardioverteren (beëindigen). Deze anti-aritmica blokkeren de snelle natrium kanalen en vertragen daarmee de electrische geleiding. In hoofdstuk 3 hebben we het effect van flecainide (een klasse IC anti-aritmica) op de electrische geleiding in gedilateerde atria onderzocht. 
Zowel atriale dilatatie als flecainide vertraagde de effectieve geleidingssnelheid en verhoogde de spatièle heterogeniteit in geleiding. De belangrijkste bevinding was dat de combinatie van atriale dilatatie en flecainide een duidelijk synergistisch effect had op de atriale geleiding.

In hoofdstuk 4 hebben we de hypothese getest dat gedurende 4 maanden boezemfibrilleren, waarin de boezems structureel geremodelleerd worden, de stabiliteit van boezemfibrilleren nog steeds toeneemt. Omdat tijdens persisterend boezemfibrilleren de duur van de episodes miet gebruikt kan worden voor de stabiliteit van boezemfibrilleren hebben we de hoeveelheid anti-aritmica die nodig is om te cardioverteren gebruikt. Met behuip van een atriale fibrillator hebben wij in geiten persisterend boezemfibrilleren opgewekt. Gedurende 16 weken werd de effectiviteit van flecainide en cibenzoline (beide klasse IC anti-aritmica) onderzocht. Het verlies van effectiviteit van deze anti-aritmica kan veroorzaakt worden door een verminderde electrofysiologische werking van het medicijn of door een toename van de stabiliteit van boezemfibrilleren. In onze studie was de sensitiviteit van de boezems voor klasse IC anti-aritmica niet verminderd na 4 maanden boezemfibrilleren. Het verlies van effectiviteit is toe te schrljven aan de toename van de stabiliteit van boezemfibrilleren.

De effecten van chronische dilatatie van de boezem op thet substraat van boezemfibrilleren hebben we onderzocht in een geiten model door middel vam chronische volume overbelasting. Deze volume overbelasting hebben we veroorzaakt door een verbinding te maken tussen de arteria carotis en de vena jugularis (AV-shunt). In hoofdstuk 5 werden de effecten van 6 weken AV-shunt op de electrofysiologische eigenschappen en de duur van de episodes van boezemfibrilleren bestudeerd. Om de effecten van chronische volume overbelasting op de atriale geleiding te bestuderen werd de electrische activatie van de vrije wand van beide boezems in kaart gebracht met een hoge resolutie mapping electrode (resolutie: $2,25 \mathrm{~mm}$ ). De druk in beide boezems was met een factor 3-4 toegenomen na 6 weken AV-shunt. De duur van boezemfibrilleren was maar zeer gering toegenomen. Deze toename in duur van boezemfibrilleren ging niet gepaard met veranderingen in de refractaire periode of electrische activatie. Om te onderzoeken of 6 weken AV-shunt te kort is om electrische veranderingen in de boezems te veroorzaken hebben we nog een studie gedaan waarin we de effecten van 20 weken AV-shunt hebben bestudeerd (hoofdstuk 6). Na 20 weken AV-shunt werden de episodes van boezemfibrilleren langer. Dit ging niet gepaard met veranderingen in de cyclus lengte van boezemfibrilleren, refractaire periode of atriale geleiding. Electrische remodellering in gedilateerde boezems veroorzaakte nog steeds wel een verkorting van de refractaire periode.

In hoofdstuk 7 word de rol van acute en chronische dilatatie van de boezem in de stabiliteit van boezemfibrilleren verder bediscussieerd. Acute rek van de boezems kan belangrijk zijn voor de gevoeligheid van de boezems voor 
boezemfibrilleren, terwijl chronische rek een belangrijke rol kan spelen bij het in stand houden van boezernfibrilleren. Middels deze studie hebben we aangetoond dat 20 weken "zuivere" dilatatie van de boezems een relatief zwakke stimulus is voor de ontwikkeling van een substrat voor boezemfibrilleren. Waarschijnlijk duurt het jaren voordat atriale dilatatie op zichzelf een substraat voor boezemfibrilleren veroorzaakt. 


\section{Dankwoord}

Tot slot wil ik iedereen die heeft bijgedragen aan het tot stand komen van dit proefschrift heel hartelijk bedanken. Sommigen wil hier in thet bijzonder noemen.

Allereerst mijn promotor prof. dr. Maurits Allessie. Beste Maurits, ik vind het echt heel bijzonder om bij jou te promoveren. Het was een waar experiment, omdat er ook een familiaire band tussen ons is, maar dat hebben we toch redelijk kunnen scheiden (al was het niet altijd even makkelijk). Jouw gedrevenheid heeft mij gemotiveerd om te proberen de kwaliteit die jij nasteeft in de wetenschap te behalen. Al voelde ik me soms moedeloos als er weer eens "BKE" (boerenkool engels) boven mijn abstract stond, als ik voor de zoveelste keer mijn opstelling moest veranderen of als $i k$ weer een protocol moest wijzigen. De inspirerende manier waarop jij de wetenschap bedrijft, heeft mede bijgedragen mijn persoonlijke groei in de afgelopen periode. Ik heb veel waardering voor de manier waarop jij onderzoek doet en jouw promovedi weet op te leiden. Maurits, heel erg bedankt voor de leuke, leerzame en inspirerende tijd in het lab.

De leden van de beoordelingscommissie, prof.dr. H.J.G.M. Crijns, prof.dr. J.M. de Bakker, prof.dr. J.G. Maessen en prof.dr. H.A.J. Struijker Boudier, voor het kritisch beoordelen van het manuscript en voor de deelname aan de verdediging.

Mijn paranimfen Marjolein de Vries en Mattias Duytschaever. Marjolein, we kennen elkaar al vanaf de eerste dag van de middelbare school toen het lot bepaalde dat wij naast elkaar werden gezet. Ik ben onze mentor "Otter Frotter Etter" daar nog altijd dankbaar voor. Ondanks dat we elkaar in onze studententijd niet erg veel zagen, is onze vriendschap in stand gebleven en de laatste jaren is zij veel hechter geworden. Ik beri heel blij dat jij mijn paranimf wilt zijn en ik vind het een eer om paranimf bij jouw promotie te mogen zijn. Mattias, met jou heb ik de begin jaren van mijn promotie gedeeld en ik zal deze nooit meer vergeten. We hebben heel wat lol gemaakt in het lab en vooral op de wekelijkse belgen-pest-dag! Ik zie je niet zo heel vaak meer, maar wanneer we elkaar weer zien is het als vanouds. Ik vind het een hele eer dat je je in alle bochten wringt om mijn paranimf te kunnen zijn. Mijn collega's van het lab wil ik bedanken voor de gezellige tijd en alle hulp die ik heb gehad. De vele etentjes en uitstapjes heb ik altijd als erg plezierig ervaren. Peter, jij was de enige met wie ik over konijnenexperimenten kon praten en wanneer ik een electrode kwijt was, wist ik meteen waar ik moest zoeken (nl. in jouw kast), Yuri, van jou heb ik veel geleerd toen ik met geiten ging werken. Jannie, soms hadden we heftige discussies met elkaar, maar we haddien tegelijkertijd ook veel lol. Ulli, jou wil ik graag bedanken voor alle goede adviezen en je luisterend oor. Hans, door jou heb ik kennis gemaakt 
met duitse chocolade, espresso en klassieke muziek. Ik zal ons uitstapje naar het concertgebouw in Keulen niet snel vergeten. Natasja, bedankt voor je collegiatileit en de lunch-praatjes over auto's. Erik en Maura, waar ik het laaste jaar de kamer mee deelde, bedankt voor de gezelligheid. Ook alle fellows die de afgelopen jaren het lab bezochten, wil ik bedanken voor de samenwerking.

Collega's van de experimentele cardiologie will ik bedanken voor de leerzame werkbesprekingen en de collegialiteit. Maaike, ons uitstapje naar Londen en Oxford zal ik niet vergeten. Bedankt voor al je gezelligheid.

Zonder ondersteuning van van Jan en Arne was het nooit wat geworden. Jan, jij moet soms echt gek van mij zijn geworden als ik weer met een kapotte mappingkast langskwam met het verzoek om die zo snel mogelijk te maken. Bedankt voor al je ondersteuning. Arne, bedankt voor je geweldige hulp tijdens de operaties en de perfecte samenwerking. De medewerkers van de CVP wil ik bedanken voor de goede verzorging van de konijnen en geiten. Jos, Claire en Vivian, bedankt voor de secretariële ondersteuning.

Graag wil ik hier ook "de buren" bedanken voor de ondersteuning die ze tijdens mijn promotie hebben gegeven. Jullie hadden altijd een luisterd oor en wanneer ik even rustig thuis wilde werken, kon ik Willemijn altijd bij jullie brengen. Eric-Jan en Renske, bedankt voor al jullie liefdevolle hulp en vriendschap.

Mijn familie en schoonfamille zijn onmisbaar voor mij en hebben mij altijd gesteund en daarvoor wil ik ze allen bedanken. In het bijzonder will ik mijn moeder en mijn schoonmoeder bedanken. Mama, bedankt voor je bemoedigende woorden en alle hulp die je hebt gegeven. Dineke, $\mathrm{jij}$ bent een schoonmoeder die iedereen zich wenst. Bedankt voor alles wat je voor ons hebt gedaan.

Tenslotte miljn aller-grootste steun en toeverlaten, Rink en Willemijn. Zonder jullie had ik het nooit gehaald. Het was soms een zware tijd en ik heb niet altijd alle aandacht aan jullie kunnen geven die ik wilde geven, maar daar gaat nu verandering in komen. Lieve Rink, ik dank je voor al je anvoorwaardelijke steun en trouw. Lieve Willemijn, jij bent samen met papa het mooiste wat ik heb! 


\section{Curriculum Vitae}

Sabine Eijsbouts werd geboren op 25 juli 1971 in Nijmegen. In 1991 behaalde zij het VWO diploma aan het Sint-Joriscollege te Eindhoven. Datzelfde jaar begon zij met de studie geneeskunde aan de Universiteit van Maastricht, waar zij in $\mathbf{1 9 9 6}$ het doctoraalexamen behaalde. Tijdens haar coschappen in 1997 begon zij als Onderzoeker in Opleiding (OIO) aan de vakgroep Fysiologie, Cardiovascular Research Institute Maastricht (CARIM), Universiteit Maastricht, onder leiding van Prof. Dr. M.A. Allessie. In 2000 behaalde zij het arts-examen aan de Universiteit van Maastricht. In juli 2004 begon zij als AGNIO Cardiologie in het Catharina-ziekenhuis te Eindhoven, waar zij vanaf september 2005 startte met de opleiding Cardiologie (opleider Dr. J.M. van Dantzig). Per 1 september is zij gestart met de vooropleiding Interne geneeskunde in het Catharina-ziekenhuis te Eindhoven (opleider Dr. B. Bravenboer). Sabine is getrouwd met Rink Lycklama à Nijeholt en samen hebben zij 1 dochter: Willemijn. 


\section{Publications}

Duytschaever MF, Danse PW, Eijsbouts S, et al. Is there an optimal pacing site to prevent atrial fibrillation? An experimental study in the chronically instrumented goat. J Cardiovasc Electrophysiol. 2002;13:1264-1271

Schotten U, Duytschaever M, Ausma J, Eijsbouts S, Neuberger $H_{*}$ Allessie M. Electrical and contractile remodeling during the first days of atrial fibrillation go hand-in-hand. Circulation. 2003;107(10):1433-1439

Eijsbouts SCM, Majidi M, van Zandvoort M, Allessie MA. The effects of acute atrial dilatation on heterogeneity in conduction in the isolated rabbit heart. I Cardiovasc Electrophysiol. 2003;14(3):269-78

Schotten U, de Haan S, Neuberger HR, Eijsbouts S, Blaauw $Y$, Tieleman R, Allessie M. Loss of atrial contractility is primary cause of atrial dilatation during first days of atrial fibrillation. Am J Physiol Heart Circ Physiol. 2004 Nov; $287(5): H 2324-31$

Eijsbouts SC, Houben RP, Blaauw $Y$, Schotten U, Allessie MA . Synergistic action of atrial dilation and sodium channel blockade on conduction in rabbit atria. J Cardiovasc Electrophysiol. 2004 Dec;15(12):1453-61

Neuberger HR, Schotten U, Verheule S, Eijsbouts S, Blaauw $Y$, van Hunnik A, Allessie $M$. Development of a substrate of atrial fibrillation during chronic atrioventricular block in the goat. Circulation. 2005 Jan $4 ; 111(1): 30-7$.

Eljsbouts S, Ausma A, Blaauw $Y$, Schotten U, Duytschaever M, Allessie M. Serial Cardioversion by Class IC Drugs during 4 Months of Persistent Atrial Fibrillation in the Goat. Submitted. 
$\beta^{\prime}$

$\therefore$

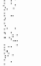

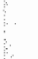

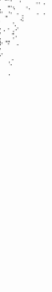

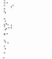

